\author{
UNIVERSIDAD DE LA REPÚBLICA \\ FACULTAD DE CIENCIAS SOCIALES \\ DEPARTAMENTO DE TRABAJO SOCIAL \\ Tesis Maestría en Trabajo Social
}

\title{
Linajes Maternos en el Uruguay Vulnerado \\ Procesos demográficos y su correlato biográfico
}

Mateo Berri

Tutora: Verónica Filardo

Montevideo, 2017 


\section{Hoja de aprobación}

\section{Título:}

Linajes Maternos en el Uruguay Vulnerado

Procesos demográficos y su correlato biográfico

Autor: Lic. Mateo Francisco Berri Cardozo

Orientadora: Prof. Dra. Verónica Filardo

\section{Tribunal integrado por:}

Prof. Dra. Verónica Filardo

Prof. Dra. Mónica DeMartino

Prof. Dra. Sandra Leopold

Prof. Mag. Ximena Baráibar

Fecha:

Calificación: 


\section{Agradecimientos}

A Verónica Filardo por el constante apoyo y el trabajo compartido.

Al equipo del Grupo de Estudios Urbanos y Generacionales por la lectura atenta, los comentarios y el enriquecedor intercambio.

A José Miguel Juanena y a Jimena Pandolfi por la ayuda con la parte estadística del trabajo.

A Mayra Aldama, Beatriz Rocco y Valeria Gradín por facilitar el trabajo en el marco del Programa Cercanías del MIDES.

A las supervisoras del Programa Cercanías Soledad Vieytes, Ivana Patritti y María del Carmen Urtasun.

A los Equipos Técnicos de Atención Familiar: SAI, Marconi, Oeste Costero-CEPID, Maracaná-Educación Solidaria.

A las mujeres entrevistadas y a sus familias, que me recibieron en su hogar, y con mucha paciencia y apertura, me permitieron conocer su historia.

A Sylvana la mejor colega y compañera. 


\section{Resumen}

El trabajo que se presenta a continuación es un estudio exploratorio centrado en las características que asumen ciertas familias en contextos de vulneración socioeconómica, en el Uruguay de hoy.

La hipótesis principal es que algunas de estas familias han asumido características de matrilinealidad y matrilocalidad. Dichas familias, dada su estructura, conciben de manera particular las relaciones de parentesco, la filiación, los roles de género, y la transición a la vida adulta. Denominaremos a este tipo de familia como Linaje Materno.

El contexto de esta proceso es la consolidación de una gran brecha (Filgueira, 2011) entre los sectores sociales en función de su acceso al bienestar y el surgimiento de lo que se ha llamado el Uruguay Vulnerado (Filgueira, 2005).

La estrategia metodológica utilizada para abordar este problema consistió en una triangulación metodológica, en la que se aplicaron técnicas estadísticas y técnicas cualitativas. Se trabajó con información del Censo 2011 y de la Encuesta Continua de Hogares 2015, y se realizaron un conjunto de entrevistas en profundidad a mujeres jefas de hogar beneficiarias del Programa Cercanías del MIDES.

Para hacer operativa esta estrategia construimos la categoría "hogar de línea materna" constituida por familias cuyo estructura responde a dos o más generaciones de mujeres sin presencia masculina.

Entre los principales resultados podemos mencionar que encontramos que este tipo de hogar representa el 4.2 \% de las personas del país, es decir unas 143 mil personas, en tanto que la misma estructura es prácticamente inexistente para el caso masculino. Asimismo el análisis de las entrevistas en profundidad arroja indicios importantes de la presencia de un modelo matrilineal, expresado como decíamos en los roles de género, en la filiación y en la transición a la vida adulta.

Este trabajo supone entonces un primer acercamiento a un problema complejo y multidimensional, colocando un conjunto de nuevas interrogantes respecto de la estructura y construcción subjetiva de la familia en el Uruguay de hoy.

Palabras Clave: 1 . Familia 2. Género 3. Juventud 4. Vulneración Social 


\section{Abstract:}

This work is an exploratory study focused on the characteristics assumed by certain families in the contexts of socio-economic vulnerability, in Uruguay today.

The main hypothesis is that families from the sectors with the greatest socio-economic vulnerability have assumed characteristics of matrilineality and matrilocality. These families, given their structure, particularly conceive the relationships of kinship, filiation, gender roles, and the transition to adult life. It is this type of family that we call Maternal Lineage.

The context of this situation is the consolidation of a great gap (Filgueira, 2011) between the social sectors. This gap is associated to their access to the welfare and to the emergence of what has been called the Vulnerated Uruguay. (Filgueira, 2005).

The methodological strategy used to address this problem consisted of a methodological triangulation, in which statistical techniques and qualitative techniques were applied. We worked with information from the 2011 Census and the Continuous Household Survey 2015, and a set of in-depth interviews were conducted focused on female heads of household who were beneficiaries of the MIDES Cercanías Program.

To make this strategy operational, we construct the category "maternal line home " made up of families whose structure responds to two or more generations of women without a male presence. We find that this type of household represents $4.2 \%$ of the people of the country, and about 143 thousand people, whereas the same structure is practically nonexistent for the masculine case.

Likewise, the analysis of in-depth interviews yields results with important indications of the presence of a matrilineal model, expressed as we said in gender roles, in filiation and in the transition to adult life.

This work represents a first approach to a complex and multidimensional problem, placing a set of new questions regarding the structure and subjective construction of the family in Uruguay today.

Keywords: 1.Family 2.Gender 3.Youth 4.Social Vulneration 


\section{TABLA DE CONTENIDOS}

$\begin{array}{ll}\text { 1. INTRODUCCIÓN } & \text { p. } 8\end{array}$

$\begin{array}{lr}\text { 2. CONCEPTOS OPERATIVOS } & \text { p. } 12\end{array}$

2.1 Conceptos operativos referidos a la Familia $\quad$ p. 13

2.1.1 Morgan y Engels: primera generación de estudios de la familia $\quad$ p. 13

$\begin{array}{ll}\text { 2.1.2 Durkheim y el método de la sociología } 15 & \text { p. } 15\end{array}$

2.1.3 Estudios antropológicos de la familia: teoría de la alianza y teoría de la filiación 16

$\begin{array}{ll}\text { 2.1.4 Parsons y la teoría sistémica de familia } & \text { p. } 18\end{array}$

$\begin{array}{ll}2.1 .5 \text { Teoría Sistémica de Familia } & \text { p. } 19\end{array}$

2.1.6 Glen Elder: El enfoque de curso de vida y sus principios orientadores $\quad$ p. 21

2.2 Conceptos operativos referidos al Género $\quad$ p. 23

$\begin{array}{ll}\text { 2.2.1 Tres generaciones de los estudios de género } & \text { p. } 24\end{array}$

$\begin{array}{ll}\text { 2.2.2 Antropología, la construcción cultural de varones y mujeres } & \text { p. } 25\end{array}$

\begin{tabular}{l|l} 
2.2.3 El género en el marco del patriarcado & p. 27
\end{tabular}

$\begin{array}{ll}2.3 \text { Conceptos operativos referidos a la Juventud } & \text { p. } 29\end{array}$

$\begin{array}{ll}2.3 .1 \text { La corriente generacional y la corriente clasista } & \text { p. } 29\end{array}$

$\begin{array}{ll}\text { 2.3.2 Juventud o juventudes, la juventud como construcción social } & \text { p. } 30\end{array}$

2.3.3 De la moratoria social a la moratoria vital p. 32

$\begin{array}{ll}\text { 2.3.4 Transiciones y trayectorias a la vida adulta } & \text { p. } 33\end{array}$

$\begin{array}{ll}2.4 \text { Resumen del Capítulo: Familia, género y juventud } & \text { p. } 37\end{array}$

3. EL CONTEXTO: LAS FAMILIAS URUGUAYAS EN EL MARCO DE UN MODELO DE DESARROLLO p. 41

3.1 La gran brecha: surgimiento y consolidación del Uruguay vulnerado p. 42

3.2 Uruguay desigualdad y empleo $\quad$ p. 44

$\begin{array}{ll}3.3 \text { Urbanización con Pobreza, segregación socio territorial } & \text { p. } 46\end{array}$

3.4 Primera y segunda transición demográfica: consolidación de un modelo dual p. 47

3.5 Arquitectura de Bienestar y transferencia entre generaciones y géneros $\quad$ p. 53

$\begin{array}{ll}3.6 \text { Los tres mundos del Uruguay social } & \text { p. } 61\end{array}$

$\begin{array}{lc}3.6 \text { Resumen del Capítulo: El Uruguay Vulnerado } & \text { p. } 63\end{array}$

\section{ANTECEDENTES:}

LINAJES MATERNOS ARTICULACIÓN DEL CAMBIO Y LA PERMANENCIA

$\begin{array}{ll}4.1 \text { Hogares de Jefatura Femenina } & \text { p. } 70\end{array}$

$\begin{array}{ll}4.2 \text { Concepciones tradicionales de género en las mujeres del Uruguay Vulnerado } & \text { p. } 71\end{array}$

4.3 Separación de páter y genitor, nomadismo y dilución del rol paterno.

$\begin{array}{ll}4.4 \text { Varones jóvenes compelidos a dejar el Hogar Materno } & \text { p. } 74\end{array}$ 


\section{METODOLOGÍA}

p. 84

5.1 Objetivo General

p. 87

5.2 Objetivos Específicos

p. 87

5.3 Preguntas de Investigación

p. 87

5.4 Estrategia de investigación

p. 88

5.4.1 Estudio Socio demográfico

p. 88

5.4.2 Estudio Biográfico y Genealógico

p. 89

\section{RESULTADOS DE LA ESTRATEGIA DE INVESTIGACIÓN CUANTITATIVA:}

\section{LINAJES MATERNOS COMO FENÓMENO DEMOGRÁFICO}

p. 92

6.1 Estrategia de Investigación demográfica, familias y arreglos familiares

p. 93

6.2 Tipos de Hogar y Pobreza según el Censo y la Encuesta Continua de Hogares

p. 95

6.3 Hogar de línea materna en los datos estadísticos

p. 101

6.4 Linajes Maternos como Fenómeno Demográfico

\section{RESULTADOS DE LA ESTRATEGIA DE INVESTIGACIÓN CUALITATIVA:} LINAJES MATERNOS COMO FENÓMENO BIOGRÁFICO

7.1 Estrategia de Investigación biográfica

7.2 Roles de género diferenciados y tradicionales

p. 110

7.3 Indicios de matrilocalidad,

7.4 Filiación que presenta indicios de Matrilinealidad

p. 113

7.5 Nomadismo y dilución de rol masculino

p. 114

7.6 Transiciones a la Vida Adulta diferenciadas por género

p. 115

7.7 Linajes Maternos como fenómeno biográfico

\section{CONCLUSIONES}

8.1 La familia desde un abordaje conceptual

p. 119

8.2 El contexto de desarrollo de la familia

8.3 Antecedentes de la aparición del Modelo

p. 123

8.4 Los resultados del trabajo empírico 


\section{ÍNDICE DE GRÁFICOS Y CUADROS}

Grafico 1 Evolución de la indigencia, la pobreza y la desigualdad en Uruguay

p. 45

Gráfico 2 Uruguay: Perfil del Déficit del Ciclo de Vida por Edad, 1994 y 2006

p. 57

Gráfico 3 Uruguay: Perfil de las Transferencias Públicas Netas, por edad, 1994 y 2006

p. 57

Grafico 4. Evolución de los hogares nucleares y monoparentales, total del país, 1963-2011

p. 97

Grafico 5. Distribución de los hogares según tipo de hogar

p. 98

Gráfico 6. Distribución de los hogares según tipo de hogar 2015

p. 99

Gráfico 7. Hogares pobres y no pobres según tipo de hogar 2015

p. 100

Gráfico 8. Distribución Quintiles de Ingreso de Hogares Monoparentales 2015

p. 104

Gráfico 9. Distribución Quintiles de Ingreso de Hogares Extendidos Monoparental Femenino 2015

p. 105

Gráfico 10. Distribución según Quintiles de Ingreso de Hogares de Línea Materna 2015

p. 106

Cuadro 1. Hogares Línea Materna. Encuesta Continua de Hogares 2015

p. 102

Cuadro 2. Hogares Línea Paterna. Encuesta Continua de Hogares 2015

p. 103

Cuadro 3. Distribución de Arreglos Familiares en función de los Quintiles de Ingreso 2015

p. 106 


\section{INTRODUCCIÓN}

Aquellos que hemos elegido desempeñarnos en el marco de las políticas públicas nos enfrentamos cotidianamente a la amplia y compleja diversidad de la condición humana. Esto no garantiza, por otra parte, que tengamos la capacidad de sorprendernos o de entender verdaderamente la realidad con la que tomamos contacto. Muy por el contrario, es relativamente fácil caer en una práctica rutinaria y acrítica. No debemos llamarnos a engaño a este respecto, no es lo mismo conocer una realidad que entenderla o comprenderla.

Sin embargo si somos capaces de mantener una actitud investigativa tenemos la oportunidad de presenciar algunos eventos de primera mano. Claro que esto, no es suficiente para elaborar conocimiento científico, pero puede permitirnos intuir la existencia de vacíos en el conocimiento de la realidad, fórmulas equivocadas, líneas de exploración por las que es posible continuar.

Para que estas intuiciones se transformen en conocimiento válido y sustentado, deberán formularse luego en la forma de hipótesis o teorías, y ser contrastadas con realidad empírica de manera sistemática y metódica.

Esta es la intención del presente trabajo de investigación que surge originalmente como un conjunto de intuiciones emergidas de mi práctica como trabajador social. En el trabajo con familias, en el contexto de diferentes planes y programas sociales, comencé a percibir ciertas regularidades que constituían un modo de concebir elementos tales como el rol de las mujeres y los hombres, en particular de madres y padres en estas familias, la forma en que se conciben las relaciones con los hijos, y finalmente las manera en que se transita de la infancia a la vida adulta.

Todas estas cosas, si bien diferían de familia en familia, poseían cosas en común, un aire de familia si se quiere, y me permitían suponer la existencia de un patrón diferencial del modo en que se concibe la familia en los sectores más pobres, respecto del resto de la sociedad.

Como decía, para que dicha intuición pueda evolucionar en una producción académica el camino supone una elaboración conceptual así como el trabajo empírico con información de la realidad. 
Una primer y tentativa versión de esta elaboración conceptual o hipótesis, que constituirá el eje central de nuestro trabajo puede elaborarse en los siguiente términos: La población que integra el Uruguay Vulnerado ha desarrollado arreglos familiares diferenciados, entendidos como las formas que asumen las unidades de convivencia, así como nuevas formas de concebir la familia en términos subjetivos, respecto de lo que podrían definirse como formas tradicionales de familia. En particular, existe evidencia que indica que algunas familias han asumido características de matrilinealidad y matrilocalidad. Dichas familias, dada su estructura, conciben de manera diferente las relaciones de parentesco, la filiación, los roles de género, y la transición a la vida adulta.

El contexto de esta transformación es el surgimiento de la "gran brecha" (Filgueira, 2011) entre los sectores sociales en función de su acceso al bienestar. Este proceso puede definirse en los siguientes términos: la Arquitectura de Bienestar (EspingAndersen, 1999) del Uruguay ha atravesado profundas transformaciones en las últimas décadas, fundamentalmente en la estructura del mundo de trabajo.

Este cambio no ha sido acompañado por una transformación concomitante de la estructura de protección social del Estado, generando de este modo un desfasaje entre las necesidades de la población y la estructura de asignación de recursos.

Estos procesos combinados han determinado el surgimiento de lo que se ha llamado el Uruguay Vulnerado (Filgueira, 2005), integrado por aquella porción de la población que sufre de manera más significativa las consecuencias del cambio en el mercado de trabajo, y que no logran acceder a las prestaciones estatales, o que aun accediendo, no consigue alcanzar mínimos de bienestar económico y social. Esta fractura social, acompañada de un proceso de segregación socio territorial impacta en la vida de las personas, de tal modo que sus consecuencias transcienden con mucho el ámbito de lo puramente material.

Por supuesto deberemos definir con mayor precisión todos los términos que componen esta formulación, sin embargo los elementos centrales resultan bastante claros, en ciertos sectores de la población, en particular en aquellos más pobres y vulnerados, en las últimas décadas, las formas de concebir la familia son particulares y diferentes respecto del resto de la población. 
Me parece muy importante en este momento poder dimensionar la relevancia política de una afirmación de esta naturaleza. De confirmarse esta hipótesis, y veremos en el documento que contamos con indicios de ello, implicaría que las desigualdades que, en principio, están presentes en el terreno del acceso al bienestar, han generado procesos diferenciadores de la población, que afectan aspectos tan profundos como la noción de familia y el conjunto de ideas, prácticas y relaciones asociados a ella.

Podría suponerse que el hecho de que no exista una noción única de familia es algo positivo, en la medida en que la diversidad de opciones podría implicar mayor libertad para las personas.

Sin embargo los procesos que estamos reseñando no suponen, en principio mayor libertad de elección para las personas, sino tal vez todo lo contrario, ya que estaríamos en presencia una asociación directa entre la pertenencia a un sector de la población y una forma de concebir la familia.

Asimismo suponen una brecha que se traslada de lo económico a lo subjetivo y lo cultural. Este hecho supondría un desafío significativo en términos de integración social, y debería ser tenido en cuenta a la hora de pensar el diseño de las políticas públicas que tenga en cuenta el modo en que los sectores vulnerables viven y conciben la familia.

En tanto que nuestro foco está puesto en la familia, los roles de género y las transiciones a la vida adulta, la propuesta de este trabajo se desarrollará comenzando con un capítulo destinado a analizar los conceptos más relevantes para el análisis de la familia, el género y la juventud. Intentaremos esquematizar su desarrollo histórico, a efectos de contar con los insumos necesarios en el momento en que debamos tornar operativas dichas ideas para guiar el trabajo empírico.

El segundo capítulo busca describir el contexto social, económico y demográfico en el que tiene lugar esta transformación. Este entorno, si bien no determina en el sentido estructuralista de la expresión, la vida de las familias, debe ser tenido en cuenta.

Entendemos que existe una coincidencia lógica entre lo que puede apreciarse desde una perspectiva macro y lo que sucede cuando nos acercamos a situaciones particulares. No se trata entonces de que los procesos estructurales definan los procesos particulares, sino que ambos son planos diferentes de una misma realidad, por lo tanto es esperable que presenten coincidencia y conexiones de sentido. 
El tercer capítulo está destinado a revisar algunas investigaciones que se han realizado en Uruguay en los últimos años y que dan cuenta del fenómeno descrito anteriormente. Si bien es cierto que no existen antecedentes que describan esta realidad en los mismos términos, si existen trabajos académicos que de un modo $u$ otro han dado cuenta de alguno de los ejes investigados.

Un cuarto capítulo destinado a la metodología. En él describiremos el enfoque metodológico, que entendemos debe ser coherente tanto con el enfoque teórico, como con las técnicas concretas de investigación llevadas adelante

Los capítulos seis y siete estarán destinados a abordar los resultados de la investigación empírica, que suponen un abordaje cuantitativo y cualitativo del fenómeno respectivamente.

Destinaremos un último capítulo a reflexiones finales, en el que buscamos dar una mirada de conjunto al fenómeno. Esto nos permitirá por un lado discutir la relevancia política de este fenómeno, y trazar algunas líneas de continuidad de la investigación. 


\section{CONCEPTOS OPERATIVOS: FAMILIA, GÉNERO Y JUVENTUD}

El trabajo que hemos llevado adelante y cuyos resultados pretendemos exponer en este documento centra su mirada en las familias uruguayas de los sectores más pobres, intentando comprender el modo en que conciben la familia de manera global y poniendo el énfasis sobre algunos aspectos de las relaciones de género y las relaciones entre jóvenes y adultos.

En este capítulo y como fundamento para el análisis de los resultados del trabajo empírico nos concentraremos en los conceptos de familia, género y juventud. La intención de abordar esta discusión es la de alcanzar algunas definiciones generales, que luego puedan ser operativas mediante el trabajo empírico.

Buscaremos abordar cada uno de estos conceptos, haciendo un breve repaso histórico de las principales aportaciones que diferentes autores han realizado en cada campo. No es intención de este capítulo agotar las discusiones teóricas en cada una de estas categorías, sino tan solo marcar aquellas que para los fines de nuestra investigación, aportan elementos sustanciales a la definición.

De modo que no pretendemos exhaustividad, lo cual por otra parte sería imposible dado que cada una de estas conceptualizaciones representa actualmente un campo científico independiente, sino marcar un conjunto de conceptos y aportes teóricos que por su importancia para nuestro trabajo, vale la pena discutir.

Como decíamos este desarrollo nos permitirá fundamentar ciertas opciones realizadas en el plano conceptual. De este modo, lo que presentaremos a continuación no es una historia del estudio científico de las categorías familia, género y juventud, sino una selección de aportes conceptuales, que desde la perspectiva de este trabajo, tienen valor heurístico y deben ser mencionados.

Como veremos a continuación, si bien cada uno de estos campos de estudio se ha desarrollado con relativa independencia, el estudio conjunto de la familia, de las relaciones de género y de las relaciones entre jóvenes y adultos brinda un rendimiento conceptual importante, fundamentalmente porque estos conceptos remiten a concepciones que son matriz de la vida cotidiana, y cuya consideración independiente solo tiene sentido a los efectos analíticos. 
En la realidad cotidiana de las personas, las nociones vinculadas a la familia están íntimamente ligadas a las ideas de género y juventud. Si pretendemos entonces, realizar un análisis que pueda reconstruir de manera analítica, aquello que sucede en el mundo de lo cotidiano, será entonces necesario considerar estos conceptos en relación.

\subsection{Conceptos operativos referidos a la Familia}

Para el desarrollo de este primer apartado sobre familia seguiremos en buena medida el itinerario conceptual que nos propone Martine Segalen (1992) en su texto clásico "Antropología histórica de la familia", en el que realiza una enumeración de diferentes aportaciones teóricas y estudios empíricos respecto de la familia.

Este trabajo, amén de su relevancia conceptual, tiene la virtud de destacar aportes de diferentes disciplinas: sociología, antropología, demografía, brindando un cuadro de contexto muy completo sobre los estudios relativos a la familia.

\subsubsection{Morgan y Engels: primera generación de estudios de la familia}

El análisis de la familia desde la ciencias sociales tiene un origen que puede remontarse a los comienzo de la ciencia social propiamente dicha. En el siglo XIX Lewis Morgan (1986) primero y a partir de su aporte Friedrich Engels (1987) luego, desarrollaron trabajos sobre la familia, su génesis y su relación con otras esferas de la sociedad.

Si bien su labor sobre la familia fue realmente pionera, tuvo debilidades en el plano de la base empírica, ya que muchas de las observaciones en que se basaron para arribar a conclusiones fueron parciales o mal interpretadas. Esta dificultad probablemente se debió al hecho de que la ciencia social no había desarrollado plenamente cuestiones metodológicas básicas.

Tal es el caso del trabajo de Morgan sobre las comunidades aborígenes norteamericanas, en particular sobre la iroquesa, que demostró luego tener debilidades importantes en el plano de las observaciones empíricas.

Asimismo la interpretación de estas observaciones se desarrolló en direcciones que luego se demostraron erróneas, en particular en la fundamentación de las tesis 
evolucionistas que sostenían, propias de una visión decimonónica de la historia y el desarrollo.

Sin embargo, y a pesar de estas dificultades, el trabajo de Morgan sentó las bases de un análisis científico de la familia desde la antropología y la sociología. Su principal hallazgo, el cual sería retomado posteriormente por Engels, fue comprender que la terminología de parentesco, es decir el modo en que se denomina a los parientes recíprocos en una cultura (padre, madre, hijos, primos) no tiene una relación directa y unívoca con las características del vínculo que se establece.

Dicho de otro modo, lo que en una cultura se define como padre, no necesariamente coincide con lo que se define como padre en otra cultura, y lo que es más importante no necesariamente coincide con lo que se definía como padre en la misma cultura tiempo atrás o en el futuro.

No existe una relación exacta o simétrica entre el modo en que se denomina a los parientes y el sistema de parentesco que se sostiene, ya que los cambios en los arreglos familiares pueden o no verse reflejados en la terminología de parentesco. El tipo de relaciones que encontramos en las familias puede modificarse más rápidamente que los nombres usados para ellas.

Así por ejemplo en nuestra cultura el hermano de la madre y el hermano del padre es denominado con el mismo término y poseen un estatus similar. Podría suceder que en el futuro el hermano de la madre adquiriera un rol de mayor importancia, incluso cumpliendo funciones que actualmente cumple el padre, como de hecho sucede en algunas culturas. Este cambio probablemente, no iría acompañado con un cambio inmediato de la denominación que actualmente usamos.

Este desfasaje entre la terminología y las relaciones es lo que visualizaron los autores, evidenciando la importancia para la investigación de esta terminología de parentesco. Esto hecho reviste gran importancia ya que permite establecer una diferencia entre una familia social construida en el imaginario y las familias reales en una sociedad en un momento dado.

Es posible suponer que la transformación de ambos planos no sea simétrica, y si bien no podemos afirmar como Engels, que la base de relaciones se modifica con mayor velocidad que la superestructura terminológica de parentesco, los cierto es que pueden existir diferencias sobre las que resulta significativo tomar nota. 
Esta diferenciación es clave para cualquier estudio que pretenda comprender los cambios históricos en las familias y sus concepciones asociadas y veremos que tendrá una relevancia central en nuestro trabajo.

\subsubsection{Durkheim y el método de la sociología}

Durkheim (1892) desarrolló una visión particular al respecto de la familia, en el marco de su concepción de la división del trabajo social, y de la importancia de este proceso en el pasaje de sociedades basadas en la solidaridad mecánica a la solidaridad orgánica. El autor postula dos conclusiones respecto de la familia, en primer lugar la necesaria división del trabajo a la interna de la familia, y en segundo término contracción desde formas de familia extensa a formas de familia nuclear.

La primera de estas conclusiones surge como una extensión de su noción de la división del trabajo social, en el marco del grupo domestico esto supone la aparición de la familia conyugal, que luego sería denominada nuclear. Para Durkheim este tipo de familia se caracteriza por tener menos funciones que los modelos extensos que la precedieron, aunque sus lazos son más fuertes.

Por otra parte, Durkheim llega a la conclusión de que las familias serán cada vez de menor tamaño, toda vez que se consolide la familia conyugal. Esto fue denominado como ley de contracción progresiva de la familia.

Más allá de su teoría concreta, Segalen propone que la aportación más importante de Durkheim es la incorporación del método estructural, el cual tuvo una influencia superlativa para las elaboraciones posteriores.

La posteridad de la sociología durkhemiana de la familia es curiosa y camina por vías separadas de la antropología social inglesa y de la sociología americana. Radcliffe-Brown y la escuela estructural funcionalista se inspiran, así como Talcott Parsons. En Francia, la influencia de la escuela sociológica ha sido mayor en otros campos sociales, y si bien Claude Lévi-Strauss aparece como un continuador de Durkheim, lo es menos en el campo de la familia en particular que en el del método de análisis estructural en general, cuyas premisas estaban ya presente en Durkheim y que él formuló definitivamente. (Segalen; 1992: 28) 


\subsubsection{Estudios antropológicos de la familia: teoría de la alianza y teoría de la filiación}

Posterior a estos primeros trabajos sobre la familia podemos mencionar a los estudios etnográficos de sociedades no occidentales, desarrollados en el contexto de la consolidación de la antropología como disciplina científica y que permitieron describir los diferentes significados que conceptos tales como matrimonio y filiación adquieren en las diferentes sociedades.

La principal discusión se estableció en la primer mitad del siglo XX, entre la perspectiva definida por la terminología de parentesco desarrollada por Levi-Strauss (1991) y una visión estructural funcionalista del parentesco desarrollada por la antropología británica de Radcliffe-Brown (1972).

Para la antropología desarrollada por Levi-Strauss a partir del estudio de comunidades en América del Sur, el parentesco se construye fundamentalmente sobre el tabú del incesto. La explicación que se brinda sobre la universalidad del tabú del incesto radica en la necesaria exogamia que impone a los grupos familiares.

Dicho de otro modo, la prohibición de buscar pareja dentro de la propia familia supone la necesidad de buscarla fuera (exogamia) y al hacerlo se constituyen lazos $u$ alianzas entre diferentes familias.

La importancia brindada por la teoría a este hecho es muy grande, dado que según el autor marca el pasaje entre la dimensión biológica del hombre y su dimensión social, en la medida en que la exogamia termina estableciendo el salto entre el grupo familiar primario, más asociado a relaciones de orden biológico y el grupo social y la construcción social de la familia.

Esta exogamia establece alianzas entre grupos familiares e impone una necesaria reciprocidad en el intercambio de parejas entre familias, base de la cooperación social. De ahí que se haya denominado a esta perspectiva como teoría de la alianza, porque remite a alianzas entre familias.

Dijimos al comienzo que la perspectiva de la alianza, que pone el acento en la prohibición del incesto y el necesario matrimonio por alianza se enfrentó a en su momento a los desarrollos de Radcliffe-Brown.

Este trabajo, asociado a la teoría funcionalista, fue denominado teoría de filiación o descendencia. En esta concepción el vínculo más importante no es ya el matrimonial, 
sino el de filiación, ya que la filiación permite establecer para cada individuo la sucesión, determinando el status relativo, y la herencia material.

Una de las principales virtudes de estos primeros estudios antropológicos de la familia fue la definición de un conjunto de categorías que permite describir los tipos de arreglos familiares, en función de sus reglas de parentesco.

Existe, por desgracia, gran libertad en el uso de los términos $<<$ matriarcal $>>y$ <<patriarcal >>, y por tal razón muchos antropólogos los rechazan. Antes de usarlos, pues hemos de definirlos exactamente. Puede denominarse patriarcal una sociedad cuando la descendencia es patrilineal (es decir, los hijos pertenecen al grupo de padre), el matrimonio es patrilocal (es decir, la mujer se trasladas al grupo local del marido), la herencia (de la propiedad) y la sucesión (del rango) se transmiten por línea masculina y la familia se rige por el sistema de la patria potestad (es decir, que la autoridad sobre todos los miembros de la misma es ejercida por el padre o sus parientes). Por otro lado, puede denominarse matriarcal una sociedad en la cual descendencia, herencia y sucesión se transmiten por línea femenina, el matrimonio es matrilocal (el marido se traslada a la casa de su mujer) y la autoridad sobre los hijos es ejercida por los parientes de la madre. (Radcliffe-Brown, 1972: 32)

Si bien Radcliffe-Brown establece una relación directa entra martriarcal, matrilineal y matrilocal, porque eso era lo que estaba observando, la antropología posterior separó estos conceptos y sus usos, asociándolos a la autoridad, la filiación y la residencia respectivamente, pero no desarrollando una relación de necesidad en la aparición conjunta de estos fenómenos. Sin embargo la definición de estas categorías analíticas es propia de esta época.

La necesidad de establecer esta sucesión responde, desde esta perspectiva, a dos cuestiones fundamentales en la sociología: la necesidad de generar estructuras que eviten el conflicto constante y el caos, y la necesidad de generar una continuidad en la sociedad.

Las leyes sociológicas, es decir, las condiciones necesarias de existencia de una sociedad que se han indicado aquí como fundamento de las costumbres de sucesión unilineal (patrilineal o matrilineal) son: 1 La necesidad de una formulación de los derechos sobre personas y cosas lo suficientemente 
precisa en su reconocimiento general como para impedir, en la medida de lo posible, conflictos irresolubles. 2 La necesidad de continuidad de la estructura social como sistema de relaciones entre las personas, siendo tales relaciones definibles en términos de derechos y deberes. (Radcliffe Brown, 1972: 59)

Vemos entonces que en este caso el vínculo que aparece como privilegiado para comprender la familia es el de filiación, a diferencia de la teoría de la alianza que pone el acento en el vínculo de pareja.

Si bien difieren en la importancia relativa que dan a cada estructura, comienzan a delinear los elementos centrales de la familia. Y estos conceptos de matrimonio y filiación remiten a ideas sobre el género y las relaciones entre adultos y jóvenes, presentes aunque no de manera explícita en estos primeros trabajos de investigación.

Ambas teorías ponen el acento en dos elementos diferentes: el matrimonio por un lado y la filiación por otro, y sus consecuencias en términos de relaciones y estructuras sociales.

\subsubsection{Parsons y la teoría sistémica de familia}

La familia también ha sido objeto de estudio desde la sociología funcionalista norteamericana de mediados del siglo XX, con la figura fundamental de Talcott Parsons (1980) a la cabeza de esta investigación.

Desde la segunda generación de la Escuela de Chicago, su tesis se centra en destacar la familia nuclear típica norteamericana, y la función que desempeña como grupo primario, y como base de interacción y asociación a nivel de la sociedad, a partir de la incorporación de componentes de la psicología, en particular del psicoanálisis.

Su trabajo se concentra en estudiar la estructura de la familia, en particular los roles de los adultos y los jóvenes, y asigna a esta estructura dos grandes funciones, la socialización de los niños y la estabilización de las personalidades de los adultos. Nuevamente el centro está puesto en relaciones en las que las nociones de género y el nexo entre adultos y jóvenes operan de modo significativo dando forma a estos vínculos.

We therefore suggest that the basic and irreducible functions of the family are two: first, the primary socialization of children so that they can truly become member of the society into which they have been born; second, the 
stabilization of the adult personalities of the population of the society. It is the combination of these two functional imperatives, which explains why, in the "normal" case it is both true that every adult is a member of a nuclear family and that every child must begin his process of socialization in a nuclear family. (Parsons, 2002: 17)

De este modo, la teoría de Parsons, al establecer un nexo entre elementos de análisis de la estructura social y de la psicología de los individuos, en su análisis de la familia, sienta las bases para la posterior teoría sistémica de familia.

Las críticas a este enfoque se centran en el hecho de que establece a la familia nuclear típica de este momento histórico y lugar, como el modelo aceptable y funcional, dejando por fuera la posible diversidad y el cambio necesario.

Sin embargo, a pesar de la validez de estas críticas, la perspectiva de Parsons respecto de la familia y respecto de otros fenómenos asociados, como el estudio de la juventud que veremos más adelante, fue el principal desarrollo teórico durante buena parte del siglo $X X, y$ aún continúa siendo hoy uno de los principales enfoques teóricos sobre la familia.

Además, al articular elementos de la sociología y la psicología, estableció las bases para los futuros desarrollos teóricos que pusieron su foco de atención en la familia como fenómeno.

\subsubsection{Teoría Sistémica de Familia}

Heredero en buena medida del trabajo desarrollado por Parsons y de la relación entre psicología y sociología, surge el enfoque sistémico de familia, y su análisis de ciclo de vida familiar.

Esta perspectiva entiende a la familia como un sistema con funciones claramente definidas: socialización, control social, mantenimiento físico de sus integrantes, función económica, función social, funciones de membrecía.

En tanto sistema, la familia tiene límites muy claros, y debe lograr funcionar en equilibrio. El sistema familiar está compuesto de subsistemas tal como el subsistema parental y asigna roles recíprocos a sus integrantes: padre-hijo, esposo-esposa.

Sin embargo tal vez el mayor aporte de esta perspectiva sea el análisis diacrónico de la biografía familiar centrado en el concepto de ciclo de vida familiar. Cada familia, 
transita por un conjunto de fases, en el desarrollo de su ciclo de vida, y cada fase le presenta desafíos particulares.

El bienestar familiar desde la teoría de sistemas consiste en lograr que la familia cumpla sus funciones en medida en que transita las distintas etapas del ciclo de vida: establecimiento de la pareja, nacimiento de los hijos, familia con hijos en edad escolar, familia con hijos en la adolescencia, independencia de los hijos, etapa post parental, etapa de retiro.

El <<ciclo vital de la familia >> se refiere a aquellos hechos nodales que están ligados a la peripecia de los miembros de la familia, como el nacimiento y crianza de los hijos, la partida de estos del hogar, el retiro y la muerte (Duvall, 1957). Estos hechos producen cambios a los que deberá adaptarse la organización formal (o simbólica) de una familia. Son cambios de composición que exigen una reorganización de los roles y las reglas. El curso vital de las familias evoluciona a través de una secuencia de etapas relativamente previsibles y, al parecer, bastante universal, pese a las variaciones culturales y subculturales. (Jaez Falicov, 1991: 44)

Estas transiciones de una etapa a otra marcan momentos de vulnerabilidad, y de crisis en el equilibrio del sistema familiar. Si bien, la teoría sistémica tiene el mérito de poner el foco en algunos momentos de transición particularmente significativos en la vida de las familias, las críticas se centran en el hecho de que implica una mirada con un fuerte sesgo de cultural y de clase, en el que la familia nuclear aparece como único modelo posible. En este sentido es heredera de la perspectiva estructural funcionalista de Parsons.

No obstante ello, la segunda transición demográfica, y otra serie de cambios sociales y culturales han determinado que cada vez menos familias respondan a este patrón de familia nuclear, y que por ende no viven estas etapas en la secuencia y el modo antes descrito. Es frente a esta realidad que han aparecido algunas opciones teóricas que, destacando la importancia del análisis de la trayectoria de los grupos familiares, desarrollan una concepción más plural de la noción de familia. 


\subsubsection{Glen Elder: El enfoque de curso de vida y sus principios orientadores}

Retomando la preocupación por analizar a la familia desde una perspectiva diacrónica y biográfica, y resaltando la importancia de los momentos de transición, es que surge el enfoque de Curso de Vida (life course).

Apoyándose en una larga perspectiva histórica, esta obra contribuyó a orientar la sociología americana hacia el redescubrimiento de una dimensión dinámica: la de las generaciones, la de la edad, desarrollada actualmente dentro del marco conceptual del family life course, que relaciona, en una perspectiva diacrónica los cambios individuales y sociales (Glen Elder, 1984). (Segalen, 1992: 29)

Este enfoque no es exactamente una teoría, ya que se concentra mucho más en el modo de investigar, que en teorizar sobre la familia como objeto. Esta propuesta es particularmente interesante en la medida en que la familia constituye un objeto muy cambiante, de modo que el establecimiento de un conjunto de premisas para la investigación resulta fundamental.

El estudio de la familia como objeto de las ciencias sociales requiere, más que una teoría o conjunto de teorías, un programa de investigación. Tal es la propuesta elaborada por el sociólogo estadounidense Glen Elder (2000) que se concentra en un conjunto de conceptos que tiene un fuerte valor heurístico para comprender el proceso de las familias a lo largo del tiempo.

Ya hemos mencionado en el capítulo anterior que el autor trabaja con un conjunto de principios de investigación y conceptos que vale la pena mencionar.

- Principio de Desarrollo en el tiempo.

- Principio de tiempo y lugar

- Principio de timinig

- Principio de vidas interconectadas

- Principio de agencia.

El principio de desarrollo en el tiempo supone realizar un análisis que tenga en cuenta el proceso biográfico de las personas y familias, así como el contexto socio histórico en el que esta familia está inserta, representado en el principio de tiempo y lugar. De este modo el estudio de la biografía familias se contextualiza en el tiempo y lugar. 
No obstante ello reconoce al igual que el enfoque de ciclo de vida, que los seres humanos nos vemos influidos por un conjunto de marcadores de orden biológico que deben ser tenidos en cuenta, tales como los procesos de crecimiento, envejecimiento, fertilidad, esto es lo que constituye el principio de timing.

Por último hace referencia a que la familia debe ser concebida como una red de relaciones significativas y no como una sumatoria de individuos lo cual da el principio de vidas interconectas, y que más allá de la consideración de los factores biográfico e históricos, los individuos y familias tiene la posibilidad de ser sujetos activos en su proceso o principio de agencia.

Life course ideas focus on the changing contexts of lives and their consequences for human development and aging. The "individual life course" is structured by social influences and by the life choices people make in constrained situations. Any change in the way people live their lives affects their development and both are subject to change in established pathways in workplaces and communities. These pathways and trajectories of development and aging are interrelated across the life span. (Elder, 2000: 7)

Todos estos principios orientan la investigación que operacionaliza estos postulados generales en un conjunto de conceptos de entre los cuales podemos mencionar tres como fundamentales:

- Trayectoria

- Transición

- Punto de inflexión

Estos conceptos que actualmente han sido utilizados por diferentes estudios en el marco de la sociología de la juventud y de los estudios de la educación, tienen su origen esta perspectiva teórica.

La trayectoria refiere a la biografía, al conjunto de eventos que por los que transita la familia o el individuo en los diferentes ámbitos de los que forma parte, tales como la educación o el mundo del trabajo.

Así, esta perspectiva teórica pone especial énfasis en el análisis del entrelazamiento de las trayectorias vitales, tanto en un mismo individuo como en la relación de éste con otros individuos o conglomerados (de manera muy importante con la familia de origen y procreación). (Blanco, 2003, 163) 
Por transición se entiende desde esta perspectiva aquellos cambios en el curso de vida de las personas, que implican un cambio significativo de la situación y del estatus de los individuos. Estas transiciones, tal como vimos cuando mencionábamos el enfoque de ciclo de vida, no están predeterminadas ni por la biología, ni por la cultura, aunque son relativamente predecibles. Nos referimos puntualmente al tránsito a la vida adulta, la conformación de una nueva familia, el tránsito de la vida adulta a la vejez. Por último los puntos de inflexión refieren a cambios en el curso de vida de las personas, que no son en modo alguno previsible o esperable, como por ejemplo la muerte de un familiar, o un cambio repentino en la integración al mundo del trabajo. Al destacar tanto la trayectoria, como la importancia de las transiciones el enfoque de curso de vida, ha sido retomado por la sociología de la edad, en particular desde los estudios de juventud al momento de estudiar el tránsito a la vida adulta.

Vimos entonces que investigar sobre la familia desde un punto de vista científico supone tener en cuenta esta serie de principios, así como poder realizar un análisis diacrónico de su dinámica.

Por otra parte el análisis de su estructura, tal como vimos en los estudios anteriores, impone la consideración de las relaciones entre varones y mujeres, y entre jóvenes y adultos. Por este motivo a continuación abordaremos algunas cuestiones conceptuales básicas de los conceptos de género y juventud.

\subsection{Conceptos operativos referidos al Género}

Si bien el concepto de género es relativamente reciente en la bibliografía especializada y más aún en el uso cotidiano, las cuestiones a las que remite, es decir a las diferencias entre varones y mujeres, desde sus bases biológicas hasta la construcción social, no lo son en absoluto, sino que es uno de los clivajes más antiguos que se puedan analizar. Por este motivo no es posible determinar un comienzo concreto respecto de la problematización política de esta relación.

Tan solo a los efectos de marcar un inicio puede ser pertinente establecer como mojón del comienzo de la discusión moderna, en el marco de la ilustración, el trabajo de Mary Wollstonecraft, Vindicación de los Derechos de la Mujer. Este trabajo desarrollado a finales del siglo XVIII, inmediatamente posterior a las primeras revoluciones liberales y sus declaraciones de derechos asociadas, representa una de las primeras expresiones, 
y conjuga una mirada liberal asociada a la idea de derechos del iusnaturalismo, con una perspectiva crítica de las desigualdades entre varones y mujeres.

Concretamente el término "género" fue acuñado por John Money desde la psicología y en relación con los estudios de la transexualidad o como fue definido en ese momento disforia de sexo.

El trabajo de investigación desarrollado por el autor, centrado en el estudio de casos clínicos de personas transgenero, postuló la independencia de la sexualidad biológica, respecto de la construcción de dicha sexualidad de manera psicológica.

Para hacer referencia a esta última es que acuñó el concepto género, el cual postuló operaba con relativa independencia respecto de la sexualidad biológica.

Vale decir que aun siendo quién tiene la paternidad del concepto, su trabajo, en particular sus intervenciones clínicas, fueron muy criticadas, y algunos casos de reasignación de género que habían sido presentadas como éxitos por el autor, se descubrieron posteriormente como grandes fracasos.

De todas formas el concepto de género, en el sentido que mencionábamos de construcción social y psicológica, que posee una relativa independencia de la sexualidad biológica fue rápidamente retomado por el feminismo académico para trabajar sobre las determinaciones sociales asignadas al ser varón y mujer.

\subsubsection{Tres generaciones de los estudios de género}

En este capítulo trabajaremos a partir de la propuesta de Gioconda Herrera (1997), quien postula que la construcción del género como categoría por parte del feminismo académico surge de la necesidad de diferenciar la construcción social, de la realidad biológica de la sexualidad humana. En tal sentido es posible determinar tres generaciones en la construcción del género como categoría científica.

La trayectoria del concepto revela tres formas de constitución de un sujeto: el género como sujeto unificado, como sujeto construido y como sujeto deconstruido. El primero respondió a las necesidades del momento: el volver visible un conjunto de realidades que las categorías analíticas tradicionales habían mantenido rezagadas. Esto se lo hizo a base de una construcción binaria fija y esencialista que contraponía la Mujer al Hombre En este marco se sitúan los intentos estructuralistas, marxistas y psicoanalíticos (de la 
escuela de las relaciones objetales) por explicar la subordinación femenina y la valoración de le experiencia femenina. El segundo- el género como sujeto construido- permitió imaginar ya no sólo a la mujer sino a las mujeres y hasta a los hombres, de forma relacional.

Esta tendencia, representada por el constructivismo social, buscó definir al sujeto a partir de las circunstancias históricas, sociales y culturales específicas en que se desenvolvía. Con ello se abrió un nuevo abanico de definiciones para las relaciones de género, algunas veces contradictorias entre sí, sin un sujeto fijo sino históricamente situado. El tercero, el sujeto de-construido, introduce el problema del poder, del control sobre el sentido en las formas de conocimiento. Mujeres y Hombres no son únicamente construcciones históricas, portadores de un punto de vista esencial, sino que constituyen posiciones sociales en el tiempo y el espacio que pueden ser cuestionadas y modificadas. La pregunta dejó de ser cómo se construyen las relaciones de género para indagar quién las construye y para qué. (Gioconda Herrera, 1997: 207)

En la primera de estas generaciones el acento estuvo puesto en la definición de las categorías de hombre y mujer con sus particularidades. En la segunda generación se avanzó sobre la idea de construcción relacional de las concepciones de género. La última generación, realizó un giro posmoderno y profundizó en el componente político de esta construcción conceptual.

\subsubsection{Antropología, la construcción cultural de varones y mujeres}

Desde el punto de vista de la antropología a comienzos del siglo XX debemos destacar el abordaje que de las cuestiones de género se realizó, en particular intentando delinear la frontera ente lo biológico y lo social, en la que tiene que ver con las ideas asociadas a ser hombre y ser mujer.

En este sentido el trabajo de Ruth Benedict (1934) cuya tesis central, basada en el estudio de sociedades de indígenas de Norteamérica, desarrolla su concepto de modelos o patrones culturales (patterns of culture), a partir de la cual defiende la importancia de que la cultura frente a la biología para la definición de la conducta. 
La idea que estaba en juego en esta clase de estudios, particularmente importante para las cuestiones vinculadas al sexo y a su implicancia social, era precisamente la importancia de la cultura, entendida como una configuración coherente, en la determinación de los roles que explican la conducta.

Esta idea fue desarrollada particularmente para el caso de las cuestiones vinculadas al género por Margaret Mead (1972) que desarrolló su trabajo de investigación etnográfico, a partir del estudio de comunidades aborígenes de la Polinesia, arribando a la idea de que la sexualidad, y la construcción de lo que se entiende por varón y mujer depende de la cultura.

Si bien su trabajo ha sido muy controvertido en su momento y continúa siéndolo hoy, sobre todo en lo referente a su base empírica, tiene la importancia de plantear la posibilidad, a partir de su descubrimiento en la realidad de una sociedad y una cultura no patriarcal. Esto sustentó por primera vez con una base empírica la idea de que el patriarcado es una construcción social, y por ende no responde a cuestiones de la naturaleza humana.

La autora encontró evidencia de que estas sociedades vivían la sexualidad de manera mucho más abierta a la occidental, estableciendo paralelamente que en algunos casos las mujeres tenían un rol mucho más importante que los varones.

Como dijimos su trabajo fue polémico y luego surgieron voces que relativizaron su descubrimiento, sin embargo comenzó una línea de investigación que sería continuada por la antropología. Estos primeros trabajos intentaron desnaturalizar el papel subsidiario de la mujer en la sociedad concibiéndolo como un producto de la cultura y no de la naturaleza.

En posteriores estudios de las relaciones de género en el marco de la cultura y también desde la antropología se avanzó mucho más en la definición concreta de los mecanismos establecidos por la sociedad patriarcal. Tal es el caso del trabajo de Sherry Ortner (1974) quien problematiza la asociación del varón a los ámbitos públicos y de la mujer al ámbito doméstico.

En este caso su análisis plantea que en las diferentes sociedades se justifica este rol secundario asociando lo femenino a lo natural, en tanto que se asocia lo masculino a lo cultural. Siendo que la cultura se entiende como el ámbito superior de desarrollo humano se explica desde este lugar el rol subsidiario asignado. 
La dicotomía entre público y doméstico se convirtió en el punto de partida de numerosos análisis de la subordinación de las mujeres dentro y fuera de la antropología. Ortner complementa la oposición público/doméstico con la contraposición entre naturaleza y cultura para explicar la valoración cultural inferior de las mujeres. Para Ortner nociones culturales de lo femenino gravitan alrededor de características naturales o biológicas como la fertilidad, la maternidad, el sexo y esto las coloca en una posición de inferioridad frente a lo masculino. (Gioconda Herrera, 1997: 191)

Si bien su trabajo es heredero de la tradición de la antropología también reconoce influencias de la filosofía, en particular del trabajo de Símone de Beauvoir (1972).

\subsubsection{El género en el marco del patriarcado}

A mediados del siglo XX el aporte desde la filosofía de Simone de Beauvoir, plantea la cuestión de la sexualidad, su importancia en la construcción de la identidad, y en el caso de las mujeres la construcción de una identidad desde la otredad, no entendida como diferencia que enriquece sino como extrañeza, como alteridad.

En parte debido a la influencia del trabajo de Simone de Beauvoir, el análisis de las desigualdades de género en la academia norteamericana hasta mediados de los años 80 tomaron como base epistemológica el principio de alteridad.

Para de Beauvoir, la identidad femenina había sido históricamente reducida al estado de "Otredad", forjándose como negación de la identidad dominante, representada por lo masculino. (Gioconda Herrera, 1997: 190)

El aporte fundamental de Simone de Beauvoir es la asociación de los conceptos de sexualidad, identidad y política. Yendo un paso más adelante que la mera demostración de que la construcción de lo que se entiende por varón y mujer en cada sociedad depende de la cultura, analiza el rol político de esta diferenciación y de la construcción de identidad que posteriormente supone.

Tales ideas serán las que darán principal sustento a los actuales estudios académicos sobre el género como construcción social, política e identitaria.

Del mismo modo de lo que sucede con otros campos de las ciencias sociales, en los que el desarrollo académico, científico y filosófico corre de manera paralela y alimenta 
la reivindicación política, los estudios de género se han nutrido de los dos ámbitos. A continuación veremos algunos aportes significativos desde el punto de vista académico.

Actualmente los estudios de género, aun teniendo una importante variedad y diversidad, asocian el término a una construcción social denominada patriarcado, construcción que es por supuesto social y cultural, pero también política.

Desde esta perspectiva el patriarcado en tanto que sistema de dominación, asigna roles, que establecen para hombres y mujeres mandatos, que a su vez interactúan de manera compleja con la identidad que cada uno construye en relación a ellos.

Joan Scott distingue cuatro elementos fundamentales de la construcción de género:

-Los símbolos y los mitos culturalmente disponibles que evocan representaciones múltiples.

-Los conceptos normativos que manifiestan las interpretaciones de los significados de los símbolos. Estos conceptos se expresan en doctrinas religiosas, educativas, científicas, legales y políticas que afirman categórica y unívocamente el significado de varón y mujer, masculino y femenino.

-Las instituciones y organizaciones sociales de las relaciones de género: el sistema de parentesco, la familia, el mercado de trabajo segregado por sexos, las instituciones educativas, la política.

-La identidad. Scott señala que aunque aquí destacan los análisis individuales las biografías- también hay posibilidad de tratamientos colectivos que estudian la construcción de la identidad genérica en grupos. Esta es una parte débil de su exposición, pues mezcla identidad subjetiva con identidad genérica. (Lamas, 2000: 330)

En tanto construcción social y política, las nociones de género y los roles que reportan, interactúan de manera compleja con las ideas de familia que en cada sociedad se sostengan.

Como decíamos el clivaje hombre-mujer define roles que están íntimamente ligados a nociones como las de paternidad y maternidad, los cuales son diferentes en cada sociedad e interactúan con la construcción individual que cada integrante hace de su identidad. 
El otro gran parteaguas en las familias está dado por las relaciones entre adultos y jóvenes, a continuación veremos algunos elementos de su análisis académico.

\subsection{Conceptos operativos referidos a la Juventud}

Los estudios e investigaciones cuyo centro es la juventud son muy variados y numerosos si bien es relativamente reciente como campo de estudio independiente. Asimismo los intereses (juventud y educación, trabajo, política, etc.) y enfoques (como generación, como etapa en el ciclo de vida, como construcción social) varían significativamente.

Antecedentes relevantes pueden rastrearse hasta comienzos del siglo XX. Siguiendo el itinerario propuesto por José Antonio Pérez Islas (2008) en su texto "Juventud: Un concepto en disputa" podemos mencionar dos grandes enfoques tradicionales: la corriente generacional dentro del cual podemos integrar el enfoque funcionalista, y la corriente clasista, en la que se destacan los estudios culturalistas británicos.

\subsubsection{La corriente generacional y la corriente clasista}

Una de las primeras formas de abordar la noción de juventud es considerar a los jóvenes de una sociedad en un momento dado como un grupo que comparte un conjunto de particularidades que lo diferencian del resto de la sociedad. Desde esta perspectiva surge la noción de generación o cohorte.

Probablemente el primer autor que desarrolla una perspectiva sistemática a este respecto sea José Ortega y Gasset.

... el español José Ortega y Gasset que publica en 1923, su artículo "La idea de las Generaciones" donde plantea que la "generación", es el compromiso más dinámico entre masa e individuo; pueden ser los hombres del más diverso temple y pensar diferente, ser reaccionarios o revolucionarios, pero son individuos de su mismo tiempo. (Pérez Islas, 2008: 7)

Posteriormente, en el marco de la segunda generación de la escuela de Chicago el trabajo de Talcott Parsons (1942) abordó el concepto de Cultura Juvenil, elaborado por el autor en el marco de su artículo "Age and Sex in the Social Structure of the United States". 
Tanto para Parsons como para otros integrantes de la corriente estructural funcionalista como Merton (2002) o Eisenstadt (1956), la juventud resultaba interesante en tanto que se tomaba en cuenta la cultura juvenil de una generación, y se observaba la importancia de dicha cultura en la incorporación de las normas socialmente aceptadas y los roles adultos.

En esta perspectiva la juventud es entendida en tanto que un grupo de individuos que poseen, en el marco de la estructura social, un conjunto de características particulares, tales como una cultura, roles, un imaginario particular etc.

Joaquim Casal describe cuatro componentes en el enfoque de las generaciones.

La perspectiva de las generaciones se basa en cuatro aspectos: la descripción de las rupturas, la propuesta de la diferenciación de las subculturas

juveniles, la hipótesis entorno del narcisismo radical de los jóvenes y la consideración de la «juventud positiva». (Casal, 2006: 27)

Una fuerte crítica a esta visión surgió de lo que Pérez Islas denomina la corriente clasista, la cual incorpora al análisis de las relaciones entre jóvenes y adultos, otras dimensiones como el enfoque de clase.

En este contexto podemos mencionar el trabajo desarrollado por Clarke, Hall, Jefferson y Roberts (1975) en el marco del Centro para Estudios Contemporáneos de la Cultura de Birmingham se centró en el carácter de clase de la cultura juvenil, en directa oposición al concepto de Cultura Juvenil desarrollado por la Escuela de Chicago.

Si bien esta corriente intentó dar un giro a la noción de cultura juvenil propuesta por la sociología funcionalista, continuó trabajando con una noción de juventud en cierta medida apriorística, ya que si bien se incorpora el clivaje de la clase social, la juventud continuaba siendo considerada como algo obvio o como algo dado, los estudios posteriores cuestionarán el centro mismo de la noción de juventud.

\subsubsection{Juventud o juventudes, la juventud como construcción social}

Otro enfoque respecto de la categoría de juventud es aquel que se pregunta por su definición misma, y hasta qué punto la misma es una construcción social.

En este sentido es central el trabajo de Pierre Bourdieu (2002), desarrollado desde una óptica que critica los sustancialismos y que destaca el carácter relacional de las categorías con las que entendemos la realidad. La célebre entrevista que publicara a 
finales de la década del setenta bajo título "la juventud no es más que una palabra", postuló el carácter de construcción social del concepto.

Esta postura no supone ignorar que existe una realidad que merece ser llamada Juventud, sino que este concepto se construye en un campo de lucha ideológica, que define qué es ser joven y qué significa ser joven, desde el punto de vista político.

La representación ideológica de la división entre jóvenes y viejos alarga a los más jóvenes ciertas cosas que hacen que dejen a cambio otras muchas a los más viejos. Esto se ve muy bien en el caso del deporte, como, por ejemplo, en el rugby, donde se exalta a los "buenos chicos", esas buenas bestias dóciles destinadas a la oscura abnegación del juego de delanteros que ensalzan los dirigentes y comentaristas. (Bourdieu, 2002: 163)

Este campo de lucha de la reproducción cultural tiene sus propias reglas y formas de funcionamiento, y cada grupo lucha por su control utilizando como herramientas las distintas clases de capital que se posee. No se trata tan solo de capital en el sentido económico, sino de capital de diversas índoles, social, educativo, etc.

Como lo he mostrado respecto de la moda o la producción artística y literaria, cada campo tiene sus leyes específicas de envejecimiento: para saber cómo se definen las generaciones hay que conocer las leyes específicas de funcionamiento del campo, las apuestas de la lucha y cuáles son las divisiones que crea esta lucha (la "nueva ola", la "nueva novela", los "nuevos filósofos", los "nuevos magistrados"...). (Bourdieu, 2002: 16)

Más allá de los diferentes cortes que pueden atravesar esta lucha, a diferencia del enfoque que encontrábamos en la escuela de Birmingham, para Bourdieu la dicotomía joven-viejo tiene una relevancia que trasciende las diferencias de clase.

La lucha por la definición de lo que se entiende como joven, es una lucha que determina los atributos establecidos a esta categoría, en función del poder de quienes detentan la posibilidad de establecer esta definición. Se trata por ende de una lucha ideológica, en el plano de la cultura, pero que refleja el lugar político que cada grupo tiene en la sociedad.

Ahora bien, en tanto construcción social, la juventud se sustenta aún en algunos marcadores que son de origen biológico y que no pueden desconocerse. Esto es lo que 
lleva al investigador argentino Mario Margulis (2008) a decir que "la juventud es más que una palabra", en clara alusión al trabajo de Bourdieu.

Asimismo la definición de Margulis hace referencia a la pertenencia a una determinada generación que comparte de manera más o menos definida un conjunto de características y señas de identidad particulares.

Ser joven, por lo tanto, no depende sólo de la edad como característica biológica, como condición del cuerpo. Tampoco depende solamente del sector social a que se pertenece, con la consiguiente posibilidad de acceder de manera diferencial a una moratoria, a una condición de privilegio. Hay que considerar también el hecho generacional: la circunstancia cultural que emana de ser socializado con códigos diferentes, de incorporar nuevos modos de percibir y de apreciar, de ser competente en nuevos hábitos y destrezas, elementos que distancian a los recién llegados del mundo de las generaciones más antiguas. (Margulis, 2008: 19)

En este sentido la definición de término juventud aparece ligada tanto al proceso biológico como a la construcción social que define uno o varios modelos de lo que ser joven significa en un momento histórico y lugar determinado.

Este hecho ha dado lugar a que en las últimas elaboraciones teóricas suele hablarse de juventudes, intentando dar cuenta de esta diversidad.

En ocasiones, el uso del plural intenta salvar esta dificultad y sus consecuencias. Se habla de las juventudes aludiendo a diferentes formas de ser joven, a la existencia de multiplicidad, pero también a distintas construcciones "objetos juventud" que pugnan por la hegemonía, o que simplemente conviven. (Filardo, 2010:7)

Más adelante en este trabajo veremos como la existencia de tales diferencias, cobra una importancia central, para concebir la transición de la vida a la vida adulta, por jóvenes de diferentes contextos socio-culturales.

\subsubsection{De la moratoria social a la moratoria vital}

Uno de los elementos centrales, que articula aspectos sociales y biológicos en la definición de juventud, y hace referencia a su carácter de categoría relacional, es el concepto de moratoria social y moratoria vital. 
El primero de estos términos se refiere al tiempo del que disponen los jóvenes, en tanto son sostenidos económicamente por su hogar de origen, tiempo que pueden destinar, entre otras cosas, a su formación para el futuro.

Este concepto, resulta problemático si se toman en cuenta las diferencias en las condiciones económicas y sociales, y el hecho de que los jóvenes de los contextos menos favorecidos pueden virtualmente carecer de esta moratoria.

Es por este motivo que Margulis retoma el concepto de moratoria vital entendida como un plus de tiempo y energía que caracteriza el periodo de la vida, y que puede formar parte de la definición de juventud.

En este sentido es que la juventud puede pensarse como un período de la vida en que se está en posesión de un excedente temporal, de un crédito o de un plus, como si se tratara de algo que se tiene ahorrado, algo que se tiene de más y del que puede disponerse, que en los no jóvenes es más reducido, se va gastando, y se va terminando antes, irreversiblemente, por más esfuerzos que se haga para evitarlo. (Margulis, 2008: 20)

Ambos elementos, el biológico y el social definidos por la categoría de moratoria vital no deben sin embargo ocultar un elemento central en el tratamiento de la idea de juventud, y este es el hecho de que si bien pueden establecerse elementos comunes, existen pronunciadas diferencias entre las formas socialmente construidas de concebir y vivir la juventud.

\subsubsection{Transiciones y trayectorias a la vida adulta}

En el último tiempo en América Latina ha cobrado importancia el estudio de la juventud y el proceso de transición a la adultez. Estos estudio son herederos directos de las teoría life course que hemos reseñado en el apartado destinado a analizar la categoría familia.

En este contexto el trabajo desarrollado por el investigador catalán Joaquim Casal (2006) se ha constituido en una referencia, en lo que respecto a los estudios de juventud.

La juventud se entiende, desde este enfoque, como un tramo dentro de la biografía, que va desde la emergencia de la pubertad física hasta la adquisición de la emancipación familiar plena. Como nuestro contexto 
histórico pasa por el cambio domiciliario respecto a la familia parental o de origen (dimensión neolocal), la juventud no es otra cosa que un proceso social de autonomía y emancipación familiar plena, que concluye con el acceso a un domicilio propio e independiente. Es, pues, una concepción de juventud que adopta algunos aspectos de la teoría de roles y que incorpora la tensión familiar entre hijos y padres, pero que se focaliza en el proceso de adquisición, enclasamiento y de emancipación familiar plena: un proceso social que tiene lugar en un determinado tramo biográfico (las edades de los jóvenes). En este "constructo», la idea de itinerario y trayectoria tiene una gran centralidad y supone otra manera de ver o pensar la inserción social y profesional de los jóvenes y su transición a la vida adulta. (Casal, 2006: 28)

Como vemos el trabajo de Casal se concentra fundamentalmente en la transición en términos de emancipación del hogar de origen. En este sentido se toma en cuenta tanto los aspectos biográficos vinculados la conclusión del periodo destinado a la educación, al ingreso al mercado laboral y a la mudanza del hogar de origen o la conformación de una nueva familia.

Estos elementos han sido analizados en Uruguay por la Encuesta Nacional de Adolescencia y Juventud, que veremos más adelante en el capítulo destinado a antecedentes.

Sin embargo vale pena mencionar aquí uno de los ejes que este trabajo está relacionado con los hogares a los que pertenecen o que constituyen los adolescentes y jóvenes en nuestro país centrándose particularmente en los eventos de emancipación, autonomización e independencia tal como se definen a continuación.

Emancipación: Se entiende emancipados a los individuos que constituyen su propio núcleo familiar (sea conviviendo con pareja -independientemente del estado civil- con hijos, o con pareja e hijos).

Autonomización: un individuo es autónomo si vive en hogar diferente al de origen que, en la mayoría de los casos, es el hogar de al menos uno de sus padres.

Independencia: Se es independiente si la persona o su pareja ocupa el rol de jefe del hogar. (Filardo, 2010: 68) 
Ahora bien, resulta claro que la diversidad de formas que asume la juventud no nos permitiría hablar de una única forma de transición a la vida adulta, ya que esto equivaldría a volver a esquemas esencialistas y apriorísticos.

Es en este sentido que aparece la idea de que existe diversidad de modos de realizar esta transición, Casal distingue cinco posibilidades en su análisis de las transiciones a la vida adulta en el marco de la sociedad europea, según la particularidad asumida por cada una de las dimensiones estudiadas: formación, inserción profesional, emancipación del hogar de origen.

Todos estos elementos dan marco al concepto de trayectorias que aparece dando cuenta de la diversidad de opciones en la transición a la adultez. A partir de la noción de trayectoria es posible establecer la relación entre la estructura de posibilidades y el modo en que cada individuo desarrolla su biografía en el marco de esta estructura.

Ahora bien, que las estructuras de las transiciones tengan un carácter histórico, no quiere decir que cada época genere un solo modo de hacerse adulto común para todos. Por el contrario, en cada época hay diferentes «libretos» para las transiciones, cada uno característico de un grupo social específicos, como también de lo que cada grupo asigna a cada género. (Dávila, 2011: 7)

El elemento común es entonces la transición a la adultez, es decir el resultado, lo que varían son la trayectorias particulares que los jóvenes siguen en este tránsito común.

A los efectos de dar cuenta de estas diferencias es que Casal (2006) ha elaborado el concepto de trayectorias, mediante el cual se busca tipificar los diferentes modos en que dicha transición se lleva adelante. A partir del cruce de las variables vinculadas a los eventos antes descritos, abandono de estudio, ingreso al mercado de trabajo, emancipación y tenencia de hijos, Casal determina seis trayectorias típicas: Trayectoria de éxito precoz, trayectoria obrera, trayectoria de adscripción familiar, trayectoria de aproximación sucesiva, trayectoria de precariedad y trayectoria errática.

Resulta de gran valor heurístico la idea de que la clase social determina como se transitan esto eventos, sobre todo en el marco del análisis social que busca develar las casusas de la reproducción de las desigualdades sociales. 
Para el caso de Uruguay, la Encuesta Nacional de Adolescencia y Juventud 2008 (ENAJ) ha estudiado estas variables clave determinando trayectorias en este caso, vinculadas a la educación:

Las trayectorias son 1) trayectoria esperada en la que finaliza la educación media sin rezago en Primaria y sin rezago en el nivel medio; 2) trayectoria esperada lenta, en la que culmina la educación media con rezago producido en alguno de los dos niveles o en los dos; 3 ) trayectoria trunca temprana, en la que se egresa de Primaria, pero no se inicia la educación media; 4) trayectoria trunca media, en la que se inicia la educación media y se deserta sin aprobar el nivel;. 5) trayectoria inconclusa, en la que aún asisten a centros de educación media, por lo que no puede determinarse si finalizarán o no el nivel. (Filardo, 2008: 12)

También ha determinado la importancia que estas trayectorias diferenciales tienen en la reproducción de las desigualdades, en la medida en que el acceso al capital educativo es fundamental para definir la inserción laboral futura de los jóvenes.

Podemos afirmar entonces que el concepto de juventud aparece como una construcción histórica y social, desarrollada sobre la base de un proceso biológico. En su definición Margulis destaca como fundamentales las ideas de formar parte de una generación, y de poseer una moratoria vital.

Por su parte Casal retoma el concepto de juventud a partir de la idea de transición a la adultez, destacando el carácter biográfico definido por un pasaje establecido en tres dimensiones fundamentales: formación, inserción profesional y emancipación.

También veíamos la tendencia actual de trabajar sobre la idea de que existe diversidad de formas de transitar la juventud, por lo que era pertinente el uso del plural: juventudes, para expresar estas diferencias.

De este modo se configura la idea de la juventud como un doble constructo, una construcción social en sentido histórico, pero también una construcción biográfica personal, en el entendido de que cada joven reconstruye su propia vivencia de juventud a partir del repertorio de nociones existentes.

El tiempo biográfico se entiende, de acuerdo con Luckmann (1993), como el proceso a través del cual el sujeto da significado al curso de su propia vida 
sobre la base de esquemas interpretativos sacados del stock de conocimientos socialmente disponibles en un determinado momento histórico.

En estos esquemas el sujeto se apoya para construir un puente entre su propio tiempo interior y el espacio temporal que lo trasciende, el tiempo histórico-social en primer lugar. (Leccardi, 2002: 43)

Todos estos elementos dan marco al concepto de trayectorias que aparece dando cuenta de la diversidad de opciones en la transición a la adultez. A partir de la noción de trayectoria es posible establecer la relación entre la estructura de posibilidades y el modo en que cada individuo desarrolla su biografía en el marco de esta estructura.

Ahora bien, que las estructuras de las transiciones tengan un carácter histórico, no quiere decir que cada época genere un solo modo de hacerse adulto común para todos. Por el contrario, en cada época hay diferentes «libretos» para las transiciones, cada uno característico de un grupo social específicos, como también de lo que cada grupo asigna a cada género. (Dávila, 2011: 7)

El elemento común es entonces la transición a la adultez, es decir el resultado, lo que varían son la trayectorias particulares que los jóvenes siguen en este tránsito común, o lo que es lo mismo diferentes caminos para un destino único.

\subsection{Resumen del Capítulo: Familia, género y juventud}

En este último punto intentaremos una síntesis de los visto hasta ahora, concentrándonos en los aportes que desde el punto de vista teórico tiene mayor relevancia para el trabajo que estamos realizando.

Las elaboraciones teóricas sobre las nociones de familia, género y juventud tienen mayor potencial a los efectos de analizar la realidad cuando los consideramos de manera conjunta.

En tal sentido podemos comenzar diciendo que el estudio de la familia supone la consideración de la realidad, es decir las familias concretas, pero también de las nociones que las personas tienen respecto de la familia en un momento particular de la historia. 
Ya vimos que unas no coinciden necesariamente con las otras, y que la familia imaginada y expresada en una determinada terminología de parentesco no necesariamente tiene una relación unívoca y exacta con la terminología de parentesco, y con las nociones en general que los individuos tienen sobre las familias.

En tal sentido merecen especial atención las relaciones de pareja y de filiación, las cuales constituye dos de las más importantes estructuras a la interna de la familia, y determinando algunas de las clasificaciones tradicionales de la antropología.

De este modo las estructuras familiares han sido clasificadas como matriarcales o patriarcales, matrilineares o patrilineares en función de la autoridad y la filiación legítima. También es importante definir a las familias en función de su lugar de residencia distinguiendo entre familias matrilocales o patrilocales.

En la filiación unilineal sólo son reconocidos como parientes aquellos que descienden de una línea paterna o de una línea materna. El reconocimiento del individuo en su grupo de parientes puede hacerse por relación a un antepasado común determinado con el cual puede establecerse un lazo genealógico: es el linaje. (Segalen, 1992: 58)

Incorporamos entonces la idea de que la autoridad, la filiación legítima y la residencia, son tres características fundamentales que deben ser observadas en las familias, definiendo opciones: familias matriarcales, patriarcales o igualitarias, familias matrilineares, patrilieares o bilaterales, familias matrilocales, patrilocales o neolocales. Algunos de los más importantes estudios de la familia desde la sociología la han caracterizado como un sistema sumando al análisis de sus estructuras, la consideración de sus funciones.

Otro de los aportes desde esta perspectiva es una mirada diacrónica de la familia que incorpora la consideración de los ciclos o trayectorias familiares, según la perspectiva teórica.

Ya vimos que el concepto de ciclo de vida presenta dificultades al suponer un conjunto de etapas como necesarias, siendo que las familias reales son diversas y no necesariamente transitan por estas fases.

Sin embargo, lo que sí resulta pertinente es la consideración de un conjunto de eventos, más o menos directamente relacionados con marcadores biológicos, que definen transiciones y puntos de inflexión en la vida de las familias. 
Estas categorías provienen de la perspectiva life course, la cual establece un conjunto de principios de investigación que deben tenerse en cuenta. Los principios de tiempo y lugar por un lado y de agencia por otro colocan a la familia en el lugar de ser protagonista de su propia biografía, pero sin desconocer el contexto en el que se desarrolla su existencia.

Por su parte el principio de timing hace referencia a la consideración de la biografía de las familias, en tanto que el principio de vidas interconectadas establece la necesidad de pensar al grupo familiar y los vínculos recíprocos de sus integrantes.

La familia a su vez está transversalizada por ideas de género que asignan roles recíprocos, particularmente importante en lo referente a las nociones de paternidad y maternidad. En los párrafos anteriores hablamos de estas concepciones como una construcción histórica y política, íntimamente relacionada con las nociones de familia. En este sentido el género es una construcción social y política que repercute sobre la identidad que a su vez elabora cada individuo. Es así que nuestra sociedad patriarcal a definido históricamente para la mujer un rol privado y asociado a los elementos biológicos como la reproducción, en tanto que para el hombre establece un rol público asociado a lo cultural como el mundo del trabajo.

Si bien esta construcción ha sido cuestionada y ha perdido potencia en la definición de las identidades individuales, continúa estableciendo mandatos socialmente aceptados. Los roles e identidad de género, elaborados por los individuos particulares en el contexto de estas construcción histórica que ha sido definida como patriarcado, se ven fuertemente determinados, definiendo nociones respecto de un deber ser, en cuestiones tan importantes como las nociones de maternidad, paternidad, lugar en la satisfacción de necesidades y acceso a la esfera pública.

Las ideas respecto de los vínculos entre adultos y jóvenes también tienen una influencia significativa sobre las ideas de familia. En este sentido también es posible determinar una construcción histórica y política de lo que se entiende como juventud, adultez y vejez respectivamente.

Asimismo estudios posteriores, comenzaron a definir la juventud en términos relacionales como una construcción social. También lo que se espera de los jóvenes está en relación al clivaje adulto-joven y es una construcción social y política que determina la construcción de identidades. 
Estas construcciones también definen identidades y roles, asignando mandatos respecto de lo que los individuos deben ser y hacer, vinculados a cuestiones como la moratoria vital, la transición a la vida adulta y los eventos que definen dicha transición: abandono del hogar, comienzo de la vida reproductiva, finalización de los estudios, inclusión en el mundo del trabajo. 


\section{EL CONTEXTO:}

\section{LAS FAMILIAS URUGUAYAS EN EL MARCO DE UN MODELO DE DESARROLLO}

En el capítulo anterior elaboramos una aproximación conceptual a las nociones de familia, género y juventud, intentando dar cuenta de las principales aportaciones teóricas. En este apartado buscamos delinear el contexto, social y económico que establece un marco para el desarrollo de la vida de las familias uruguayas. Asimismo estas trayectorias familiares se expresan luego, de manera agregada en las transformaciones demográficas vividas por la población uruguaya.

El modo en que cada familia particular y el conjunto de ellas en general organiza y concibe su vida no surge de manera independiente del contexto, sino por el contrario estas transformaciones en las estructuras de las familias se ven condicionadas en buena medida por un contexto económico y social.

En este sentido buscaremos describir ciertas tendencias histórica de largo plazo que se pueden delinear en nuestro país en relación a procesos asociados acceso al bienestar por parte de las familias, y que han determinado el surgimiento y consolidación de un sector de población caracterizado por su dificultad en acceder a dicho bienestar y que ha sido definido, como veremos más adelante, como el Uruguay Vulnerado (Filgueira, 2005)

La consolidación de este sector de población con dificultades en el acceso al bienestar habla de la generación de distancias importantes entre la población, es decir de la instalación de una "gran brecha" (Filgueira, 2011) entre clases o estratos sociales. Veremos cómo esta brecha, si bien se establece en la segunda mitad del siglo XX, forma parte de un modelo de desarrollo cuyas raíces son más profundas y que compartimos con el resto de América Latina.

Asimismo queremos en este capítulo abordar las transformaciones demográficas que estos cambios socio-económicos han acompañado y en alguna medida generado, hablamos de la primera y segunda transición demográfica.

Veremos en este capítulo que si bien estos procesos poseen algunas características típicas que pueden delinearse, el Uruguay desarrolló ciertas particularidades estableciendo en ambos casos una pauta dual de transición, presentando cambios 
diferentes según clase social. Esta pauta demográfica dual, así como la breve ventana de bono demográfico forman también parte de nuestro modelo de desarrollo.

Por último describiremos en este capítulo algunas particularidades del Estado uruguayo, y su rol en la configuración de acceso de la ciudadanía al bienestar, intentando definir qué papel ha cumplido en la profundización o atenuación de esta gran brecha y este modelo demográfico dual.

\subsection{La gran brecha: surgimiento y consolidación del Uruguay vulnerado}

Durante décadas los uruguayos hemos sostenidos dos verdades que nos parecían evidentes: en primer lugar el Uruguay ha sido desde muy temprano una sociedad que tiende a la homogeneidad social y la integración, en segundo lugar esta característica nos hacía diferentes de lo que sucedía en gran parte del resto del continente.

Ambas afirmaciones formaron parte del imaginario de una "sociedad amortiguadora" (Real de Azúa, 1984) o del "Uruguay hiperintegrado" (Rama, 1987), sin embargo cabe preguntarse ¿en qué medida esta imagen refleja verdaderamente la historia de nuestro país?

Mirado con mayor detenimiento, el problema de la supuesta integración de la sociedad uruguaya no parece tan evidente. Tal es la conclusión a la que arriba Fernando Filgueira (2011) en un reciente trabajo de investigación denominado The Great Gap.

En este artículo el autor trabaja con dos premisas fundamentales, que contradicen el imaginario del que hablábamos. La primera es que existe un modelo de desarrollo latinoamericano, con ciertas características comunes a pesar de las diferencias entre los países, y que por supuesto nos incluye.

El segundo punto fundamental es que dicho modelo, implica para todas las sociedades latinoamericanas la existencia de una gran brecha (gap) entre sectores socioeconómicos. Esto echa por tierra la noción del imaginario uruguayo que nos sindicaba como diferentes dentro del continente, y suponía una sociedad de la integración.

Veamos con mayor detenimiento algunos de los elementos destacados como características fundamentales de este modelo de desarrollo propio de Latinoamérica. Filgueira expone que existen tres elementos constitutivos a saber: 
1. En primer lugar la fuerte desigualdad.

2. En segundo término procesos de urbanización signados por la pobreza.

3. En tercer lugar un bono demográfico corto dado la práctica coincidencia de la baja de la mortalidad y natalidad propias de la primera transición demográfica.

The high inequality, the urbanization whit poverty, and the short window of demographic opportunity are the result of a long-established historical features of the Latin American development models and are also related to and deepened by the transformations that occurred mainly between the late 1980 s and the beginning of the twenty-first century. The increase of inequality arose from several sources. These include the labor market; changes in family structure and arrangements, notably the new gender and social division of paid and unpaid work; the intergenerational challenge, evidenced in the changing ratios of child and old-age dependency; changes in the structures of opportunities for workers in these different generations; and changes in urban sociospatial segregation and segmentation. Indeed, these transformations produced even more stress on the historically fallible concordance between the social structure of risk in the region and its social protection framework. All these factors present a threat to any comprehensive transformation project, either because of the technical difficulties of shaping these policies or because of obstacles to obtaining the basis for political support. (Filgueira, 2011: 34)

El autor marca algunas de las posibles causas de la profundización de esta esta brecha: cambios en el mercado de trabajo, en las familias, en las relaciones de género vinculadas a cuestiones de cuidados, elementos vinculados a la cuestión generacional. Sin embargo el origen último de esta brecha surge históricamente por el desfasaje entre la estructura de riesgos y el sistema de protección social.

En los próximos párrafos abordaremos algunos de los puntos constitutivos de este modelo, cuyo carácter inequitativo se profundizó a partir de la década 80 del siglo pasado, ensanchando la fractura social, muchas veces a pesar de los esfuerzos redistributivos de los gobiernos progresistas. 


\subsection{Uruguay desigualdad y empleo}

El primero de estos puntos referidos a la alta desigualdad de la región es un elemento constitutivo del modelo de desarrollo uruguayo. Siendo América Latina el continente más desigual tal vez pueda parecer que el Uruguay tiene buenos niveles de distribución de la riqueza. Sin embargo el contexto no debe hacernos perder de vista nuestra realidad y el desarrollo histórico de este proceso.

El imaginario de país integrado, surge en buena medida del hecho de que Uruguay desarrollo en la primera mitad del siglo XX una sociedad de bienestar, en el que la gran mayoría de la población accedió como mínimo a la satisfacción de sus necesidades básicas, con la posible excepción de ciertos sectores de población rural.

Basado en un modelo sustitutivo de importaciones y de un amplio Estado interventor, este modelo de acceso al bienestar nunca resultó fuertemente igualitario y mantuvo en su seno importantes desigualdades. Tan es así, que ha sido definido como un modelo universalista estratificado (Filgueira, 1994), con pautas de acceso al bienestar bien diferenciadas.

Frente a la crisis internacional y nacional, y el agotamiento del modelo que se produjo en la segunda mitad del siglo $\mathrm{XX}$, estas desigualdades se ampliaron y la brecha entre pobres y ricos comenzó a ampliarse.

Si bien es cierto que en la última década, el crecimiento económico y la implementación de una batería de políticas sociales han disminuido la pobreza y la indigencia, la desigualdad se ha mantenido estable.

En un reciente trabajo desarrollado en conjunto por el PNUD y la Facultad de Ciencias Económicas y Administración, los autores Colafranceschi, Failache y Vigorito (2013) destacan el descenso de la pobreza que ha descendido muy fuertemente en la última década, pero que si se compara con los niveles previos a la crisis de 2002, los resultados son más humildes. Asimismo la desigualdad ha variado de manera mucho menos significativa.

En la gráfica 1 puede observarse que, en 2011 la incidencia de la pobreza de ingresos presenta su valor mínimo en 21 años, situándose claramente por debajo de los niveles previos a la crisis de 2002. Mientras tanto, el descenso de la desigualdad ha sido menos pronunciado, aunque en 2011 se ubica en 
valores similares los correspondientes a los primeros años de restauración democrática.

Sin embargo, desde la perespectiva del desarrollo humano, un mayor acceso a los reucross, en cuanto medios, no asegura que estos se traduzcan en logros en otras dimensiones del bienestar, por lo que resulta importante analizar estos aspectos en el período considerado. (Colafranceschi, Failache y Vigorito, 2013: 15)

Grafico 1 Evolución de la indigencia, la pobreza y la desigualdad en Uruguay. Línea INE (2006). Localidades de 5000 habitantes y mas, 1990-2011.

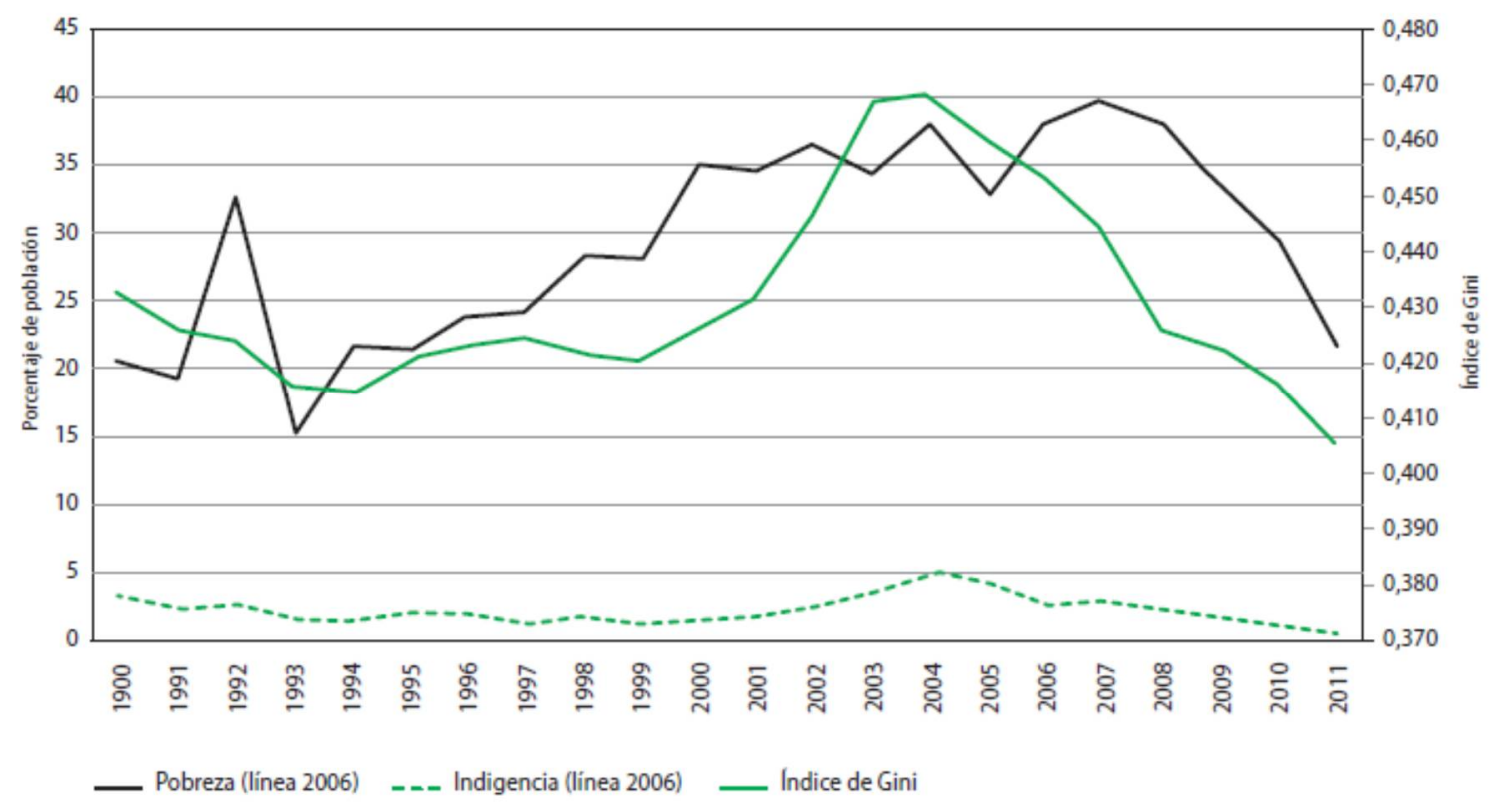

Fuente Colafranceschi, Failache y Vigorito, 2013

Esta desigualdad histórica de nuestro país se amplió y consolidó frente al agotamiento del modelo sustitutivo de importaciones, y su concomitante e incipiente proceso de industrialización. Gran parte del modelo de acceso al bienestar se sostenía en el acceso de importantes sectores de población al empleo, con ciertos niveles de calidad.

La crisis económica impactó directamente en los niveles de empleo, y desempleo, pero fundamentalmente en la calidad del empleo de tal suerte que aún en contextos de expansión económica y altos niveles de ocupación como el actual, la población empobrecida tiene dificultades para satisfacer sus necesidades básicas aun contando con un trabajo remunerado. 
Si bien en los últimos años las cifras de desempleo ha disminuido de manera significativa, al punto en que estaríamos cercanos a los guarismos de desempleo estructural, también es cierto que la calidad del empleo y las remuneraciones continúan siendo problemas significativos para el país.

Del estudio se concluye que ha habido importantes avances en términos de formalización de los trabajadores, pero estos avances han sido dispares y han dejado atrás algunos grupos que es necesario atender. Los rezagos en la formalización de los trabajadores menos educados y la persistencia de la brecha salarial formal-informal señala uno de los flancos que aún permanecen débiles. La informalidad concentrada en pocos sectores es otra dimensión que agrega complejidad al problema. La asociación de la informalidad a sectores de bajo requerimiento de calificaciones, ya señalada también en otros trabajos, podría ser una guía adicional para orientar las políticas tendientes a la regularización y mejora de la calidad del empleo, en torno al estímulo a la generación de las capacidades adecuadas. (Doneschi, Patrón, 2012: 17)

\subsection{Urbanización con Pobreza, segregación socio territorial}

Los procesos de consolidación de una brecha social entre sectores sociales tienen un correlato claro en los procesos de segregación socio territorial. Al igual que lo que sucede en para el caso del acceso al bienestar, no es cierto que el Uruguay haya sido nunca una sociedad en la que la población se distribuyera homogéneamente en el territorio más allá de su clase social.

Sin embargo la consolidación de la brecha social, a partir de la segunda mitad del siglo $\mathrm{XX}$, ha tenido un correlato en la profundización de este proceso de separación de la población.

Nuevamente, si bien la relativa bonanza económica y aumento de la inversión pública han tenido cierto impacto en la mejora de los problemas de hábitat, esto no ha logrado revertir la tendencia de segregación.

Estos procesos tienen a su vez impacto en la consolidación de las diferencias a nivel socio-económico, dado que aquellos uruguayos que residen en las zonas pobres de las ciudades, tienen más dificultades para acceder al empleo y la educación de calidad. 
Ya sea por cuestiones de capital social, de locomoción o simplemente de estigma que genera, las investigaciones demuestran que vivir en un barrio pobre disminuye las posibilidades de protagonizar procesos de ascenso social.

Los hogares pobres tienden a agruparse en espacios urbanos más homogéneos, alentando una lógica de segregación residencial, pero esta segregación a su vez, deprime la capacidad para generar ingresos autónomos y por este motivo transforma la privación en exclusión social, pues se deterioran los canales que permitirían el tránsito de una situación de ingresos deprimidos a otra con remuneraciones relativamente más altas. (Arim, 2008: 92)

\subsection{Primera y segunda transición demográfica: consolidación de un modelo dual}

El tercer elemento destacado como parte del modelo de desarrollo latinoamericano es la existencia de un bono demográfico de relativa corta duración, dada la cercanía en el tiempo de la baja de la natalidad y mortalidad, propias de la primera transición demográfica.

Para poder comprender a cabalidad el significado de este proceso será necesario introducir aún de modo esquemático algunos conceptos propios de la demografía, en particular aquellos vinculados al estudio de la familia.

El análisis demográfico de la familia supone el examen de la agregación de las unidades domésticas u hogares, de su tipología, y de las consecuencias poblacionales de dicha agregación.

Los tipos de hogar predominantes en una sociedad son elementos centrales en el análisis demográfico. Asimismo el cambio en los tipos de hogar presentes en la sociedad determinará luego cambios poblacionales que deben ser tenidos en cuenta.

Dos de las más importantes proceso demográficos que pueden visualizarse en diferentes países, en el marco de su proceso de modernización son las denominadas primera transición y segunda transición demográfica.

Si bien no puede decirse que operen del mismo modo en todos los países existen ciertas regularidades, originadas fundamentalmente en el hecho de que las mismas causas pueden identificarse en el origen de estos cambios. 
Estos procesos poblacionales remiten a cambios en las estructuras familiares y de edad, típicamente la primera transición demográfica se produce como consecuencia de la instalación y expansión de tipo de familia nuclear, aunque hay otros procesos asociados y la segunda transición demográfica está relacionada con el retroceso de la universalización de este modelo de familia.

Aun cuando estos procesos son globales, y remiten a grandes números poblacionales, difícilmente pueda decirse que son procesos homogéneos. Muy por el contrario la evidencia empírica demuestra que el Uruguay ha transitado en ambos casos a partir de modelos duales.

La primera transición demográfica fue descrita originalmente por Notestein (1945) quien estableció cuatro etapas: pre-transicional, primera etapa de la transición, segunda etapa de la transición, y tercera etapa de la transición en la que el fenómeno está completo.

Las causas de este fenómeno, si bien las particularidades divergen de país en país, son fundamentalmente dos: la primera de ella tiene que ver con los procesos de mejora de la calidad de vida y adelantos a nivel del cuidado de la salud, que permiten disminuir la mortalidad general de la población. La segunda causa, ya la mencionamos y está relacionada con la instalación del tipo de familia nuclear, una de cuyas consecuencias habitualmente observada es la disminución de la natalidad.

La primera etapa de la transición describe el estado de situación de una sociedad previo a la transición. Se trata de sociedades con altos niveles de mortalidad compensada con altos niveles de natalidad, asimismo existen con altos porcentajes de población infantil y joven, en relación al total de la población. Se trata de sociedades en las que predominan los arreglos familiares extensos y con alto número de niños.

La segunda etapa, primera de la transición propiamente dicha está caracterizada por la baja en la mortalidad como consecuencia de la mejora tecnológica y de calidad de vida. Recordemos que esta transición se establece de modo paralelo al crecimiento económico y la modernización de la sociedad. Este proceso determina directamente el crecimiento de la población.

En la tercera etapa de la transición disminuye la natalidad como consecuencia de la mejora en la calidad de vida y el establecimiento del tipo de familia nuclear como tipo 
dominante. Esto provoca que el crecimiento poblacional que se verificó en la anterior comience a sufrir un declive.

Durante esta etapa puede describirse el fenómeno denominado bono demográfico. Dado que la mortalidad suele disminuir primero que el fenómeno de disminución de la natalidad, y teniendo en cuenta que la mortalidad suele disminuir como resultado de la disminución de la mortalidad infantil, existe un periodo de tiempo en el que la población joven aumenta en relación a la población envejecida, esto determina que la relación entre población activa y población pasiva sea muy positiva.

Este proceso tiene una duración variable según el país, pero tarde o temprano termina, debido a que la disminución de la natalidad compensa la disminución de la mortalidad.

La última etapa describe el estado de situación al final del proceso, caracterizado por una estabilización del crecimiento poblacional, en muchos casos en tasas cercanas a los guarismos mínimos de recambio poblacional, hecho que determina un envejecimiento relativo de la población en comparación a la etapa pre transicional.

Este proceso de transición vivido por el Uruguay tempranamente, teniendo sus primeras expresiones al final del siglo XIX.

Uruguay, a diferencia de la mayoría de los países de América Latina, inició las transformaciones propias de la primera transición demográfica a fines del siglo XIX y principios del XX. La precocidad de este proceso determinó que en los años sesenta los niveles de fecundidad y mortalidad estuvieran ubicados en una etapa transicional avanzada, con una tasa global de fecundidad (TGF) de 3 hijos por mujer. En los años siguientes continuó el descenso paulatino de estos indicadores, aunque a un ritmo bastante menor que el registrado en la primera mitad del siglo (Pellegrino, 2003), lo que en la actualidad posiciona al país en una fase muy avanzada del proceso - en el 2005 la TGF era 2,04 (INE, 2006). (Varela, 2007: 21)

Los motivos que llevaron a que este proceso de transformación se diera tempranamente en el Uruguay son los mismos que explican la temprana emergencia de otros procesos sociales, y han sido descritos de la siguiente forma:

Las evidencias disponibles permiten visualizar como principales factores de incidencia: a) el impacto cultural de la inmigración europea sobre un territorio 
escasamente poblado; b) la incorporación temprana al modelo occidental; c) unida a todo ello, una urbanización temprana que ha llevado a que hoy el 91\% de la población sea urbana; d) una actividad económica basada fundamentalmente en la ganadería extensiva; e) el reparto latifundario de la tierra, que ha impedido el desarrollo de una población rural, la cual suele tener altos niveles de reproducción; f ) una forma de explotación de la tierra que no genera alta demanda de mano de obra; g) características de la actividad económica que no estimulan el crecimiento de núcleos urbanos intermedios y consolidan el crecimiento de la ciudad capital, principal puerto exportador (Barrán y Nahum, 1979; Pellegrino y Pollero, 1998; Varela, 2004). (Varela, 2007: 23)

No obstante su temprano surgimiento, cuando se mira en detalle este proceso que refleja grandes números de población, puede encontrarse una pauta dual que define pautas reproductivas modernas, y otro con pautas reproductivas tradicionales, asociado al nivel socioeconómico.

Ello ha dado lugar a la convivencia de modelos demográficos distintos. En términos extremos: a) uno está compuesto por población en condiciones sociales y económicas privilegiadas, que le permiten adoptar pautas de comportamiento reproductivo de tipo moderno, con un bajo número de hijos por mujer y un calendario de la fecundidad más tardío; y b) otro está integrado por grandes sectores en condiciones sociales desprotegidas, que muestran un comportamiento de tipo tradicional, con un inicio más temprano de la trayectoria reproductiva (20 años en promedio), lo cual da como resultado un número elevado de hijos y concluye en muchos casos en una fecundidad no deseada (Varela, 1995, 2004; Paredes y Varela, 2005; Cabella, 2006). (Varela, 2007: 24)

Esto significa que, si bien a grandes números el Uruguay desarrolló y concluyó la primera transición demográfica, la desigualdad instalada en el país, nunca permitió generar una pauta homogénea en esto procesos poblacionales.

Como correlato de esto, al final de la primera transición demográfica era posible encontrar familias que respondían al modelo nuclear, y otras que mantenían viejas pautas reproductivas: familias jóvenes, con muchos hijos. 
Sobre esta pauta dual el Uruguay ha vivido la segunda transición demográfica, proceso que vino a consolidar la separación mencionada.

El proceso denominado Segunda Transición Demográfica, concepto de Lesthaeghe (2011), ha sido observado también en múltiples sociedades y está caracterizada fundamentalmente por cambios en los arreglos familiares, asociados a la disminución de la tasa de natalidad en los sectores socioeconómicos medios, aumento significativo de familias recompuestas, aumento significativo de nacimiento de hijos fuera del matrimonio y aumento de la tasa de divorcios.

Todos estos cambios tienen en común el hecho de distanciar a los hogares del tradicional modelo de familia nuclear. Tal evento se refleja en los datos de la Encuesta Continua de Hogares (ECH), para el año 2014 el tipo de hogar nuclear con hijos representaba tan solo el $34.5 \%$ del total de hogares existentes en el país.

Las tendencias que caracterizan a la segunda transición demográfica refieren básicamente a los niveles de fecundidad, que descienden luego del fin del baby boom (llegando a ubicarse por debajo del nivel de reemplazo poblacional) y a las transformaciones familiares que operan en función del incremento de divorcios, de la menor durabilidad del vínculo matrimonial, de la aparición y extensión de la cohabitación pre-matrimonial y del aumento de los nacimientos fuera del matrimonio. La conjunción estos factores genera nuevos modelos de convivencia y nuevos arreglos en la conformación de las familias. (Paredes, 2003: 74)

A nivel de las familias, estas transformaciones han sido definidas como la segunda transición demográfica y puede caracterizarse de la siguiente manera:

Estos cambios reflejan profundas transformaciones en el mundo del trabajo y del empleo, en los roles sociales, en las expectativas reproductivas y en la convivencia. Entre ellas, se pueden destacar:

- Expectativas de las mujeres de sectores medios de aplazar la maternidad hasta alcanzar metas laborales y académicas.

- Incremento de los divorcios y aumento de la cohabitación prematrimonial.

- Incremento de los nacimientos fuera del matrimonio.

- Disminución del número de hijos deseados.

- Convivencia de nuevas uniones familiares con hijos de uniones anteriores. 
Si bien estos cambios están sujetos a los diferentes grados de pertenencia a estratos socioeconómicos y culturales, algunas expectativas atraviesan el discurso de mujeres y varones de todos los sectores. (Güida, 2007: 15)

La desigualdad económica que hemos descrito como propia del modelo de desarrollo de nuestro país y que impactó en la primera transición demográfica, también tuvo repercusiones para el caso de la segunda transición demográfica estableciendo un patrón dual de población.

Pero más allá de estas especificidades, Uruguay comparte una característica de la región: los comportamientos demográficos se han diferenciado por sectores sociales. Como mencionábamos más arriba, si bien en el caso de la primera transición demográfica podemos hablar de dos modelos distintos que se presentan en el contexto latinoamericano en función de los sectores sociales, en el caso de la segunda transición demográfica se imponen similares consideraciones. (...) Aun cuando no podemos explayarnos aquí en el análisis de estos procesos por sectores sociales conviene adelantar que para el caso de la fecundidad, los avances realizados demuestran un desequilibrio grande por el cual el promedio de los hijos tenidos por las mujeres menos educadas, inactivas y con condiciones de vida carentes es sensiblemente mayor al promedio alcanzado por el otro extremo de las condiciones sociales mencionadas. (Paredes, 2003: 96)

En definitiva puede observarse como, si bien el Uruguay se destaca en el contexto latinoamericano desarrollando tempranamente ambas transiciones, no es menos cierto que comparte con los otros países el hecho de que este proceso global, adquiere características diferenciadas por clase social, si se mira con mayor detalle.

Esto ha determinado la consolidación de una pauta reproductiva doble, en la que un sector de la población, particularmente el más pobre no ha acompañado, o lo ha hecho con particularidades, las dos transiciones demográficas.

Un detalle mayor de los procesos vividos por las familias uruguayas desde el principio del siglo XX supondría un trabajo en sí mismo. Sin embargo podemos decir que durante la primera transición demográfica ciertos sectores poblacionales no acompañaron la instalación del modelo de familia nuclear que implicaba, sosteniendo arreglos familiares amplios y jóvenes. 
Asimismo durante la segunda transición demográfica esta pauta diferenciada se mantuvo y si bien el cuestionamiento al modelo de familia nuclear es global, es en los sectores de mayor pobreza donde pueden observarse pautas más tradicionales en lo que respecta a los roles de género.

Finally, economic inequality is reflected in fecundity patterns and polarized family arrangements where the risk is focused on poor families and particularly on their children, who increasingly represent the majority in the biological reproduction on the Latin America countries. Deep inequalities and superficial states are the distinctive features of Latin America development. An additional, aggravating factor is that inequality has come of age. This means that countries have begun aging, and therefore, their inequality structures have become more rigid. This increased rigidity has at least two causes. First, welfare states tend to focus their expenditures on seniors, and thus the shares of spending that could have been allocated to attacking the original inequalities decreases. (Filgueira, 2011: 54)

Esta pauta dual presenta las siguientes dificultades. En primer lugar, en tanto que los números globales de nuestra sociedad definen una primera transición demográfica muy avanzada, el bono demográfico está en pleno desarrollo, lo cual implica un desafío para el país, en la medida en que no es esperable que se extienda por muchos años más.

Sin embargo la pauta dual de comportamiento reproductivo mantiene a un sector de la población con características de familias tradicionales. Esto se refleja en los patrones de fecundidad diferenciales de las familias pobres con alto número de hijos y padres jóvenes, lo que las torna aún más vulnerables, dado que en nuestro país el gasto público está fuertemente dirigido a los adultos.

\subsection{Arquitectura de Bienestar y transferencia entre generaciones y géneros}

En orden de comprender los procesos vividos por las familias resulta necesario analizar las respuestas del Estado, paralelamente y en constante interacción con los procesos socio-económicos, urbanos y demográficos descritos. La consideración conjunta de todos estos factores ha sido definida como Arquitectura del Bienestar (EspingAndersen, 1999). 
Dicho concepto presupone la idea de que a lo largo de su vida, las personas y las familias obtienen su bienestar y satisfacen sus necesidades a partir de recursos obtenidos en diversos ámbitos de la sociedad. Ya sea a través de actividades productivas en el contexto del mercado de trabajo, mediante recursos obtenidos a partir de su vínculo con el Estado o a partir de transferencias de la familia o la comunidad. El estudio de cómo se produce y distribuye la riqueza, así como su consumo y ahorro es objeto de diferentes análisis desde la economía y la sociología. Cada uno de estos tres componentes (mercado, Estado, familia y comunidad) integran lo que se ha definido como la Arquitectura de Bienestar y si bien pueden ser estudiados de manera independiente, solo la visión de conjunto permite comprender cabalmente sus impactos ya que la interacción y sumatoria de sus efectos es lo que define el bienestar de una persona o una familia en un momento particular.

Esta Arquitectura del Bienestar, entendida como una particular configuración histórica de los tres ámbitos otorgadores de bienestar es resultado, al tiempo que repercute de manera significativa con las características demográficas que asume la población.

El Uruguay tiene, desde esta perspectiva, algunas particularidades como veíamos antes, se trata de un país que realizó tempranamente la primera transición demográfica, y que también de manera temprana desarrolló una estructura de protección social de carácter universal, asociada a un modelo sustitutivo de importaciones que proveía empleo.

Si bien no puede decirse que el nivel de acceso al bienestar fuera igualitario sino más bien estratificado (Filgueira, 1994), lo cierto es que, aun reconociendo los niveles de desigualdad, el acceso al bienestar abarcaba prácticamente a la totalidad de la población.

Dicha particular configuración de la Arquitectura de Bienestar comenzó a resquebrajarse con el agotamiento del modelo sustitutivo de importaciones, y las transformaciones demográficas que mencionábamos.

Frente a estas transformaciones la respuesta del Estado no ha logrado adaptarse con la rapidez necesaria, produciendo un importante desfasaje entre la estructura de protección y las necesidades de la población, producto de la precarización de las condiciones del empleo, y transformaciones en los tipos de arreglos familiares. 
Dos cambios fundamentales se producen en las esferas del mercado y de las familias. Por un lado, los mercados laborales empiezan a presentar signos claros de desempleo estructural y precarización de las relaciones laborales (PNUD, 2003; Kaztman et al., 2003). Por otro, los arreglos familiares se tornan notoriamente más inestables y aparecen nuevos arreglos, especialmente aquellos vinculados a la unión libre y a la monoparentalidad con jefatura femenina. (Filgueira, 2005: 9)

La respuesta del Estado frente a estos fenómenos permaneció incambiada, produciendo un desfasaje. No se puede sostener que se haya producido, como en otros países de la región, un desmantelamiento de la estructura de protección estatal, pero si podemos hablar de la falta de respuestas adecuadas a los procesos que estaban sucediendo.

El análisis de las transferencias intergeneracionales marca con claridad esta falta de respuesta. El monto de estas transferencias puede establecerse a partir de la metodología NTA (national transfer accounts) o sistema de transferencias inter generacionales elaborada por un conjunto de investigadores de la Universidad de California y aplicado a nuestro país por Bucheli, González y Olivieri (2010).

Esta metodología plantea como punto de partida una igualdad contable entre las fuentes de recursos que tienen las personas y los usos que hacen de dichos recursos. 0 dicho de otro modo, cada vez que un individuo o grupo de individuos consume o ahorra, debe obtener los recursos para esto mediante un flujo de ingreso que puede provenir de diversas fuentes.

Las fuentes de ingresos tipificadas son tres: ingreso laborales (Y1), ingresos provenientes de bienes o activos $(\mathrm{Ya})$ y transferencias recibidas $(\mathrm{T}+)$. Por otra parte los flujos de egreso, o usos de recursos están tipificados como: el consumo (C), el ahorro (S) y las transferencias realizadas (T-). Las transferencias recibidas o realizadas se viabilizan tanto a nivel privado como por ejemplo las transferencias intrafamiliares, o a través del Estado mediante el pago de impuestos que financian prestaciones para otras personas.

De este modo se obtiene una ecuación, a partir de la igualdad planteada al comienzo que puede formularse en los siguientes términos: 


$$
\frac{Y^{1}(e)+Y^{a}(e)+T^{+}(e)}{\text { Inflows }}=\frac{C(e) S(e)+T^{-}(e)}{\text { Outflows }}
$$

Reordenando los factores de dicha ecuación podemos obtener dos conceptos claves que tienen a su vez una expresión numérica concreta para cada caso particular: el déficit de ciclo de vida y las transferencias netas.

El primero de estos conceptos establece para cada tramo de edad la diferencia entre lo que se produce y lo que se consume. Concomitantemente las transferencias netas establecen la diferencia entre las transferencias realizadas y los beneficios obtenidos mediante estas transferencias.

$$
\begin{aligned}
& \frac{C(e)-Y^{1}(e)}{\text { Déficit del ciclo }}=\frac{Y^{a}(e)-S(e)}{\text { Reasignaciones con }}+\frac{T^{+}(e)-T^{-}(e)}{\text { Transferencias }} \\
& \text { de vida base en activos netas }
\end{aligned}
$$

Existen típicamente dos períodos de la vida en los que se expresa un déficit del ciclo de vida y en el que por ende es necesario que las transferencias netas tengan un carácter positivo, estos son la infancia y la vejez.

Por otra parte, la etapa de actividad de los individuos se caracteriza por un nivel de producción mayor al consumo y por ende una tasa de transferencias netas negativas. Mediante esta metodología es posible visualizar los montos de este déficit en el ciclo de vida y estudiar la magnitud y el origen de las transferencias inter generacionales que vienen a cubrir dicho déficit.

El caso uruguayo ha sido analizado como decíamos por Bucheli, González y Olivieri (2010) en un estudio que permite analiza los datos de los años 1994 y 2006 y permite comparar sus resultados. En los dos gráficos que vemos a continuación, podemos observar la variación del déficit del ciclo de vida y el perfil de las transferencias netas para los años establecidos. 
Tal como lo decíamos las etapas de mayor déficit del ciclo de vida es en la infancia coincidente con la moratoria de la infancia y juventud, y la vejez luego de la edad de retiro. Correspondientemente es en estas etapas en las que las personas reciben transferencias, tanto del Estado como de la familia y la comunidad.

Gráfico 2 Uruguay: Perfil del Deficit del Ciclo de Vida por Edad, 1994 y 2006 (pesos uruguayos de 1994)

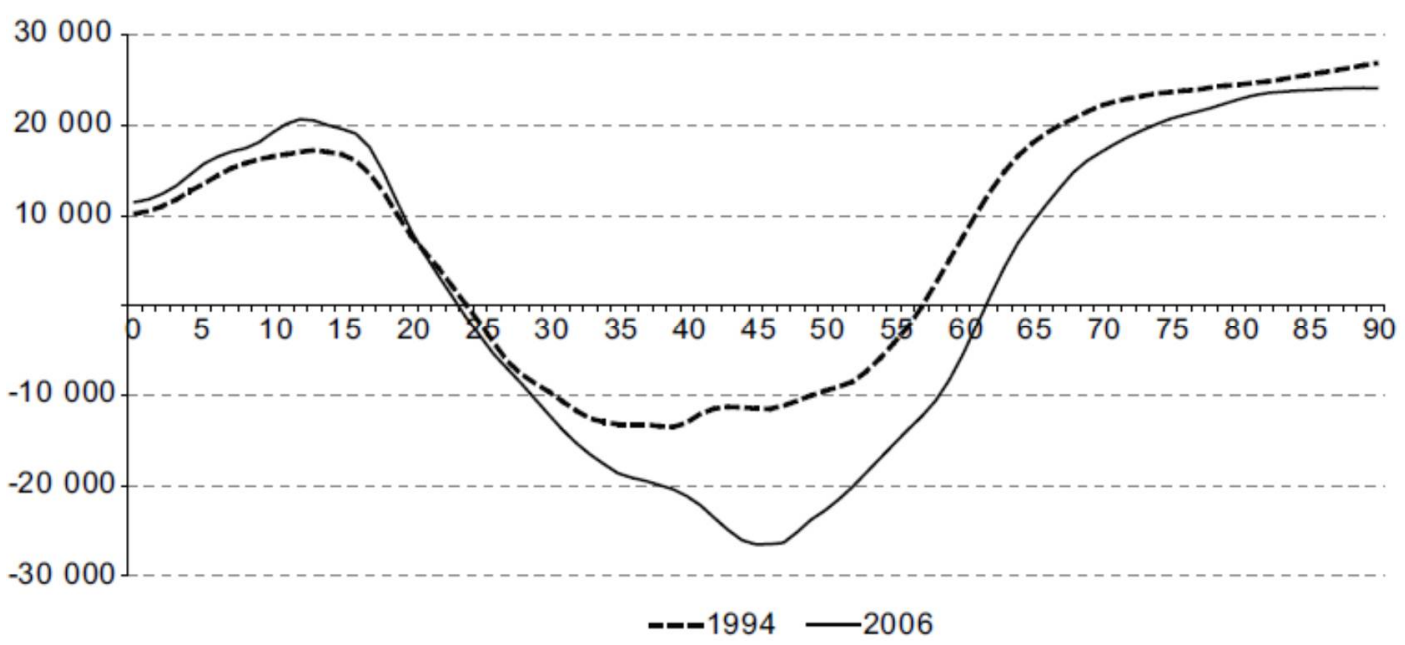

Fuente: Bucheli, González y Olivieri (2010)

Gráfico 3 Uruguay: Perfil de las Transferencias Públicas Netas, por edad, 1994 y 2006 (pesos uruguayos de 1994)

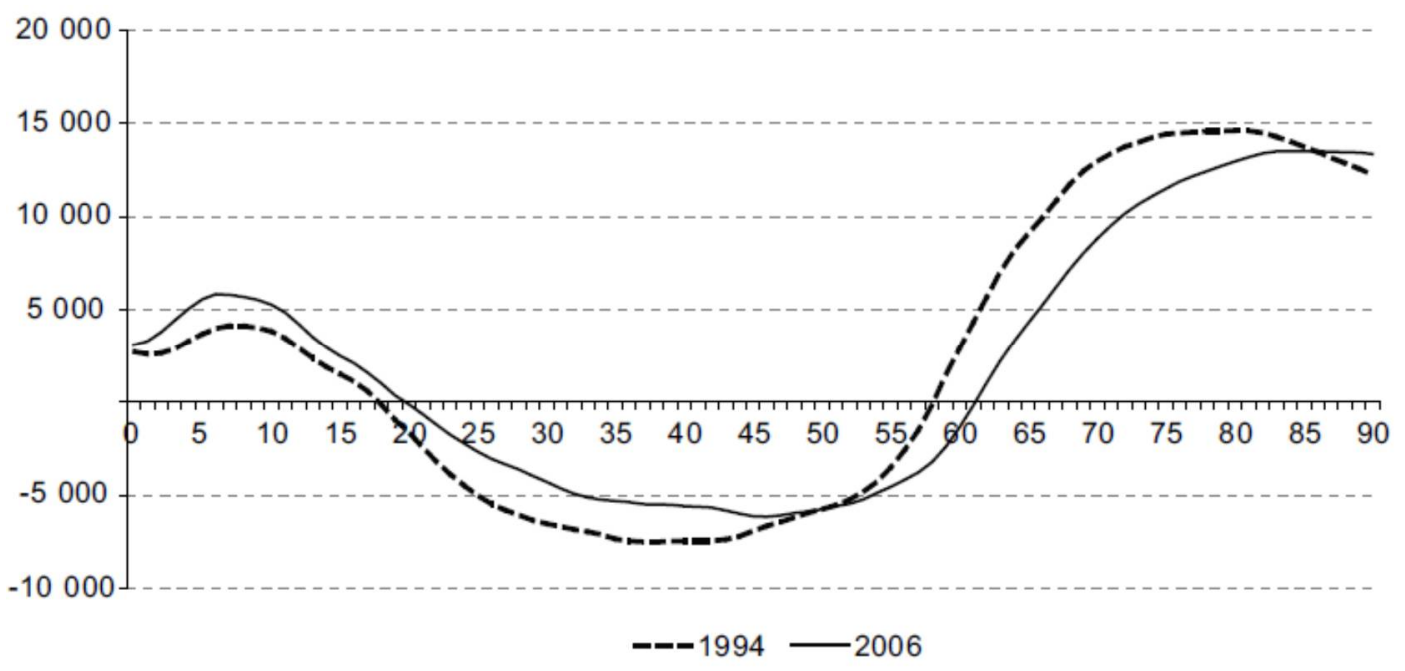

Fuente: Bucheli, González y Olivieri (2010) 
Sin embargo estas gráficas nos permiten ver otras características importantes de la configuración de la Arquitectura de Bienestar para el caso uruguayo.

En primer lugar es posible observar una importante diferencia en el nivel de las transferencias que favorece ampliamente a la población envejecida por encima de las transferencias realizadas hacia la infancia y juventud.

Esto se explica en buena medida por el sistema de protección establecido para el caso uruguayo asume que buena parte del costo de la moratoria social de la infancia y juventud debe ser asumido por las familias, sin embargo desarrolla un sistema de protección social para la vejez.

Aun así es posible observar una variación importante en ambos indicadores en el período que va desde 1994 a 2006. En primer lugar se observa que el déficit de ciclo de vida se ha postergado para el caso de vejez, alargando la etapa activa de los individuos. Esto se explica por la transformación en las leyes jubilatorias que aumentaron la edad de retiro para hombres y mujeres así como otros cambios demográficos tales como el alargamiento de la esperanza de vida.

A su vez se puede percibir una disminución en el monto de transferencias a la vejez, que se explica en parte por el alargamiento de la etapa activa así como también por la reforma del sistema jubilatorio.

Por su parte el aumento de las transferencias a los más jóvenes se explica fundamentalmente por las transformaciones en el sistema educativo que implicaron la universalización de la educación pre escolar y el aumento de la matrícula general.

No obstante esta variación, la brecha que separa las transferencias generacionales realizadas a jóvenes y viejos sigue siendo muy importante.

En el caso de los menores, prácticamente todo el consumo fue financiado mediante transferencias, en su gran mayoría privadas, tanto en 1994 como en 2006. Las transferencias públicas, en tanto, financiaron cerca de la quinta parte del consumo de este grupo etario. En cambio, entre los mayores de 64 años predominaron las transferencias públicas y la reasignación sobre la base de activos. Las transferencias realizadas a través de los canales públicos financiaron alrededor de la mitad del consumo en su caso. Obsérvese que si bien las personas de edad fueron receptoras netas de transferencias públicas 
en los dos años considerados, efectuaron transferencias (en términos netos) por los canales privados. (Bucheli, et al. 2010: 180)

Esta brecha implica importantes riesgos a largo plazo teniendo en cuenta los cambios sociales y demográficos que transita Uruguay y aquellos que puede preverse.

Las transformaciones sociales a las que nos referimos están vinculadas la precarización del mercado de trabajo y a cambios estructurales en los arreglos familiares. Ambas tienen un impacto importante en la Arquitectura de Bienestar.

El proceso de precarización del mercado de trabajo, concentrado fundamentalmente en un sector de la población, tiene como consecuencia la dificultad en el acceso al bienestar por esta vía. Por otra parte las transformaciones en los arreglos familiares han determinado cambios en la fecundidad y estructura familiar, que determinan una menor capacidad de enfrentar riesgos para las familias más pobres, en la medida en que en ellas la tasa de fecundidad es mayor así como el número de hogares monoparentales.

En las mujeres pertenecientes a los hogares más pobres esta realidad no se constata, como mencionamos más arriba, un $20 \%$ de estos hogares son monoparentales, y entre los biparentales poco más de un $32 \%$ se encuentra en unión libre. ¿ Responde esta realidad a mujeres que han disminuido y postergado la fecundidad, orientado su emancipación a completar el ciclo educativo y luego al mercado laboral? La respuesta, con excepción de lo que refiere a la disminución de la fecundidad (modesta, al menos hasta la fecha considerada), es un rotundo no. (Filgueira, 2005: 27)

Estas transformaciones en el mercado de trabajo y en los arreglos familiares, asociadas a la inadecuación de una estructura de políticas públicas que fue diseñada en otro momento histórico, han determinado el surgimiento de lo que se ha definido como Uruguay vulnerado, caracterizado por tener lazos débiles con el mercado y el Estado, altos niveles de pobreza, y tazas mayores de fecundidad, lo que determina mayor presencia de niños y jóvenes.

El segundo tipo de transformaciones son más generales y tienen que ver con la primera transición demográfica que vimos antes. Dicho proceso histórico, determina lo que se ha llamado bono demográfico, situación que se presenta dado que la baja en las tasas de fecundidad suceden antes que el aumento de la esperanza de vida, 
estableciendo para un período histórico determinado, una relación ideal entre el número de activos y el número de pasivos.

Esto sucede porque en las primeras etapas de la transición, durante el bono demográfico, la población en edad de trabajar crece rápidamente, lo cual determina una reducción de la carga fiscal sobre los Estados. Conforme avanza la transición demográfica la población adulta mayor comienza a crecer y el bono demográfico llega a su fin.

Si tomamos en consideración lo dicho hasta ahora veremos que la metodología de NTA nos permite establecer, para el Uruguay una diferencia importante en las transferencias pública hacia las personas de mayor edad por sobre las realizadas hacia los más jóvenes.

Si bien esto ha disminuido en los últimos años, continúa siendo una característica fundamental de nuestra Arquitectura de Bienestar, el hecho de que las transferencias hacia los niños y jóvenes sean de carácter privado a través de la familia, en tanto que gran parte del bienestar de los adultos mayores provenga del sistema de jubilaciones y pensiones.

A este panorama se suma el hecho de que Uruguay ha procesado ciertos cambios en su estructura social, caracterizados por la segmentación social, y por el surgimiento de un Uruguay vulnerado, pobre, con escaso vínculo con el Estado y el mercado. Este sector de la población se caracteriza por mayores niveles de fecundidad y por mayor presencia de niños y jóvenes.

Vimos que en términos demográfico el Uruguay se encuentra en la fase de bono demográfico, sin embargo es de esperar que dicha fase termine, por lo que la cantidad de población envejecida, que recibirá su bienestar mediante transferencias estatales aumentará en las próximas décadas.

Por último debemos mencionar la transferencia de género, entendida como el trabajo no remunerado que realizan las mujeres, y cuyo importancia supone en definitiva una transferencia de las mujeres a los varones.

Observando ahora lo que sucede dentro de cada grupo y analizando cómo se distribuye el tiempo de varones y mujeres en ambos tipos de trabajo, en el Cuadro 2 vemos que las mujeres dedican mayor proporción de su tiempo al trabajo no remunerado $(64,6 \%)$ y menor al remunerado $(31,9 \%)$. En los 
varones ocurre lo contrario, dedican el $68,1 \%$ de su tiempo de trabajo al remunerado y el $35,4 \%$ restante al no remunerado. Estos datos mantienen la tendencia observada en el 2007, que mostraba a un uso muy diferente del tiempo de varones y mujeres y, por tanto, costos y beneficios asociados a esa dedicación también muy diferentes. En este sentido es importante destacar que en la sociedad, la valoración del trabajo remunerado y no remunerado no es equivalente. (Batthyány, 2015: 55)

\subsection{Los tres mundos del Uruguay social}

La idea de un Uruguay dividido en tres mundos sociales diferentes ha sido elaborada por Fernando Filgueira para dar cuenta de las diferencias que aparecen cuando se analiza a la población uruguaya, atendiendo a las principales variables vinculadas a la distribución del riesgo.

La idea de Arquitectura del Bienestar (Esping-Andersen) supone mirar el conjunto de estructuras sociales que determinan la distribución del bienestar. Los ámbitos que tienen valor explicativo en este sentido son claramente el mercado, el Estado y las familias y comunidades. Es a través de estas tres esferas que los individuos acceden al bienestar y se protegen de los riesgos sociales.

Sin embargo, los autores afirman que en las últimas décadas del siglo XX se ha producido un desfasaje entre la estructura de protección contra riesgos y ciertos procesos de transformación en la estructura social. Estos cambios están vinculados fundamentalmente a la precarización de las condiciones del empleo, y transformaciones en los tipos de arreglos familiares. Como consecuencia de este proceso un sector de la población ha quedado desprotegido contra riesgos sociales y con dificultades para acceder al bienestar por vía del mercado.

Por otra parte la estructura estatal de protección no ha logrado transformarse y adaptar su respuesta a esta nueva realidad.

Estas transformaciones en la Arquitectura de Bienestar implican para un sector de la población quedar desprotegido, y tiene como resultado la emergencia de tres mundos bien diferenciados, en cuanto las fuentes de acceso al bienestar, y a otras características demográficas asociadas a ellas. 
El primero de estos mundos ha sido definido como el Uruguay vulnerado, y está constituido por la población que ha sufrido de manera más directa el impacto del desfasaje entre la estructura de protección social y las transformaciones en el nivel del mercado y la familia.

“El Uruguay vulnerado, el de la pobreza informalizada, infantilizada y excluida de sistemas de protección robustos.

Este Uruguay presenta edades jóvenes, alta probabilidad de ser pobre, bajos ingresos, niveles educativos de intermedios a bajos. Es el Uruguay joven e infantil, vulnerado y con lazos debilitados con Estado y mercado. Es un Uruguay fecundo de hogares grandes, donde en forma imperfecta $y$ apresurada los y las jóvenes se emancipan de hogares empobrecidos o pobres para formar hogares también frágiles en sus capacidades de sustento y socialización de las nuevas generaciones." (Filgueira, 2005:16)

Por otra parte está el Uruguay corporativo, integrado fundamentalmente por la población que aún logra beneficiarse de la antigua estructura de protección social, y que obtiene niveles medios de acceso al bienestar y consumo.

"El Uruguay de pasado corporativo y estatal: donde la tercera edad, las corporaciones y clases medias y medio-bajas vulnerabilizadas en sus fuentes de ingreso enfrentan deterioros debido al debilitamiento de la capacidad protectora de sus viejos sistemas de prestaciones sociales.

El segundo Uruguay presenta ingresos medio-bajos, muy bajo nivel educativo, edades cercanas a la vejez en promedio y menor tamaño de los hogares. Su probabilidad de ser pobre es baja." (Filgueira, 2005: 17)

Por último encontramos al Uruguay Privatizado, que refiere al sector de la población con mayores ingresos, obtenidos fundamentalmente en el mercado. Este conjunto de población no se ha visto afectado por los cambios en el mercado de trabajo, y tampoco recibe el grueso de sus prestaciones sociales en el Estado.

"El Uruguay privatizado: los sectores medios altos y altos crecientemente autoexiliados de los bienes públicos.

El tercer Uruguay es de ingresos medio-altos y altos. Con un tamaño de hogar no que se ubica entre el Uruguay corporativo y el Uruguay vulnerado, es un país que complementa su protección social de base estatal y corporativa con 
un fuerte vínculo formal con el mercado de empleo y con demanda y adquisición de bienes y servicios sociales en el mercado." (Filgueira, 2005: 17) Si bien en la última década hemos asistido a un proceso de crecimiento económico y distribución de la riqueza, estos cambios no permiten augurar una transformación significativa en cuento a cohesión social en el corto plazo, ya que se trata de procesos establecidos durante décadas y no es razonable pensar en una reversión inmediata.

\subsection{Resumen del Capítulo: El Uruguay Vulnerado}

Varios son los procesos que hemos reseñado en orden de comprender el surgimiento y consolidación del Uruguay Vulnerado. Dichos procesos claramente son movimientos históricos de larga duración, y si bien pueden haberse morigerado en la última década de crecimiento y redistribución, difícilmente puedan visualizarse como superados.

En términos globales el Uruguay comparte con América Latina un Modelo de Desarrollo, caracterizado por una particular configuración de la Arquitectura de Bienestar.

Este modelo de desarrollo está caracterizado por tres grandes procesos: desigualdad históricamente instalada, urbanización con pobreza y una demografía caracterizada por la dualidad y por el corto bono demográfico.

A la desigualdad económica, producida en buena medida por problemas de empleo que se han sostenido desde la ruptura del modelo de bienestar construido en la primera mitad del siglo $X X$, se suma un proceso de segregación socio territorial que dificulta las trayectorias de movilidad ascendente y aísla a los diferentes sectores sociales.

En segundo término, vinculado a la estructura demográfica del Uruguay vimos que nuestro país desarrolló tempranamente la primera transición demográfica, aunque lo hizo de manera incompleta, o dicho de otro modo, no toda la población transitó hacia un modelo nuclear de familia. Otro tanto puede decirse de la segunda transición demográfica, que está viviendo nuestro país, que tampoco supone una pauta homogénea.

Esto establece una pauta dual en lo que respecta a los arreglos familiares, determinando diferencias significativas entre los tipos de hogar según la estratificación social. 
Otro elemento a destacar, vinculado a la estructura demográfica es el breve bono demográfico que actualmente se encuentra en fase de desarrollo.

Estos procesos económicos signados por la desigualdad y la vulneración económica de un sector de población y a los procesos demográficos marcados por una pauta dual debemos sumar que las respuestas del Estado, fuertemente inerciales, continúan privilegiando el gasto en los sectores de mayor edad, impactando negativamente en este sector de población que como vimos está compuesto por familias jóvenes y con muchos hijos.

Si bien es cierto que los gobiernos progresistas han aumentado el gasto social en la última década, el monto y la forma del gasto no han permitido revertir los procesos de vulneración.

Todo esto ha determinado la instalación y consolidación de un sector de la población que no solo tiene un acceso deficitario al bienestar, sino que desarrolla pautas reproductivas diferenciales, supone un complejo desafío para nuestra sociedad en términos de integración social.

Este sector de la población ha sido denominado Uruguay Vulnerado, y si bien la última década de crecimiento y redistribución ha mejorado el acceso al bienestar para todos los sectores de la población, los procesos históricos de largo término no se han revertido de manera definitiva aun. 


\section{ANTECEDENTES:}

\section{LINAJES MATERNOS ARTICULACIÓN DEL CAMBIO Y LA PERMANENCIA}

En la introducción de este trabajo decíamos que nuestro interés se centra en el análisis de la particular configuración que asumen las familias que pertenecen al Uruguay Vulnerado.

Decíamos entonces que era posible definir un conjunto de características o particularidades asociadas a la filiación y locación de las familias. También mencionábamos que estas características tenían incidencia en los modos de concebir el parentesco, los roles de género y la transición a la vida adulta.

En este apartado intentaremos determinar si la existencia de este tipo de arreglo familiar ha sido vislumbrada por otros trabajos de investigación en Uruguay o si por el contrario constituye un vacío en la producción académica.

Este estudio de antecedentes pone especial atención en aquellos trabajos en los que se ha desarrollado una investigación original y que sustentan sus conclusiones en material empírico primario, ya sea a partir de análisis cualitativo de las opiniones de los actores, como de trabajos estadísticos.

Para poder sopesar los antecedentes deberemos primero determinar con claridad las características del fenómeno, en este sentido será necesario establecer su alcance, así como las características generales del fenómeno concreto que estamos intentando comprender.

Con relación al primer punto, referido al alcance del fenómeno, debemos decir lo siguiente. El hecho que las familias en el Uruguay han procesado cambios significativos en las últimas décadas resulta evidente y ha sido descrito abundantemente a partir de trabajos basados en las estadísticas poblacionales del CENSO y la ECH. Ya hemos visto en capítulos anteriores el proceso vivido en Uruguay definido como segunda transición demográfica.

Ahora bien, estos cambios que vienen a cuestionar la hegemonía estadística del modelo de familia nuclear tradicional, no implican necesariamente el surgimiento de un modelo alternativo en sentido estricto. Antes bien, la existencia de nuevos y diversos arreglos familiares cuestionan la existencia de un único modelo hegemónico. 
En este sentido, cuando hablamos de linajes maternos no estamos suponiendo la existencia concreta de familias que responden a un nuevo modelo, siguiendo un patrón punto por punto alternativo al modelo de familia nuclear, consolidado y asociado a un nuevo conjunto de concepciones. No estamos diciendo que un modelo hegemónico ha sido sustituido por otro.

Sin embargo tampoco sería razonable suponer que el nuevo estado de cosas es un caos sobe el que no pueden establecerse ciertas líneas de interpretación. En el marco de esta nueva diversidad de familias, es posible trazar tendencias y vislumbrar algunas regularidades, en ciertos sectores de la población.

Es probable, además que muchas familias respondan a alguna de estas características, que a los efectos de nuestra investigación presentamos en conjunto, y no a todas. Lo que nos interesa es caracterizar en el marco de este proceso de transformación de las familias uruguayas, algunos patrones o regularidades que entendemos puede ser pertinente estudiar.

En lo concerniente a las características generales del fenómeno, podemos decir que estos linajes maternos, son entonces familias que asumen algunas características particulares, articulando elementos nuevos, que suponen cambios importantes respecto del modelo tradicional, con elementos antiguos, que conservan elementos que en otros sectores sociales ya se han transformado. Por este motivo decimos que son una combinación entre el cambio y la permanencia.

Dentro de los elementos novedosos están su característica de ser arreglos con una fuerte tendencia a la matrilinealidad y la matrilocalidad. Los elementos tradicionales del modelo son su fuerte carácter patriarcal y la concomitante diferenciación por género de los roles femenino y masculino. Asociado a esto último las transiciones a la vida adulta aparecen claramente diferenciadas por género.

El conjunto de elementos que constituyen estos linajes maternos y que describiremos a continuación son: 1. Matrilinealidad, 2. Matrilocalidad, 3. Patriarcado y roles de género tradicionales, 4. Movilidad de los referentes adultos varones, 5. Transiciones a la vida adulta diferenciadas por género.

Respecto de los dos primeros elementos, cuando decimos que algunas familias han adquirido características de matrilinealidad y matrilocalidad estamos haciendo referencia a dos conceptos que provienen originalmente de la antropología y que 
fueron utilizados para describir sociedades no occidentales en los que la línea de filiación y el lugar de residencia de las familias estaba determinado por la familia de origen de la madre.

Matrilinealidad es la característica de aquellas sociedades que definen la línea de la filiación por la rama femenina. Dicho con palabras más llanas, en estas sociedades, cada vez que se conforma una nueva pareja, lo hijos que de ella surjan pertenecen a la familia de madre y no a la del padre.

Esto puede verse reflejado en elementos como el apellido, pero más generalmente en la concepción de pertenencia a una familia, a diferencia del modelo tradicional de familia en occidente, que tiene una filiación bilateral, perteneciendo los hijos de la pareja a ambas familias, la de la madre y la del padre.

El concepto de matrilocalidad puede estar asociado al anterior, aunque no es necesario que así sea, y significa que cuando se conforma una nueva pareja, esta establece su residencia en el hogar de la familia de mujer y no en la del hombre. Los conceptos opuestos a los anteriores son los de patrilinealiad y patrilocalidad.

Los elementos novedosos de este modelo, teniendo en cuenta la realidad uruguaya, son entonces aquellos vinculados a la residencia dado que no se trata de un modelo neolocal, ya que rara vez la pareja que se compone y da lugar a los hijos constituye un nuevo hogar independiente. En términos generales es el hogar materno quien recibe a la nueva generación, esto es lo que se define un arreglo matrilocal.

Concomitantemente con el elemento anterior se constituye una situación de filiación por línea materna. Este componente resulta más difuso ya que remite al modo en que se entiende el parentesco, más allá de la residencia. Sostenemos que la filiación es visualizada como proveniente de la línea materna.

Esto se expresa en diferentes elementos, por ejemplo el hecho de que el vínculo madre-hijo resulta mucho más significativo en el largo plazo que el vínculo padre-hijo. Esta diferencia se extiende a las relaciones establecidas con la familia de la madre que con la familia del padre, extendiéndose también a generaciones anteriores.

Ambos elementos combinados, y asociados a otras características que veremos después, debilitan el rol de figura paterna, generando una cierta labilidad de la presencia y permanencia de los hombres en los hogares. Hay una identificación entre 
la idea de hogar y la idea de madre, que determina que una vez que se rompe la pareja, se entiende que quien debe dejar el hogar sea el hombre.

Es importante mencionar que esto no supone en modo alguno hablar de un matriarcado, concepto que remite al poder o la autoridad. Definir el lugar de residencia o la línea familiar no implica que la mujer sea quien ejerza el poder o detente una autoridad particular. Muy por el contrario, estas familias otorgan al varón una autoridad muy importante, desde una construcción de género tradicional.

Este es uno de los elementos tradicionales con una construcción de roles de género que asigna a la mujer un rol privado y asociado a las tareas de reproducción (crianza, cuidado, alimentación, mundo privado) y a los hombre un rol público y asociado al mundo de la producción (trabajo remunerado, mundo público).

Por estos motivos, los eventos que establecen el pasaje a la vida adulta se diferencian de tal forma que, para los hombres suele constituir la salida del hogar materno es el hecho que marca la transformación en adulto, con el concomitante ingreso al mundo del trabajo o más ampliamente el desarrollo de diferentes estrategias para la satisfacción de necesidades.

Esto redunda en un cierto "nomadismo" de la condición masculina, con varones que se ven compelidos tempranamente a la salida del hogar de origen, hecho que repiten cada vez que un vínculo de pareja se disuelve y son ellos quienes deben abandonar el hogar. Este fenómeno es la contracara de esta asociación que mencionábamos de mujer-hogar y podría definirse como hombre-espacio públicos.

Por otra parte el pasaje a la vida adulta constituye para las mujeres fundamentalmente el hecho de convertirse en madres, lo cual no implica el abandono del hogar materno necesariamente.

En resumen los elementos que forman parte de este modelo son:

1. Matrilocalidad: expresada en la asociación entre las ideas de hogar y madre, y en el hecho de que cuando se forma un nuevo hogar suele estar asociado físicamente a la vivienda materna.

2. Matrilinealidad; que se expresa en la percepción de que los hijos son parte de la familia materna exclusivamente, o en mayor grado de lo que integran la familia paterna. 
3. Roles de Género tradicionales: Estableciendo para la mujer el lugar privado de cuidados y crianza, y para el hombre el lugar público y proveedor. A diferencia de lo que podría esperarse se trata de familias patriarcales.

4. Movilidad de los Referentes Varones: las características anteriores, sumadas a un debilitamiento del rol proveedor, dadas las condiciones de vulneración, redundan en una frecuente separación de los referentes varones del hogar de origen.

5. Transiciones a la vida adulta diferenciadas por género: siendo la salida del hogar materno y el ingreso a la vida pública el marcador para los varones y la maternidad para las mujeres.

Ahora bien cabe preguntarse si existen antecedentes de investigaciones que hayan dado cuenta de dicho fenómeno. No hemos encontrado ningún trabajo que remita específicamente de estos elementos mencionados en términos de un modelo coherente, sin embargo existe un conjunto de investigaciones que de manera indirecta han vislumbrado las diferentes dimensiones de este tipo o modelo de familia.

En particular nos referimos a los siguientes trabajos de investigación:

- El primero de ellos elaborado denominado "Jefatura femenina en los hogares uruguayos" y elaborado por Mathías Nathan y Mariana Paredes (2012) estudia el fenómeno de los hogares con jefatura monoparental femenina desde un punto de vista estadístico. A pesar de describir el fenómeno de manera significativa, este trabajo continúa centrándose en la idea de jefatura de hogar, más restringida que la idea sugerida por nosotros como linaje materno.

- El segundo es un artículo desarrollado por Andrés Peri (2004) titulado "Dimensiones ideológicas del cambio familiar", cuyo centro es el análisis de factores ideológicos referidos por las jefas de hogares, con base en la encuesta sobre Situaciones Familiares y Desempeños Sociales de las mujeres en Montevideo y el Área Metropolitana. En este trabajo se establece una relación muy clara entre la pertenencia a cierto sector social y la probabilidad de adscribir a una mirada tradicional de la familia y las relaciones de género.

- Tomaremos en consideración el artículo denominado "Procesos de selección social y vulnerabilidad. Varones jóvenes viviendo en la calle" se trata de una investigación cualitativa elaborado por Virginia Rial, Eloísa Rodríguez y Fabricio Vomero (2011) con una mirada desde la antropología, respecto de la vida en la 
calle de varones jóvenes en Montevideo. Este trabajo nos ha permitido problematizar algunos elementos de la transición a la vida adulta, desde una perspectiva de género.

- El cuatro trabajo "De paternidades y exclusiones", cuyos autores son Carlos Güida, Ivone Martínez, Gonzalo Salles y Laura Scarlatta (2007). El lugar de los varones en los sectores de pobreza extrema" aborda el tema de la paternidad en una perspectiva que compara los modos subjetivos en los diferentes sectores sociales. Nos permitirá explorar la filiación, y el rol masculino.

- También tomaremos en consideración la pesquisa realizada en el marco del proyecto "Reproducción biológica y social de la población uruguaya, una aproximación desde la perspectiva de género y generaciones", coordinado por Alejandra López Gómez (2006), que aborda el tema del embarazo en las adolescentes y jóvenes y su sentido subjetivo, lo que nos permitirá pensar el tema de la transición a la vida adulta.

- Por último queremos hacer referencia a los informes desarrollados por Verónica Filardo sobre la ENAJ 2007 y Santiago Soto sobre la ENAJ 2013. Asimismo tomaremos en consideración otros trabajos que se desarrollan a partir de los datos de la ENAJ.

\subsection{Hogares de Jefatura Femenina}

Uno de los primeros elementos a tener en cuenta si pensamos en arreglos familiares en los que la mujer tiene un lugar importante, es el análisis demográfico de las familias que cuentan con hogares monoparentales de jefatura femenina.

En tal sentido el trabajo desarrollado por Mathías Nathan y Mariana Paredes, denominado "Jefatura femenina en los hogares uruguayos" utilizando información de los censos de población 1975, 1985 y 1996, 2008, y de la Encuesta Continua de Hogares, establece con claridad un aumento significativo de este tipo de arreglo familiar entre las últimas décadas del siglo XX y la primera del siglo XXI.

Los autores mencionan dos tipos particulares de arreglos familiares en los que se expresa la jefatura femenina, los hogares monoparentales y los hogares unipersonales. Estos últimos asociados al divorcio y la viudez fundamentalmente. 
No obstante, hemos podido corroborar algunos fenómenos vinculados a este proceso en Uruguay. Las mujeres han aumentado significativamente su participación como jefas de hogar entre los años 1975 y 2008. (...)

Es importante entonces tener en cuenta que, más allá de constituir un fenómeno global, oculta especificidades que deben ser contempladas, sobre todo a la hora de pensar en políticas públicas dirigidas a estas poblaciones. En este sentido, no es lo mismo atender la jefatura femenina en un hogar envejecido, que la misma situación en un hogar que recién se está formando. Por lo tanto, hay que tener en cuenta la diversidad de situaciones en términos de acceso a bienes y servicios, así como de focalización de diversos programas y políticas públicas. (Nathan, 2012: 94)

Es importante destacar que los autores no establecen una relación entre el fenómeno y una situación de vulneración social o económica, si bien mencionan que las mujeres jefas de hogar tienden a haber alcanzado menores niveles educativos.

Por otra parte debemos mencionar que el concepto de jefatura femenina de hogar no remite necesariamente a una concepción de género particular, sino a una respuesta concreta en el marco de la realización de una encuesta.

En tal sentido, si bien resulta significativo destacar este incremento en el tiempo de los hogares con esta definición de jefatura de hogar, esto solo puede ser tomado como un indicio del fenómeno que queremos vislumbrar. Aun así resulta pertinente para nuestra investigación, tener en cuenta el dato de esta transformación.

\subsection{Concepciones tradicionales de género en las mujeres del Uruguay Vulnerado}

El segundo elemento a destacar tiene que ver con una concepción tradicional de los roles de género presente en los sectores de población más vulnerable. En tal sentido la investigación desarrolladas por Andrés Peri sobre los factores ideológicos en las familias tiene algunos puntos de gran interés. Este trabajo desarrollado a partir del material empírico brindado por la encuesta sobre Situaciones Familiares y Desempeños Sociales de las mujeres en Montevideo y el Área Metropolitana, busca establecer una posible correlación entre algunos factores socio demográficos y algunos aspectos ideológicos. 
En la encuesta, que preguntaba a mujeres entre 25 y 54 años, se puede observar una correlación inversa entre la igualdad de género y la educación. Asimismo este indicador correlaciona de manera inversa con el índice de bienes en el hogar, aunque esta correlación es hasta el índice medio y luego se mantiene estable.

Por ejemplo, el factor "igualdad de género" se relaciona positivamente con la educación formal de la mujer y con el nivel de bienestar material del hogar. Sin embargo, existen matices interesantes en el comportamiento de estas dos variables con el índice de igualdad de género que nos llevan a ser cautos con el uso indiscriminado de la educación como proxi de nivel socio-económico.

Mientras que el índice de igualdad de género crece casi monotónicamente para cada nivel de educación, en relación al índice de bienes del hogar se observa que el nivel de igualdad de género crece hasta la categoría media y luego se mantiene estable de ahí en adelante. (Peri, 2004: 152)

Esto parece indicar que las concepciones tradicionales de género están presentes a menor nivel educativo. Además marca un quiebre entre las mujeres más pobres que tienen una concepción de género más tradicional, frente al resto de las mujeres, con concepciones de género más igualitarias, en este caso de manera homogénea entre lo que podríamos definir como sectores medios y sectores altos.

Asimismo aparecen otras concepciones vinculadas de manera más indirecta, aunque clara con nociones tradicionales de género, como la interpretación de la importancia de los hijos, en particular teniendo en cuenta que las entrevistadas eran mujeres.

En las otras dos dimensiones ideológicas construidas, "hijocéntricos" y "conservadurismo", se verifica el mismo comportamiento descendente con respecto a la educación y el índice de bienes del hogar, siendo la relación con la educación la más importante como diferenciadora de grupos. (Peri, 2004: 152)

Vemos entonces como este trabajo de investigación muestra una relación clara entre la pertenencia a un determinado sector socio económico y la existencia de ciertas nociones de género que podríamos definir como tradicionales. 


\subsection{Separación de páter y genitor, nomadismo y dilución del rol paterno.}

El siguiente trabajo de investigación que tomaremos como base fue desarrollado para indagar sobre las concepciones de paternidad en los sectores de pobreza: "De paternidades y exclusiones. El lugar de los varones en los sectores de pobreza extrema." (Güida; 2007) Este trabajo aborda el tema de la paternidad en una perspectiva que compara los modos subjetivos en los diferentes sectores sociales y económicos. En este caso la mirada está puesta en las representaciones de los sujetos asociadas al ejercicio de la paternidad en el marco de la vida cotidiana.

En el presente estudio se buscó una aproximación a las prácticas sociales sobre paternidad en varones padres en sectores de pobreza extrema. Para ello, se indagaron dos áreas estrechamente vinculadas: la identidad paterna, entendida como las representaciones que el sujeto tiene sobre sí mismo en función de su condición de varón-padre, y el paternaje, entendido como el ejercicio de la paternidad en la vida cotidiana y su relación con las expectativas que tal condición genera en su entorno familiar, comunitario y social. (Güida; 2007: 41)

Si bien, a partir de la investigación se accede a la conclusión principal de que la paternidad resulta un hecho significativo para los varones pobres. También resulta claro que esta concepción de la paternidad es muy diferente según el sector socioeconómico al que se pertenece, y está asociada fundamentalmente a un rol proveedor y no tanto, o en menor medida a tareas vinculadas la crianza.

En los varones entrevistados, el querer hacer y el deber hacer en relación con el ejercicio de la paternidad, se encuentran fusionados en el rol de provisión económica. Se observa, con claridad, cómo en este rol se inscribe la masculinidad adulta y sobre él se edifica el ejercicio paterno. Un padre es evaluado y se autoevalúa de acuerdo a esta capacidad y construye su espacio, tanto en lo familiar como en lo comunitario, de acuerdo al éxito de esa tarea. (Güida; 2007: 51)

Esto determina que, dado que son padres de hogares vulnerados, no pudiendo hacer realidad este rol proveedor, se desdibuja el rol paterno asumido. Paralelamente, si otro hombre cumple el rol proveedor asume los derechos del padre. 
Así como el no convivir determinaría una ruptura en la relación con sus hijos y se dejaría de ejercer el rol paterno con sus derechos y responsabilidades, la convivencia con hijos no biológicos habilita el ejercicio de este rol, y en muchos casos la generación de un vínculo paternal. Entonces, a partir de la convivencia con los hijos no biológicos, estos varones asumen las responsabilidades y roles paternos. Los hijos no biológicos, dados determinados méritos afectivos del padrastro, pueden llegar a investir a este varón como padre. El otro, el padre biológico, se vuelve fondo en esta historia: se sabe que ha sido el genitor $y$ en él queda un grado de reconocimiento por haberle dado la vida. (...)

De acuerdo al material disponible, estos padres, una vez que se retiran del hogar, pasan breves períodos de tiempo solos y luego se integran a nuevos hogares, a partir de una nueva relación de pareja con mujeres, muchas veces, madres. (Güida; 2007: 61)

Vemos un conjunto de coincidencias con elementos antes destacados. En primer lugar aparece una diferenciación importante de lo que se entiende que es el rol masculino en la paternidad, comparando la situación hombres de sectores vulnerables con relación a hombres de otros sectores. En el primer caso la paternidad está vinculada fundamentalmente al rol tradicional proveedor, de manera más acentuada que en el resto de los sectores en lo que se asume que el rol paterno está vinculado también a cuestiones de afectivas y de cuidados.

En segundo lugar, y asociado a lo anterior, la inestabilidad de este rol y una suerte de nomadismo masculino que se establece debido, en primer lugar a la asociación de la paternidad con el rol proveedor, y en segundo lugar frente a la imposibilidad de cumplir con este mandato en función de las condiciones. Parece estar establecido que el rol paterno debe ser ejercido por quien tienen las condiciones para hacerlo, se o no el genitor de los hijos.

\subsection{Varones jóvenes compelidos a dejar el Hogar Materno}

La siguiente investigación fue desarrollada por Virginia Rial, Eloisa Rodriguez y Fabricio Vomero, y aborda la situación de jóvenes varones de entre 14 y 29 de Montevideo, que optaron o se vieron forzados a dejar hogar familiar y por ende a desarrollar 
diferentes estrategias de sobrevivencia en el contexto de la calle, y en algunos casos vivir en ella.

La pertinencia de poner nuestra atención en esta investigación, está dada por el hecho de que remite a jóvenes pobres que se sintieron compelidos de abandonar el hogar materno. Si bien no es posible afirmar que estos varones provengan de hogares como los que estamos reseñando, si es cierto que provienen de hogares particularmente vulnerados y además han hecho una salida muy temprana del hogar de origen.

Este trabajo de investigación nos ha permitido explorar algunas dimensiones que definíamos como parte del modelo, particularmente aquellas que están relacionadas con los roles de género y las transiciones a la vida adulta. Recordemos lo que mencionábamos respecto a cierto nomadismo de la condición masculina en la pobreza. Los autores de este trabajo definen los objetivos de su investigación en los siguientes términos:

El objetivo general de la investigación fue producir conocimiento original sobre causales que determinan la salida o "huída» hacia la calle de varones jóvenes de bajos recursos en Montevideo (entre catorce y 29 años). Propusimos que dichas causales se vinculan no sólo con determinantes económicas, sino con problemáticas familiares, con distintas formas de conflictividad en el pasaje por instituciones (hogares sustitutos, cárcel y otros), relacionado con la existencia de vínculos violentos y con consumos adictivos. (Rial, 2011: 13)

Como vemos a continuación la hipótesis de los autores se concentra en la posibilidad de explicar esta salida del hogar de origen, relacionándola con factores de origen socio económico por un lado, y otros factores como: conflictividad con instituciones, vínculos familiares violentos y consumo problemático de drogas.

Cuando se abordó el tema de las causas que esgrimían los jóvenes para explicar la vida en la calle, encontramos que éstas eran muy variadas. Una de las más recurrentes en las entrevistas fue que «se iban» de la casa y del barrio para poder alejarse del tema de las drogas, ya que en la zona en que viven en «cada esquina hay una 'boca' [punto de venta de drogas] y entonces es muy grande la tentación, no podés zafar...». (Rial, 2011: 22) 
Si bien este conjunto de factores explicativos pueden dar cuenta de una parte el fenómeno de la salida temprana del hogar de origen, esto no explica el hecho fundamental de que este comportamiento de salida temprana del hogar se registre fundamentalmente en varones.

Este hecho es coincidente con las cuantificaciones realizadas sobre el fenómeno de la situación de calle que destaca una fuerte masculinización de la población. El primer Censo (MIDES, 2006) de personas en situación de calle realizado en el año 2006 realizado por el Ministerio de Desarrollo Social arrojó que el 75,6 \% eran varones en tanto que el $9 \%$ eran mujeres. El total no suma $100 \%$ dado que la metodología de observación no permitía determinar en muchos casos el sexo de la persona avistada. Por este motivo, el segundo relevamiento realizado en 2011 no diferenció entre sexos, motivo por el cual no se cuenta con datos al respecto. Sin embargo, aún con el margen de error que la metodología supone, está claro que se trata de una población fuertemente masculinizada.

Otras posibles explicaciones brindadas por los autores para explicar el fenómeno tienen que ver con la acción del Estado. A partir de ciertas políticas sociales podría constituirse en un factor que determine la masculinización y rejuvenecimiento de la población que vive en la calle.

Por otra parte, la percepción social y planes asistenciales, se alinean con representaciones de género tendiendo a priorizar a mujeres con hijos pequeños, sin contemplar en toda su gravedad la situación de varones jóvenes que se alejan del hogar. Este hecho tiene como efecto el incremento de la masculinización y rejuvenecimiento de la población que vive en la calle. (Rial, 2011: 25)

Un elemento que resulta significativo es el vínculo con la figura adulta masculina, ya sea el padre o el padrastro, como determinante de la salida del hogar de origen. Una de las causas citadas es la recurrencia de la presencia de violencia familiar o diferentes formas de abuso.

En muchos de los jóvenes la ausencia del padre biológico se ve reemplazada por la presencia de un «padre-padrastro» tan o más violento o ausente que el padre biológico. (Rial, 2011: 41) 
Otro elemento central que aparece en el discurso de los jóvenes, y que merece la pena ser tenido en cuenta, es el rol del trabajo tanto en la salida del hogar, como en la construcción de una identidad masculina y el auto estima.

En resumen los autores sostienen que los motivos que operan en la salida de estos jóvenes de su hogar de origen, tienen que ver con el tipo de entorno del que provienen y las condiciones familiares, ciertas problemáticas específicas, y el refuerzo de las políticas que se constituyen con una mirada de género.

Es a partir de las conclusiones de esta investigación que podemos intentar realizar una relectura de sus resultados. En primer lugar tenemos un fenómeno de salida del hogar de origen de un conjunto de jóvenes, cuyo destino es la situación calle.

De estos jóvenes la gran mayoría son varones, lo que hace suponer que la construcción del género debe operar como una causa, toda vez que las jóvenes mujeres están sometidas a las mismas condiciones en sus hogares y no optan por emanciparse. Esto es así aun cuando los propios jóvenes puedan no ser conscientes de ello.

También aparecen dos elementos importantes y que resultan muy sugestivos con relación a la investigación que estamos llevando adelante.

En primer lugar la figura del varón jefe de hogar aparece como inestable, siendo muchos los casos en los que la convivencia no es con el padre, sino con un padrastro con el que no se tiene buen vínculo.

Esto tiene al menos dos consecuencias muy claras, una identificación del hogar de origen con la figura de la madre, y una actitud móvil de los hombres. No se hace mención en ningún caso a problemas de vínculo con la madre, ni al vínculo con figuras femeninas que no sea la madre. Esto nos permite suponer que para estos jóvenes el hogar de origen es allí donde está su madre.

En segundo término hay una construcción del género que, coincidentemente con lo que veíamos respecto de la figura paterna, obliga a los jóvenes a dejar su hogar de origen una vez que se vuelven adultos. Ellos expresan que esto es su obligación como adultos, parece que esto no resulta así para las mujeres.

En esta investigación vemos evidencia empírica de algunos elementos constitutivos de una forma de entender el género en las familias vulneradas, en las que la clásica dicotomía que establece lo privado como femenino y lo público como masculino, se expresa como una asociación entra la figura de la madre, la mujer y el hogar por un 
lado, y la fluidez de la vinculación de los hombres a estas mujeres, madres, hogares, dotándolos de una característica que podríamos definir como nómade.

\subsection{Transiciones a la vida adulta fuertemente diversificadas por género}

El siguiente trabajo a tener en cuenta como antecedente de esta investigación es el trabajo "Reproducción biológica y social de la población uruguaya, una aproximación desde la perspectiva de género y generaciones" (López Gomez; 2006) en el que abordaron la subjetividad de las adolescentes en relación a la maternidad. En esta investigación se abordó el tema de la transición a la vida adulta y sus marcadores, según género y pertenencia a determinado sector social.

La población del estudio comprendió mujeres y varones adolescentes entre 15 y 20 años de edad de Montevideo urbano, teniendo en cuenta los criterios generales determinadas para los distintos componentes que comprenden la fase cualitativa de la investigación "Reproducción biológica y social de la población uruguaya, una aproximación desde la perspectiva de género y generaciones". (López Gomez; 2006: 126)

Gran parte de los resultados de esta investigación son coincidentes con los datos arrojados por la Encuesta Nacional de Adolescencia y Juventud en sus ediciones de 2007 y 2013, y son muy reveladores en relación a nuestra hipótesis de trabajo en cuanto a las diferencias en relación al sector social.

En este trabajo se plantea que la maternidad cumple un rol central en el pasaje a la vida adulta de las adolescentes mujeres pobres, esto no se confirma del mismo modo en las adolescentes de otros sectores sociales.

Las adolescentes, tanto aquellas que tienen hijos como las que no los tienen, perciben a la maternidad como una entrada súbita al mundo adulto. Pero en este punto, la pertenencia de clase si maraca las diferencias entre ellas: las jóvenes de estrato bajo la asumen con mayor naturalidad, quizá porque los proyectos de vida están más acotados por las propias condiciones en las cuales ha transcurrido su historia. (López Gomez; 2006: 172)

Por otra parte en el caso de los adolescentes varones padres, se configura una diferencia significativa, en tanto que los más pobres entienden que su rol paterno está 
asociado al rol proveedor, mientras que los de otros sectores sociales estiman que el costado afectivo y de crianza de la paternidad está más marcado.

La significación de la paternidad presenta matices diferenciales, de acuerdo al sector social. En sectores sociales bajos, hay una mayor priorización de las responsabilidades paternas respecto de la satisfacción de necesidades básicas, por la vía de la obtención de recursos económicos. En los sectores medios, es más directa la adscripción de la afectividad a la función paterna. (López Gomez; 2006: 234)

Vemos como en esta investigación se confirma nuestra hipótesis de que la transición a la vida adulta en los adolescentes pobres está fuertemente segmentada por género, en tanto los varones pobres la entrada al mundo del trabajo ocupa un lugar central, en las mujeres pobres esto está relacionado con la maternidad.

Este fenómeno no ha sido descrito en estos términos por la literatura especializada, sin embargo, esto no implica que no podamos encontrar algunos indicios en investigaciones y trabajos académicos recientes.

A nivel estadístico y agregado la Encuesta Nacional de Adolescencia y Juventud (ENAJ) que llevara adelante durante 2007 por el Instituto Nacional de la Juventud (INJU) arrojó datos cuya lectura resulta muy interesante, a la luz de nuestras hipótesis. En este sentido el segundo informe de la ENAJ (Filardo, 2008) presenta algunos resultados que mirados en conjunto nos presentan un cuadro de situación significativo.

El primer elemento que es posible destacar es el hecho de que existe una importante diferencia entre los sexos en cuanto a la salida del hogar de origen. El informe muestra además que es mucho más frecuente en el caso de las jóvenes mujeres el hecho de tener hijos sin abandonar el hogar de origen.

En tanto que en el caso de los jóvenes varones es más frecuente la situación contraria de abandonar el hogar de origen sin tener hijos. Situación parece darse con mayor intensidad en el tercil de menores ingresos. Esto refuerza la idea que hemos manejado en este documento, respecto de que ciertos roles tradicionales de género se reproducen más vigorosamente en los sectores vulnerados de población. 
En tal sentido cabe destacar las conclusiones a las que llega el segundo informe y que definen la situación de los arreglos familiares en el contexto de vulneración económica y social:

De los 20 años de edad en adelante se constatan algunos aspectos:

1) La emancipación es más temprana en las mujeres que en los varones.

Ellos postergan el rol de hijos en los hogares en que viven. En esta condición se encuentra más de la mitad de los varones de 25 a 29 años que aprueban nivel terciario.

2) La emancipación sin autonomía, es decir, que forman un núcleo familiar propio, pero continúan viviendo en la casa de al menos uno de sus padres, es más frecuente en las mujeres que en los varones.

3) La autonomía sin emancipación, es decir, que constituyen un domicilio diferente al del hogar de origen, pero sin conformar núcleo propio, es más frecuente entre los varones.

4) De los dos puntos anteriores se derivan varias interpretaciones: en primer lugar los hijos son para las mujeres determinantes más permanentes de la condiciones de emancipación que para los varones, y enfrentan mayores dificultades relativas a la autonomización que sus coetáneos del otro sexo. Este hecho supone, por otra parte, arreglos familiares intergeneracionales en los que las familias de las mujeres jóvenes cobran un rol fundamental portador de capital social y relaciones intergeneracionales que más que enfrentamiento y conflicto suponen cooperación. (Filardo, 2008: 80)

El informe de la ENAJ 2007 nos permite arribar a ciertas conclusiones que modelizan transiciones a la vida adulta fuertemente diferenciadas por género en el marco de las familias más vulneradas.

Tenemos por un lado jóvenes y adolescentes de sexo femenino que en este contexto abandonan tempranamente los estudios. Asimismo se emparejan y tienen hijos, pero esto no implica abandonar el hogar de origen.

Su ingreso al mercado de trabajo es tardío y precario, o eventualmente no sucede. Esto también ha sido destacado por otros trabajos de investigación, que han utilizado como fuente de información a la ENAJ 2007. 
El estudio de la edad al primer hijo en las dos generaciones de jóvenes revela la coexistencia de dos modelos de transición a la maternidad en Uruguay: temprano y tardío. Ellos están dibujados por las brechas en las condiciones sociales de vida, que se asientan para el caso de la transición temprana en contextos de socialización precarios, bajos niveles educativos y residencia fuera de la capital del país. (...) A partir de estos escenarios es posible plantear la hipótesis de que entre las jóvenes donde predomina el modelo tardío, la transición a la maternidad podría constituir el último de los eventos del pasaje a la vida adulta en el marco de una TA signada por la dimensión pública: la inversión en altos niveles de educación y una sólida inserción en el mercado de trabajo. Mientras que las mujeres con un modelo de transición del primer hijo temprano el dominio privado-familiar tendría un lugar preponderante y los roles de género estarían más presentes. (Varela, 2014: 83)

Por otra parte, los jóvenes y adolescentes de sexo masculino que se relacionan con ellas, tienen una trayectoria educativa más corta aún. Sin embargo su ingreso al mercado de trabajo es temprano, más allá de que esté marcado por la precariedad. Pero la diferencia más importante es que su abandono del hogar de origen es mucho más temprano.

Concretamente, los jóvenes de los estratos más altos y aquellos que acumulan más años de educación, retrasan levemente su salida del hogar, mientras que los varones de menor nivel educativo tienden a adelantarla. (Ciganda; 2014: 35)

Se forma entonces la imagen de una forma de arreglo familiar en el que los jóvenes varones abandonan el hogar de origen para formar parejas con jóvenes mujeres que continúan viviendo en el hogar de sus padres. Mientras que ellas concentran sus esfuerzos en la crianza de los hijos, ellos cumplen un rol más tradicionalmente proveedor. Esto no implica luego la constitución de un hogar con características nucleares, o nuclear extendido, dado que la monoparentalidad femenina es muy frecuente. 
Estos datos son confirmados por el informe de la ENAJ 2013. Si bien los datos no han sido tan analizados todavía, las conclusiones del informe van en el mismo sentido antes descripto.

La distribución de los jóvenes emancipados por quintiles de ingreso per cápita muestra que los jóvenes pertenecientes a los hogares de más bajos ingresos son los que presentan porcentajes más altos. El porcentajes de jóvenes emancipados del quintil cinco es tres veces menor al del quintil uno. Esto probablemente esté vinculado con la edad de salida del sistema educativa. (...) Al analizar esta información por sexo, se identifica que las mujeres respecto a los varones se van a vivir con sus parejas en mayor proporción. Asimismo también se observa que la proporción de varones que se van a vivir solos es el doble que la de las mujeres jóvenes. (ENAJ, 2015: 16)

\section{6 Linajes Maternos articulación del cambio y la permanencia}

En este capítulo hemos visto como, si bien no existe una investigación que dé cuenta del fenómeno en su unidad, sí existe un conjunto de trabajo empíricos de los últimos tiempos que describen algunas de las características que hemos mencionado.

Estos trabajos dan cuenta de que existe evidencia empírica que permite afirmar que en los sectores más vulnerados del país, las familias adquieren alguna de las siguientes características:

1. Jefatura de hogar femenina en mayor frecuencia que en el resto de la sociedad.

2. Las mujeres sostienen valores tradicionales, particularmente en lo que respecta a los roles de género y la importancia de los hijos.

3. Los varones sostienen valores tradicionales, particularmente en lo que respecta a los hijos y la crianza. Esto genera una suerte de vaciamiento de la figura paterna cuando no cumplen el típico rol proveerdor. Lo que podría interpretarse como la separación de las funciones de pater y genitor.

4. Los jóvenes presentan transiciones a la vida adulta marcadamente diferenciadas por género: En el caso de las mujeres la tenencia de hijos es predominante en el pasaje a la vida adulta aunque no significa la salida del hogar de origen. En el caso de los varones la transición a la vida adulta está 
marcada por ingreso al mundo público, lo que sí implica la salida del hogar de origen.

Todos estos elementos, revisados en conjunto apuntan a la existencia de un modelo en ciernes, una forma de concebir la familia, los roles de género, la paternidad y la maternidad, y la transición a la vida adulta que tiene características particulares en las familias del Uruguay vulnerado.

Este modelo se caracteriza por presentar algunas novedades tal como la de tratarse de matrilinajes como fuertes componentes matrilocales. Esto redunda a su vez en transiciones a la vida adulta diferenciadas por género, en la que el marcador del pasaje a la adultez es para las mujeres la maternidad, en tanto que para los varones es la salida del hogar y el ingreso al mundo del trabajo.

En los próximos capítulos desarrollaremos las estrategias de investigación que hemos definido previamente, con la intención de vislumbrar si estos indicios que hemos descrito de manera aislada, se presentan de manera conjunta en la realidad, describiendo asimismo con mayor detalle este fenómeno. 


\section{METOdOLOGÍA}

A diferencia de lo que sucede con los fenómenos que estudian otras ramas de la ciencia, en ciencias sociales el objeto de investigación, constituido por los seres humanos y sus relaciones, presenta ciertas particularidades que merecen nuestra atención.

A continuación nos referiremos a tres de estas características que determinarán algunas de las elecciones metodológicas que hemos realizado. En particular nos referimos a los conceptos de: permanencia ontológica, necesidad lógica y doble hermenéutica.

Si bien esto nos introduce en temas que podrían considerarse dentro de la epistemología más que en la metodología propiamente dicha, consideramos que será necesario hacer una breve discusión a este respecto, para dar un sustento sólido a las opciones metodológicas que hemos hecho.

Los dos primeros conceptos están estrechamente ligados y han sido descritos por Jürgen Habermas (1993) en su texto Teoría y Praxis en el que aborda la diferencia existente entre ciencia y filosofía práctica.

A diferencia de lo que sucede con lo humano, los objetos de las ciencias naturales, tienen identidad ontológica, es decir la característica no variar en el tiempo. Por ejemplo una molécula de hidrógeno es siempre una molécula de hidrógeno.

Tan es así que de hecho es indiferenciable de otra molécula de hidrógeno, desde el punto de vista puramente ontológico, no sería correcto hablar de dos objetos sino del mismo repetido dos veces. Es por este motivo que es posible inducir principios generales a partir de un objeto particular.

Esta característica determina la segunda que es la necesidad lógica. Toda vez que los objetos de la naturaleza poseen la propiedad de permanencia ontológica se puede establecer, respecto de dichos objetos, relaciones lógicas necesarias, que dadas ciertas condiciones podamos esperar que ocurran siempre.

Volviendo a los ejemplos básicos de la química, se puede establecer una temperatura a la que el agua cambia de estado líquido a gaseoso, y es razonable esperar que esto siempre ocurra bajo ciertas condiciones. 
Ahora bien, nada de esto puede decirse respecto de los objetos que estudian las ciencias sociales, ellos no tienen ni permanencia ontológica ni necesidad lógica. Un ser humano nunca es igual a otro, ni siquiera a si mismo conforme pasa el tiempo. No hay modo de determinar algo similar a un punto de ebullición para una sociedad, ni tan siquiera desde un uso metafórico de la expresión.

En resumen, las ciencias sociales no pueden aspirar a construir regularidades que puedan definirse como leyes o principios universales. Esto contradice gran parte de lo que, desde una mirada ingenua se supone es la tarea científica.

A estas dos características diferenciadoras hay que agregar una tercera, que fue descrita por Anthny Giddens (1995) con su concepto de doble hermenéutica. En las ciencias sociales trabajamos con objetos de estudio que hablan, tienen opinión y justificación de sus propios actos.

Esto no significa que el investigador automáticamente deba asumir que la explicación dada por el sujeto de su investigación es la de mayor validez, pero sin duda debe tenerla en cuenta como parte de la realidad a investigar. Esto supone establecer al menos dos planos en la investigación, aquel que brinda una explicación externa de las causas de un comportamiento social, y aquel que busca comprender las motivaciones internas de dicho comportamiento. En algunas tradiciones de investigación social esta diferencia ha sido descrita con los términos explicar y comprender.

Ahora bien, si damos por ciertas esta diferencias, ¿Cuál es entonces la tarea de la ciencia social, si no es la de establecer regularidades universalmente observables? ¿Cómo enfrentar el desafío de dar cuenta tanto de las posibles explicaciones externas, como de la comprensión de las motivaciones internas?

Comencemos por responder la primera pregunta, partiremos de la idea de que la tarea de la ciencia, ya sea que concentre su atención en la naturaleza o en el hombre, es el ordenamiento racional de la realidad empírica, siguiendo el planteo de Max Weber (1977) la ciencia "aspira al orden racional de la realidad empírica", la investigación supone fundamentalmente dos instancias, un elemento de acercamiento empírico a la realidad y un ordenamiento racional de dichos datos.

Ambas dimensiones de la ciencia son imprescindibles, de lo contrario caeríamos o bien en la especulación o bien en el empirismo. El diseño de investigación que presentaremos a continuación busca dar cuenta de ambas dimensiones. 
Asimismo cabe mencionar que, si bien la predictibilidad del comportamiento social en términos estrictos no es posible, si es razonable suponer que dicho conocimiento científico social brinda herramientas para planificar la acción en términos de políticas públicas, describiendo escenarios de posibles consecuencias.

En segundo término, dada esta característica que denominábamos doble hermenéutica, resulta fundamental tener en cuenta la voz de los actores, no como única o principal fuente de información, pero como una dimensión central de la investigación.

De modo que el desafío está en incorporar en la investigación tanto el punto de vista que podríamos denominar externo, como aquel que da cuenta del sentido mentado de la acción.

Por este motivo una comprensión cabal de los fenómenos sociales implica la triangulación de técnicas que estudien de maneara externa los fenómenos, con técnicas que apunten a conocer la dimensión subjetiva.

La triangulación en metodología, al igual que sucede con la triangulación en la cartografía, nos brinda coordenadas diferentes sobre un mismo fenómeno, lo cual nos habilita a definir con mayor precisión sus características.

A continuación veremos cómo la articulación de métodos orientados al estudio de dimensiones estadísticas macro con métodos que indagan sobre el sentido que los propios actores dan a su situación es central en nuestra investigación.

Por último queremos mencionar que entendemos que un diseño de investigación debe ser coherente en todos sus componentes. El enfoque de investigación del que partimos realza un conjunto de principios de investigación. Esta propuesta es particularmente interesante en la medida en que la familia constituye un objeto muy cambiante, de modo que el establecimiento de un conjunto de premisas para la investigación resulta fundamental.

El estudio de la familia como objeto de las ciencias sociales requiere, más que una teoría o conjunto de teorías, un programa de investigación. Tal es la propuesta elaborada por el sociólogo estadounidense Glen Elder (2000) que se concentra en un conjunto de conceptos relevantes a la hora de comprender el proceso de las familias a lo largo del tiempo. 
Esta perspectiva trabaja con conjunto de principios que orientan la investigación en relación a las familias. Ya hemos descrito estos principios en el capítulo destinado a analizar conceptos operativos:

- Principio de Desarrollo en el tiempo.

- Principio de tiempo y lugar

- Principio de timinig

- Principio de vidas interconectadas

- Principio de agencia.

A continuación presentaremos los objetivos y estrategia de investigación, en la que hemos intentado tomar en consideración estas consideraciones metodológicas así como estos principios de investigación.

\subsection{Objetivo General}

Contribuir al conocimiento de las características que asumen las familias en contextos de vulneración socio económica, en el Uruguay de hoy.

\subsection{Objetivos Específicos}

1. Describir y tipificar las principales características demográficas de las familias que responden al modelo de "linajes materno" y que integran el Uruguay vulnerado.

2. Describir las concepciones subjetivas asociadas al modelo de "linaje materno" que sostienen las mujeres jefas de hogar que integran estas familias.

\subsection{Preguntas de Investigación}

1. ¿Cuál es la magnitud relativa de los arreglos familiares matrilocales y matrilineales en el contexto del Uruguay vulnerado?

2. ¿Cuáles son las características demográficas que asumen las familias que responden a este tipo particular de arreglo familiar?

3. ¿De qué modo conceptualizan subjetivamente las jefas de hogar integrantes de estas familias las categorías de: matrimonio, filiación, parentesco, roles de género?

4. ¿De qué modo conceptualizan subjetivamente las jefas de hogar integrantes de estas familias el tránsito a la vida adulta en el marco de su trayectoria vital? 


\subsection{Estrategia de investigación}

El problema que abordamos se expresa tanto en términos demográficos como en términos subjetivos. Dicho de otro modo podemos afirmar que las transformaciones que la demografía describe a nivel de las poblaciones, tienen un correlato en el modo en que los individuos conciben su realidad familiar.

Por este motivo el abordaje intentó triangular un abordaje cuantitativo y macrosocial que dio cuenta de la expresión demográfica del fenómeno familiar, con un abordaje cualitativo que se centró en la subjetividad con que los individuos conciben estos procesos.

La estrategia de investigación se desarrolló entonces en dos etapas.

\subsubsection{Estudio Socio demográfico}

En un primer momento se trabajó con datos secundarios provenientes de la Encuesta Continua de Hogares (ECH) 2015 y del Censo de Población 2011, a partir de la cual se tipificaron los arreglos familiares presentes en los sectores de mayor vulnerabilidad socioeconómica.

Se buscó crear de una tipología que nos permitiera delimitar los tipos de hogares en Uruguay y su correlación con indicadores de pobreza tales como Necesidades Básicas Insatisfechas y Línea de Pobreza según se trate del Censo o de la Encuesta Continua de Hogares.

Luego se procedió al análisis de la distribución demográfica de dicho fenómeno, a partir del cruce con variables referidas fundamentalmente a la estratificación socioeconómica.

En un segundo momento se elaboró una tipología de hogar que definiremos como "hogar de línea materna" cuyo arreglo familiar nos permite asumir que se trata de un linaje materno. La definición metodológica de este tipo de hogar es el de tres generaciones conviviendo donde todos los mayores de edad son mujeres, sin la presencia de varones mayores de edad.

Se procedió luego a verificar la magnitud de este tipo de hogar y a chequera la correlación de su presencia con los indicadores de pobreza antes mencionados, a los efectos de determinar si es más frecuente en el Uruguay Vulnerado. 


\subsubsection{Estudio Biográfico y Genealógico}

En una segunda etapa se trabajó a partir de la base de datos de MIDES-DINEM y se seleccionó un conjunto de mujeres referentes de familias, en función de su pertenencia a los sectores vulnerados y al tipo de arreglo familiar, a quienes se invitó a participar del estudio. Para ello se realizó un muestreo teórico recurriendo a familias del programa Cercanías.

El propósito del muestreo teórico es maximizar las oportunidades de comparar acontecimientos, incidentes o sucesos para determinar cómo varía una categoría en términos de sus propiedades y sus dimensiones. Por tanto no es un muestreo de personas per se, sino de situaciones o casos que llevan problemas, asuntos o fenómenos en los cuales se encuentra que una serie de personas, organizaciones, comunidades, etcétera es de alguna manera problemática o rutinaria y a la cual se da respuesta por medio de alguna acción o interacción. (Quiñones, 2015: 127)

En particular se recurrió a familias del Programa Cercanías del MIDES, ya que dicho programa utiliza un doble criterio de selección de población vulnerada:

El primer criterio está constituido por una indicador probabilístico de pobreza denominado Índice de Carencia Críticas (ICC). Dicho indicador opera como un proxi de pobreza medida por ingreso.

EI ICC se aproxima a determinar los hogares con menores ingresos mediante otras dimensiones del bienestar, por lo que se diferencia de la metodología más usual para definir la pobreza, que es la monetaria. Esta última intenta reflejar la capacidad de adquirir ciertos bienes y servicios definidos como básicos, entendiendo que el principal medio que tienen los hogares para adquirirlos es el ingreso del que disponen. (Colombo, 2013: 5)

El segundo elemento para la selección estudia un conjunto de ejes de deprivación o no cumplimiento de ciertos derechos y se denomina Indicie de Vulneración (I.V.). Todas las familias que forman parte del programa deben encontrarse por debajo de ciertos umbrales en relación a ambos índices.

Los grupos familiares invitados por los ETAF a participar son seleccionadas a partir de un índice acumulado que integra la situación de pobreza extrema (identificada por equipos de la Dirección Nacional de Evaluación y Monitoreo - 
DINEM-MIDES) y la situación de vulnerabilidad socio-familiar identificada a través del diagnóstico que realizan servicios sociales en territorio (Nodos/redes locales, Oficinas del MIDES, SOCAT, Centros de INAU, referentes de servicios sociales, etc.).

La pobreza extrema se mide a través del índice de carencias críticas que mide la DINEM con la aplicación de un formulario en visitas a hogares (esta información facilita el acceso a AFAM y Tarjeta Uruguay Social- TUS). Se prioriza la atención de familias destinatarias de TUS doble.

La vulnerabilidad socio-familiar (VSF) se valora a partir de la información incluida en un formulario que es completado por operadores del MIDES (Oficina Territorial, SOCAT), equipos de INAU, y/u otros técnicos de cada territorio; quienes consultan a la red local de servicios en el espacio técnico de articulación (ej. Nodo de Familia). Las dimensiones consideradas en el formulario VSF refieren a la presencia de situaciones de riesgo en la familia: dificultades en cuidados familiares, violencia intrafamiliar, consumo problemático de sustancias psicoactivas, situaciones de calle, mendicidad o trabajo infantil de algún integrante, desnutrición, problemas de salud, integrantes privados de libertad o en conflicto con la ley, hábitat degradado o vivienda precaria, desempleo, trabajo precario o de riesgo. (Cercanías, 2012: 7)

Del universo de familias, fueron seleccionada en conjunto con los equipos técnicos del Programa Cercanías, aquellas que respondieron al criterio de ser hogares monoparentales de jefatura femenina. Se trabajó con familias de Montevideo.

Con estas mujeres referentes de los se trabajó a partir de entrevistas semiestructuradas. A partir de esta selección buscaremos construir una mirada genealógica de cada familia, que nos permita explorar la dimensión subjetiva, de los fenómenos antes descritos de manera demográfica.

Podemos definir el método genealógico como el procedimiento técnico por el cual un investigador efectúa, mediante entrevistas, una recolección de ciertos datos sobre los integrantes -tanto ascendientes como descendientes- de una o más familias y realiza luego el procesamiento y análisis de esa información. Todo ello lo expresa gráficamente en un documento denominado genealogía, que muestra las conexiones familiares entre los diferentes sujetos 
entrevistados. Este documento se erige en representación gráfica de una situación social e histórica determinada, lo que posibilita brindar una visión de conjunto mostrando a sus miembros distribuidos en generaciones $y$ relacionados con algún tema específico. (Davinson Pacheco, 2007: 168)

La pauta de entrevista en profundidad se concentró en indagar sobre las siguientes categorías:

- $\quad$ Relaciones de pareja y matrimoniales.

- $\quad$ Roles de género y expectativas recíprocas.

- $\quad$ Filiación

- Parentesco

- Transición a la Vida Adulta

La articulación de la estrategia de investigación socio demográfica, que nos permitió aproximarnos a una cuantificación del proceso y su ubicación en términos de estratificación social, con una estrategia de investigación biográfica y genealógica, nos habilitó a delimitar con más claridad el fenómeno y describir algunas de sus particularidades.

Aun así es menester decir que este proceso de investigación es exploratorio, y que dado lo arriesgado de la elaboración conceptual en comparación con los medios empíricos de verificación, solo aspiramos a desarrollar una mirada exploratoria, que brinde indicios sobre el fenómeno y nos permita trazar un plan de trabajo para futuras investigaciones. En los próximos capítulos presentaremos los resultados más significativos de ambas estrategias. 


\section{RESULTADOS DE LA ESTRATEGIA DE INVESTIGACIÓN CUANTITATIVA LINAJES MATERNOS COMO FENÓMENO DEMOGRÁFICO}

\subsection{Estrategia de Investigación demográfica, familias y arreglos familiares}

La estrategia de investigación que hemos desarrollado, en este caso para abordar las transformaciones demográficas de las familias, busca sacar el mayor rendimiento posible a los recursos limitados con los que se cuenta, ya que dichos recursos no fueron creados específicamente para dar respuesta a las necesidades de la investigación.

Tal es el caso de la información secundaria, de tipo estadístico a la que puede accederse a partir del Censo o de las Encuestas estandarizadas que habitualmente los países realizan respecto de su población. En este sentido cabe realizar una precisión antes de continuar. La información que utilizaremos en este capítulo releva una dimensión del fenómeno que estamos estudiando, sin embargo no puede brindarnos una imagen completa porque los datos no fueron relevados para este fin.

En este documento cuando hablamos de linajes maternos nos referimos a un modo particular de familia, tanto en lo que se refiere a su estructura, como a la subjetividad arraigada en sus integrantes. Como hemos dicho antes, cada familia en particular puede acercarse un poco más o menos al modelo teórico, ya sea por su estructura o por las ideas de familia que sostienen sus integrantes. $Y$ si bien el primer elemento, es decir la estructura o tipo de arreglo familia puede establecerse a partir de Censo o de la Encuesta Continua de Hogares, las concepciones de los integrantes no, simplemente porque ambas herramientas no han previsto preguntas que den cuenta de dicha información.

En este sentido, en este capítulo nuestra intención es presentar algunos resultados originales de nuestra investigación a los que hemos arribado a partir del análisis de fuentes secundarias de información. Las fuentes de información de las que nos valdremos, para este caso particular son dos: El Censo desarrollado por nuestro país en el año 2011 y la Encuesta Continua de Hogares con sus resultados para el año 2015.

Ambas fuentes de información brindan datos generales sobre las familias uruguayas, pero dicha información, toda vez que no fue construida pensando en una investigación 
como la que estamos llevando adelante debe ser abordada mediante una estrategia particular.

Dicho de otro modo, el fenómeno que estamos intentando analizar, o sea la existencia de hogares que hemos definido como linajes maternos, solo puede ser vislumbrado parcialmente a partir de los datos estadísticos del Censo o la ECH. Esto es así al menos por dos motivos. El primero es que ninguna de las dos fuentes de información fue creada para la detección de este fenómeno en particular, esto nos enfrentará a la necesidad de desarrollar algunas estrategias puntuales para detectar el fenómeno de un modo que podríamos definir como indirecto.

El segundo motivo es el fenómeno está vinculado a la subjetividad de las personas, a sus nociones de familia, género y de las transiciones a la vida adulta, y si bien es posible establecer una relación entre las convicciones personales y algunas conductas objetivas observables en los datos del Censo y la ECH, esta relación está lejos de presentar una correspondencia bis a bis.

Sin embargo si es posible diseñar una estrategia de investigación que nos permita detectar indicios de esta forma particular de concebir la familia, los roles de género y la transición a la vida adulta.

Ya hemos delimitado alguno de los elementos centrales del modelo que estamos intentando definir. Dijimos entonces que existían en el Uruguay Vulnerado hogares en los que se presentaban alguno de los siguientes componentes:

- Roles de género fuertemente diferenciados: Estableciendo para las mujeres roles vinculados a la crianza y a los varones un rol proveedor. Al no poder ejercer estos roles proveedores los varones ven desdibujada su presencia e importancia dentro de la familia.

- Indicios de matrilinealidad: Como consecuencia de lo anterior, los roles femeninos suelen ser mucho más fuertes y la familia se define por el parentesco del costado materno.

- Indicios de matrilocalidad: Este elemento surge del hecho de que luego del emparejamiento, como consecuencia de la matrilinealdad y de la pérdida de importancia del rol masculino, la nueva familia se establece en el hogar materno. 
- Por último, en este modelo los elementos centrales de la transición a la vida adulta de hombres y mujeres se diferencian, siendo el ingreso a la vida productiva en el caso de los varones, y el inicio de la vida reproductiva en el caso de las mujeres.

La estrategia de investigación consistirá entonces en un análisis de los arreglos familiares que presentan las familias uruguayas. En este sentido será fundamental determinar el peso relativo de ciertos arreglos familiares particulares, tales como los hogares monoparentales femeninos.

Sin embargo avanzando un poco más hemos definido la construcción de un tipo particular de arreglo familiar, caracterizado fundamentalmente por la presencia de dos o más generaciones donde todos los adultos son mujeres que, perteneciendo al mismo hogar, no conviven con ningún hombre mayor de edad.

Hemos llamado a estos hogares de dos o más generaciones de mujeres hogares de línea materna, por el hecho de que existan varias generaciones de mujeres conviviendo, por lo que existe una importante probabilidad de estar frente a familias que tiene características de matrilinealidad y matrilocalidad.

Es importante recalcar que esto es solo una estrategia de investigación, y que no podemos afirmar que todos los hogares que presentan estas características en su arreglo familiar responden al modelo que hemos definido como linaje materno.

Asimismo el inverso también se cumple, de tal modo que muchos hogares con verdaderas características de un linaje materno, no serán capturados por esta metodología que solo detecta la conformación de los arreglos familiares.

Sin embargo, como los fenómenos demográficos tienen un correlato con los biográficos, es posible asumir, que de encontrar realmente este tipo de arreglo familiar esto constituiría un indicio muy significativo de la presencia de este tipo de hogar. 


\subsection{Tipos de Hogar y Pobreza según el Censo y la Encuesta Continua de Hogares}

El análisis a partir de la información debe partir, como decíamos de un mapeo general de los arreglos familiares en el Uruguay, que nos permita delimitar la presencia de ciertos fenómenos descritos teóricamente.

Para ello partiremos de la tipología de hogares que habitualmente utiliza el INE. Los informes y desarrollos del INE suelen establecer seis categorías de arreglos familiares:

1. Hogar unipersonal: Es el hogar particular integrado por sólo una persona.

2. Nuclear sin hijos: Corresponde al hogar integrado sólo por la pareja, sin hijos.

3. Nuclear con hijos: Corresponde al hogar integrado por ambos cónyuges y sus hijos.

4. Monoparental: Es el hogar particular integrado por sólo uno de los cónyuges y sus hijos

5. Hogar extendido: Corresponde a un hogar nuclear más otros parientes, o a una persona con otros parientes.

6. Hogar compuesto: Corresponde al hogar nuclear o al hogar extendido más otra u otras personas cuya relación con el jefe del hogar no es de parentesco.

Sin embargo, dado que para nuestro estudio el género un concepto clave, hemos decidido dividir las categorías hogares con jefaturas monoparentales en función de que posean un jefe de hogar de sexo femenino o masculino.

Por otra parte hemos decidido dividir la categoría de hogares extensos en función de las características del núcleo básico estableciendo cuatro categorías: extenso de base nuclear con hijos, extenso de base nuclear sin hijos, extenso de base monoparental femenina y masculina. Este ejercicio nos ha permitido construir una tipología de 12 tipos de hogar:

1. Hogar unipersonal masculino

2. Hogar unipersonal femenino

3. Nuclear sin hijos

4. Nuclear con hijos

5. Monoparental Femenino 
6. Monoparental Masculino

7. Extendido de Base Nuclear sin hijos

8. Extendido de Base Nuclear con hijos

9. Extendido de Base Monoparental Femenina

10. Extendido de Base Monoparental Masculina

11. Unipersonal Extendido: Una persona con otro pariente

12. Compuesto

Dada esta nueva categorización de los arreglos familiares, el primer elemento que puede apreciarse con claridad, a partir de los datos del Censo es el hecho de que los hogares nucleares con hijos, si bien continúan representando el arreglo familiar más frecuente, no alcanza a representar un tercio de los hogares totales del país.

Nótese que según la metodología aplicada, se considera hogar nuclear a cualquier constitución que implique un jefe de hogar, su pareja e hijos, sin importar si se trata de hijos de ambos, o se trate hijos de parejas anteriores. De este modo las familias recompuestas pueden considerarse familias nucleares según esta metodología.

De este modo el hogar nuclear constituye menos de un tercio del total de hogares que fueron censados en el año 2011. Esto revela con claridad que el proceso que hemos descrito como segunda transición demográfica evidentemente ha tenido un impacto significativo en nuestro país.

Si vemos los censos entre 1963 y 2011 se aprecia claramente una tendencia sostenida de disminución del peso porcentual relativo de los hogares nucleares, así como un crecimiento sostenido de los hogares monoparentales 


\section{Grafico 4.}

Evolución de los hogares nucleares y monoparentales, total del país (en porcentaje) Censos 1963-2011

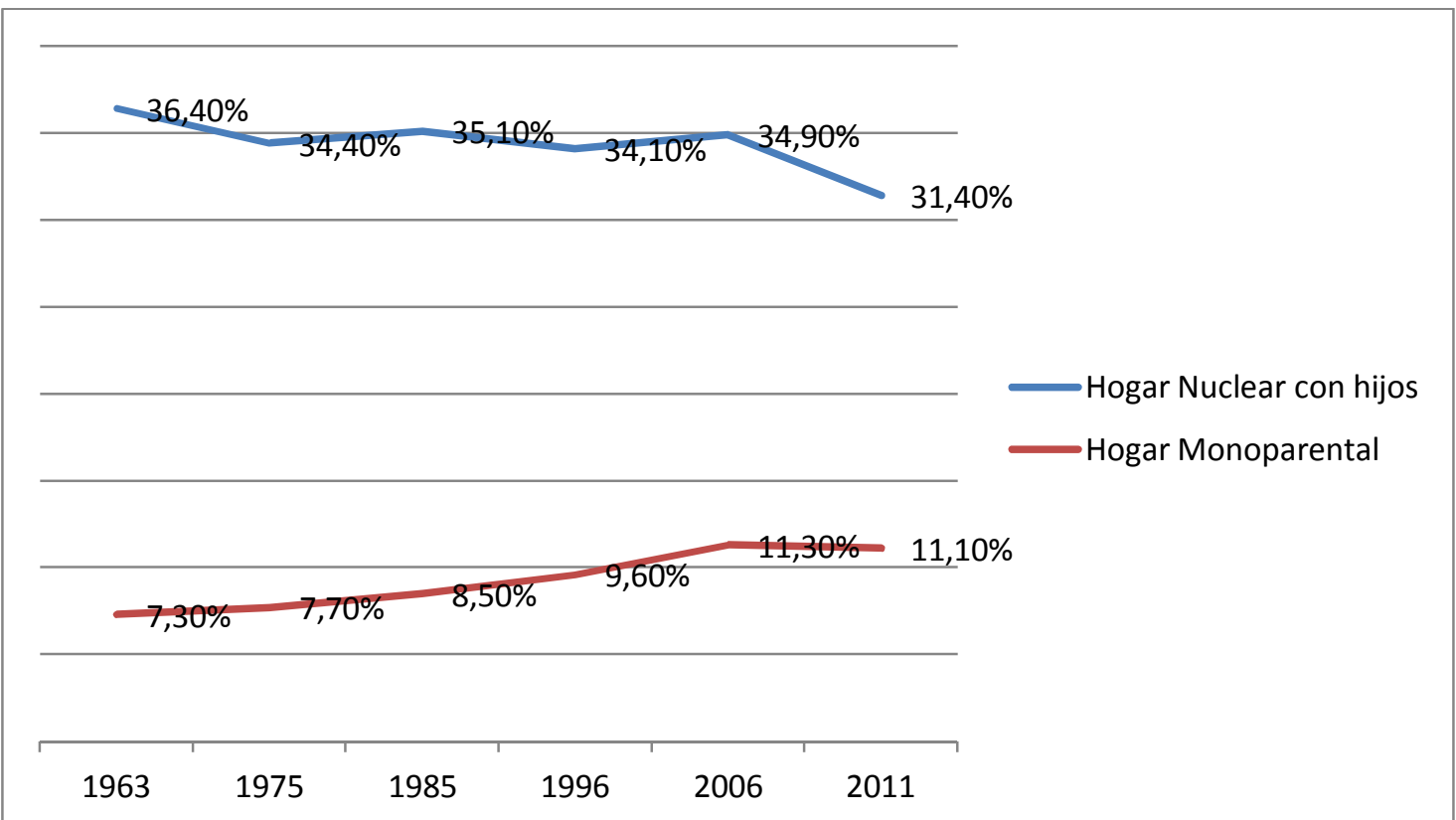

Fuente: Atlas Socio demográfico, fascículo 6 INE

El segundo elemento que queremos destacar y que representa un dato importante en el contexto de nuestra investigación es la importancia de los arreglos familiares monoparentales femeninos y extendidos de base monoparental femenina. Juntos, ambos tipos de arreglos constituyen el $13,1 \%$ del total de hogares del país, según el Censo 2011.

Este dato, significativo por sí mismo, se torna aún más significativo cuando compararnos lo que sucede con la misma situación a la inversa, siendo los hogares monoparentales masculinos, y extendidos de base monoparental en conjunto tan solo el $2 \%$ del total de los hogares.

En línea con lo que decíamos al comienzo, si bien no es posible afirmar que todos estos hogares constituyan linajes maternos, solo por el hecho de tener arreglos con jefatura femenina, lo cierto es que existe una significativa diferencia por sexo, que nos permite concluir que existen pautas de comportamiento diferenciales, que reflejan nociones respecto a la responsabilidad diferencial de mujeres y hombres en relación a la convivencia con los hijos. 


\section{Grafico 5.}

Distribución de los hogares según tipo de hogar en base al Censo 2011, total del país (en porcentaje)
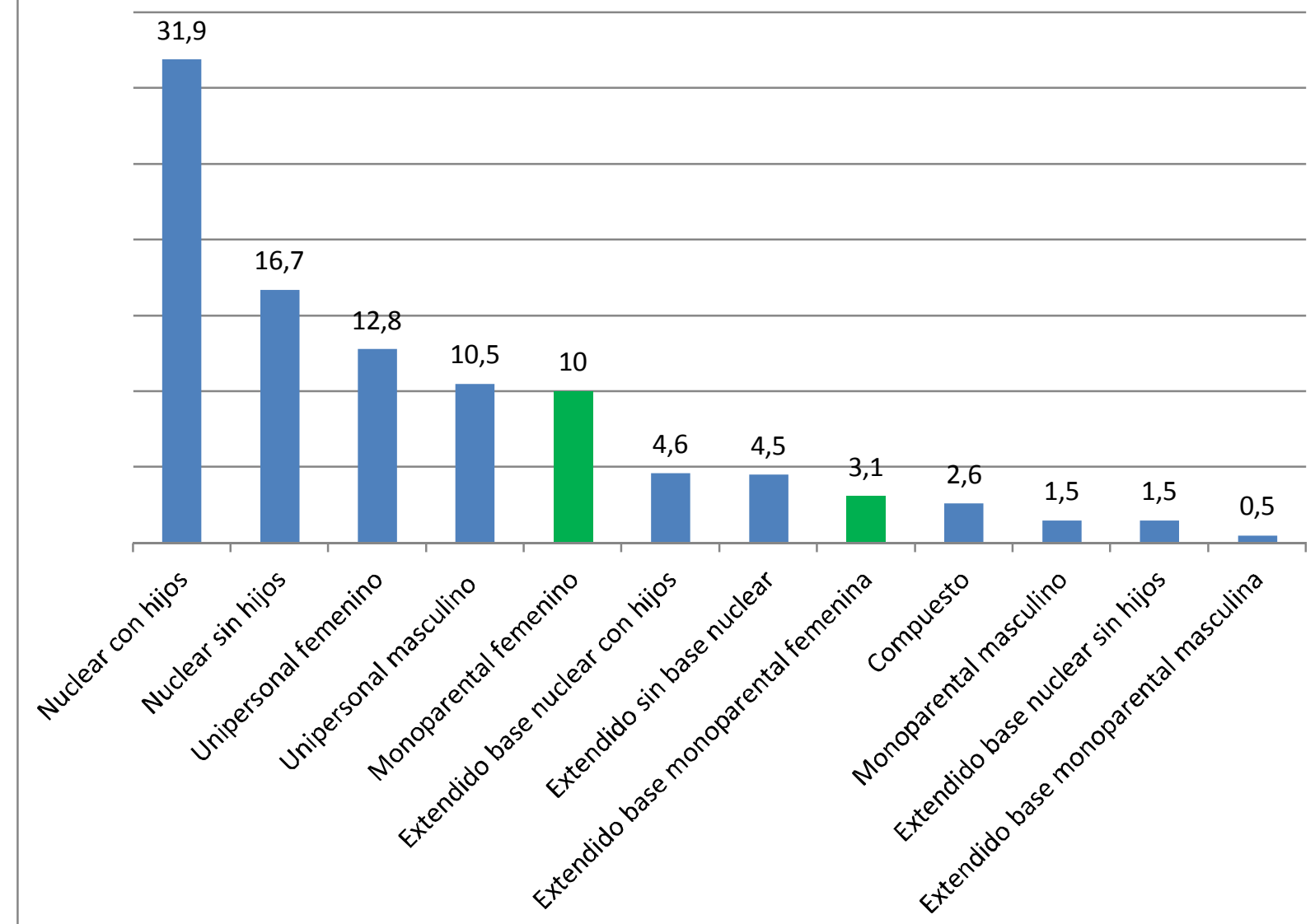

\begin{tabular}{|l|c|l|l|c|}
\hline Unipersonal femenino & $12,8 \%$ & & Extendido base nuclear sin hijos & $1,5 \%$ \\
\hline Unipersonal masculino & $10,5 \%$ & & Extendido base nuclear con hijos & $4,6 \%$ \\
\hline Nuclear sin hijos & $16,7 \%$ & & Extendido base monoparental femenina & $3,1 \%$ \\
\hline Nuclear con hijos & $31,9 \%$ & & Extendido base monoparental masculina &, $5 \%$ \\
\hline Monoparental femenino & $10,0 \%$ & & Extendido sin base nuclear & $4,5 \%$ \\
\hline Monoparental masculino & $1,5 \%$ & & Compuesto & $2,6 \%$ \\
\hline
\end{tabular}

Fuente: Elaboración propia a partir de datos del Censo 2011-INE

Como podemos ver la información arrojada por la Encuesta Continua de Hogares 2015 coincide en término generales con la arrojada por el Censo 2011. 


\section{Gráfico 6.}

Distribución de los hogares según tipo de hogar en base a Encuesta Continua de Hogares 2015, total del país (en porcentaje)

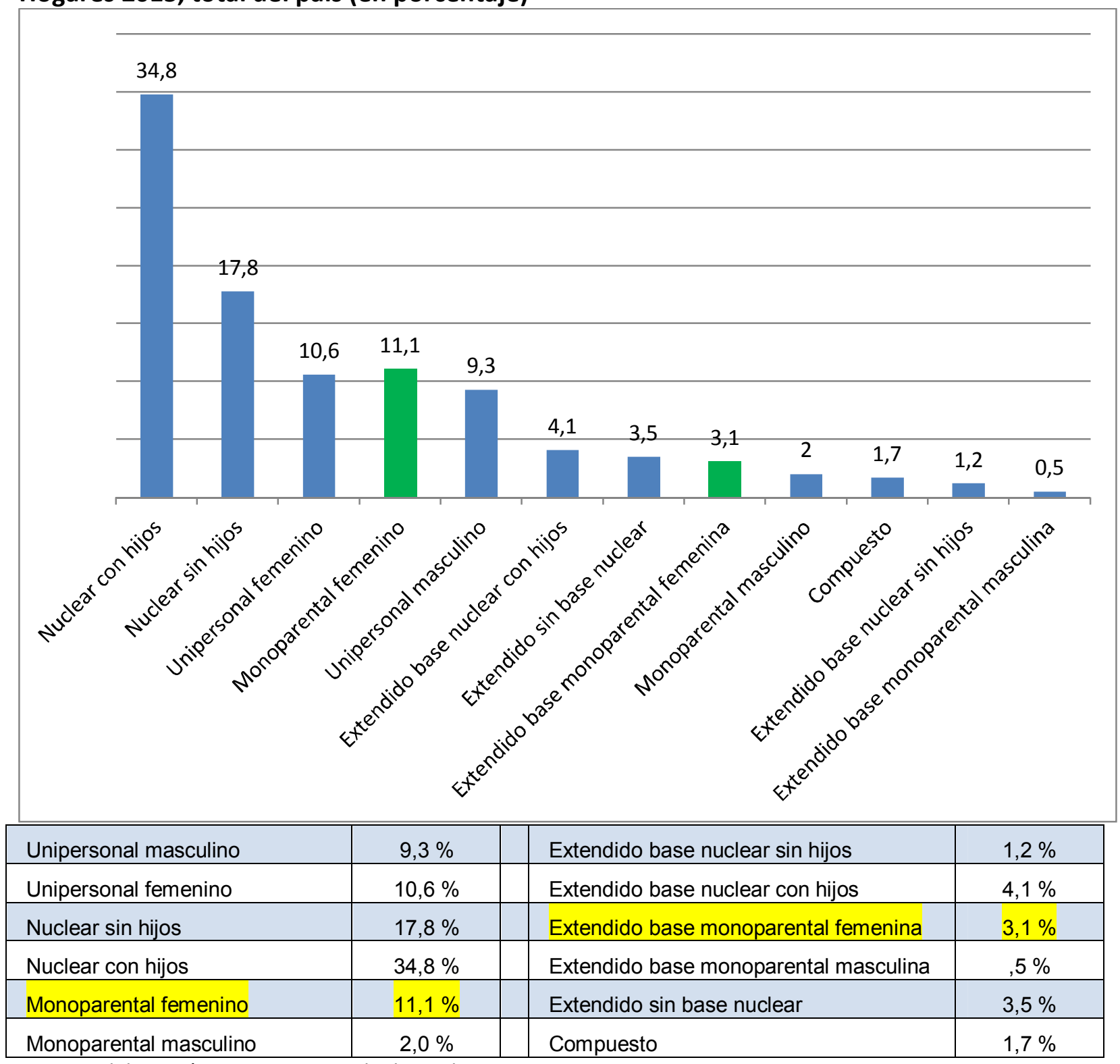

Fuente: Elaboración propia a partir de datos de ECH 2015-INE

El segundo elemento que es podemos definir, una vez que hemos determinado la existencia de un importante número de arreglos familiares, cuyas jefas de hogar son mujeres, es el hecho de que este tipo particular de arreglo presenta una tendencia importante a la vulnerabilidad socio-económica.

Es menester aquí señalar dos cosas, en primer lugar hay que decir que esto es cierto, tanto en los hogares monoparentales masculinos como femeninos, y esto se debe probablemente a la explicación más obvia de que se trata de hogares con menores a 
cargo, pero que cuentan con un solo aportante en comparación a los hogares de base nuclear que tienen, al menos potencialmente dos aportantes potenciales.

\section{Gráfico 7.}

Hogares pobres y no pobres según tipo de hogar Encuesta Continua de Hogares 2015, total del país (en porcentaje)

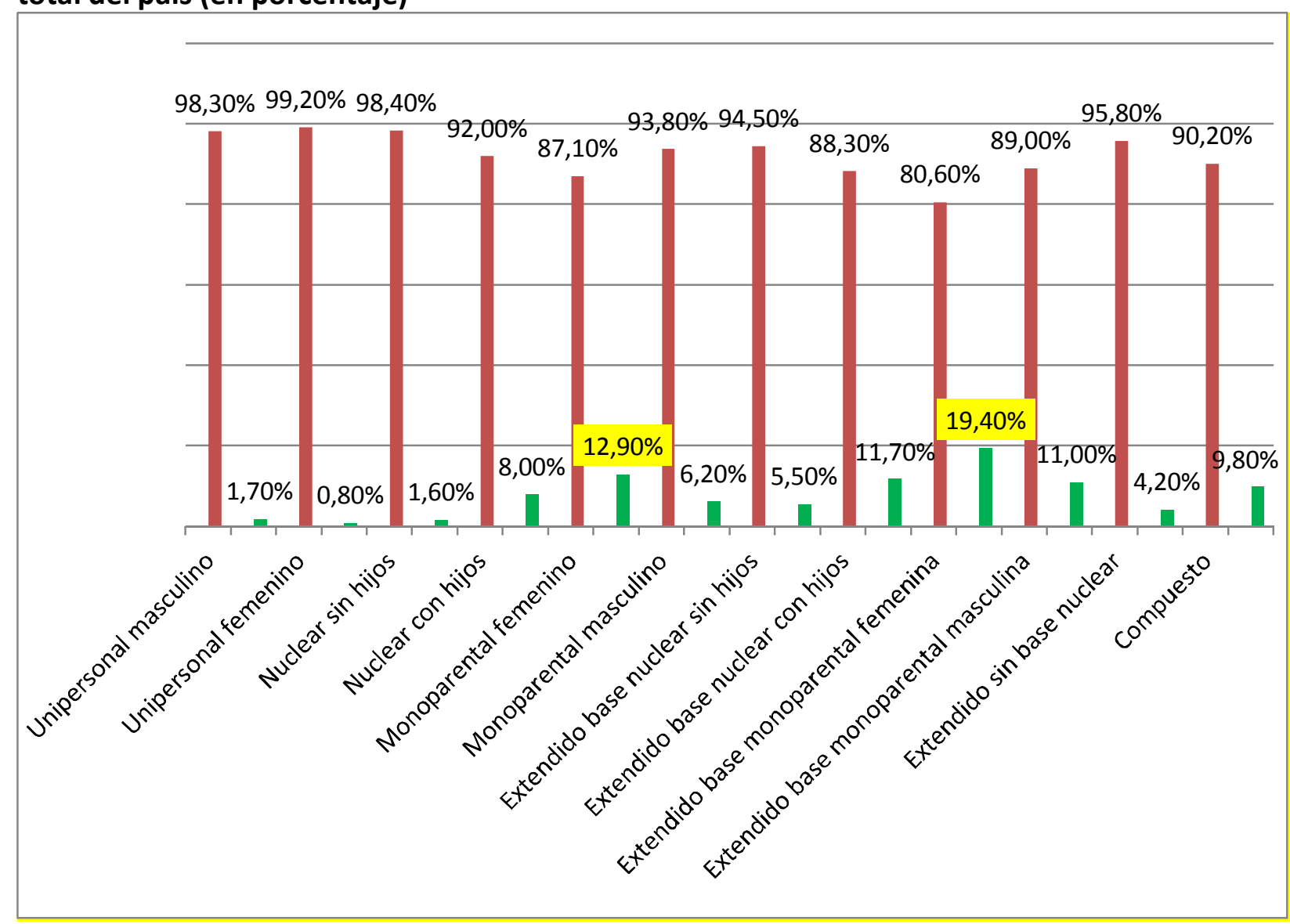

\begin{tabular}{|c|c|c|c|c|c|}
\hline \multirow[t]{2}{*}{ Unipersonal masculino } & No pobre & $98,3 \%$ & \multirow{2}{*}{$\begin{array}{l}\text { Extendido base nuclear sin } \\
\text { hijos }\end{array}$} & No pobre & $94,5 \%$ \\
\hline & Pobre & $1,7 \%$ & & Pobre & $5,5 \%$ \\
\hline \multirow[t]{2}{*}{ Unipersonal femenino } & No pobre & $99,2 \%$ & \multirow{2}{*}{$\begin{array}{l}\text { Extendido base nuclear con } \\
\text { hijos }\end{array}$} & No pobre & $88,3 \%$ \\
\hline & Pobre & $0,8 \%$ & & Pobre & $11,7 \%$ \\
\hline \multirow[t]{2}{*}{ Nuclear sin hijos } & No pobre & $98,4 \%$ & \multirow{2}{*}{$\begin{array}{l}\text { Extendido base } \\
\text { monoparental femenina }\end{array}$} & No pobre & $80,6 \%$ \\
\hline & Pobre & $1,6 \%$ & & Pobre & $19,4 \%$ \\
\hline \multirow[t]{2}{*}{ Nuclear con hijos } & No pobre & $92,0 \%$ & \multirow{2}{*}{$\begin{array}{l}\text { Extendido base } \\
\text { monoparental masculina }\end{array}$} & No pobre & $89,0 \%$ \\
\hline & Pobre & $8,0 \%$ & & Pobre & $11,0 \%$ \\
\hline \multirow[t]{2}{*}{ Monoparental femenino } & No pobre & $87,1 \%$ & \multirow[t]{2}{*}{ Extendido sin base nuclear } & No pobre & $95,8 \%$ \\
\hline & Pobre & $12,9 \%$ & & Pobre & $4,2 \%$ \\
\hline \multirow[t]{2}{*}{ Monoparental masculino } & No pobre & $93,8 \%$ & \multirow[t]{2}{*}{ Compuesto } & No pobre & $90,2 \%$ \\
\hline & Pobre & $6,2 \%$ & & Pobre & $9,8 \%$ \\
\hline
\end{tabular}

Fuente: Elaboración propia a partir de datos de ECH 2015-INE 
Sin embargo, cuando destacamos la cantidad de hogares pobres según el tipo de hogar vemos que los dos valores más altos son el hogar extendido de base monoparental femenina con un $19 \%$ de hogares pobres y el monoparental femenino con un $13 \%$ de hogares pobres.

Estos datos coinciden en términos generales con los del Censo 2011 que establece para los hogares monoparentales femeninos un porcentaje de $35,6 \%$ con Necesidades Básicas Insatisfechas y un $41,4 \%$ para los hogares extendidos de base monoparental femenina, siendo el promedio de los hogares $31,6 \%$.

Estos datos nos permiten establecer al menos dos conclusiones importantes y que coinciden en términos generales con nuestras hipótesis.

En primer lugar existe una fuerte diferencia por sexo en lo que se refiere a la jefatura de hogar, siendo significativamente más frecuentes los hogares monoparentales de jefatura femenina que los hogares monoparentales de jefatura masculina, en una relación de entre 13,1 \% o 14,2\% según se mire el Censo o la Encuesta Continua de Hogares, frente a un $2 \%$ o $2,5 \%$.

Este dato puede ser leído razonablemente como un reflejo de nociones vinculadas al género y a las responsabilidades diferenciales de hombres y mujeres en la crianza de los hijos.

La segunda conclusión importante es que estos hogares son claramente más frecuentemente pobres que los masculinos, y que todos los otros tipos de hogar en general.

Si bien es cierto que la tendencia general indica que la tenencia de hijos y la presencia de un único aportante son explicativas de la pobreza, el sexo aquí opera intensificando este fenómeno, siendo los hogares de jefatura femenina aquellos que están más frecuentemente por debajo de la línea de pobreza.

Esto coincide con nuestra identificación de los linajes maternos como pertenecientes a lo que se ha definido como el Uruguay Vulnerado.

\subsection{Hogar de línea materna en los datos estadísticos}

Como decíamos al comienzo de este capítulo, el hecho de trabajar con datos secundarios supone desarrollar estrategias tendientes a visualizar en estos datos evidencias toda vez que la medición del fenómeno no es directa. 
Es así que nuestra hipótesis es la presencia de linajes maternos, es decir arreglos familiares en los que la línea familiar se conserva por la rama femenina, y que a su vez tienen características de matrilocalidad, entre otras.

En este sentido es posible pensar que muchos de estos hogares responderán a una estructura de varias generaciones de mujeres conviviendo. De este modo se cumplirían, en teoría ambas características, la de la línea conservada por rama femenina y la de la convivencia.

En este sentido, como estrategia de investigación, nos hemos propuesto cuantificar el número de hogares que cuenten con las siguientes características:

1. Jefatura femenina.

2. Dos o más generaciones de mujeres adultas conviviendo.

3. Ningún varón mayor de edad conviviendo.

Llamaremos a este tipo de arreglo familiar hogar de línea materna, y si bien no es posible asegurar que todos estos hogares respondan a lo que hemos definido como un linaje materno, y lo que es más importante no todos los linajes maternos deben responder a este arreglo, como venimos diciendo, lo cierto es que encontrar evidencia de este tipo de arreglo coincidiría fuertemente con nuestra hipótesis.

Los resultados obtenidos muestran que el $2.4 \%$ de los hogares responden a este tipo particular de arreglo familiar según el Censo, y el $2.6 \%$ de los hogares según la ECH, y si bien este número es relativamente bajo debemos tener en cuenta que se trata de unos 30 mil hogares en todo el país.

Sin embargo, teniendo en cuenta que se trata de hogares extendidos y que por ende tienen un promedio mayor de personas, es importante decir que se este tipo de hogar representa el $4.2 \%$ de las personas del país, es decir unas 143 mil personas.

\section{Cuadro 1.}

Hogares Línea Materna. Encuesta Continua de Hogares 2015. Total del país.

\begin{tabular}{|l|l|l|}
\hline & Frecuencia & Porcentaje \\
\hline Hogares línea materna & 32469 & $2,6 \%$ \\
\hline Otros hogares & 1197738 & $97,4 \%$ \\
\hline Total hogares & 1230207 & $100,0 \%$ \\
\hline
\end{tabular}

Fuente: Elaboración propia a partir de la ECH 2015. 
Estos resultados parecen significativos además si realizamos el ejercicio de aplicar la metodología inversa, esto es intentar detectar hogares de línea paterna, es decir la misma metodología exactamente, pero cambiando el sexo, los resultados son muy claros. Encontramos tan solo un 0.3 \% de los hogares según la ECH que responden a esta patrón. Los resultados del Censo no son muy diferentes arrojando tan solo un 0,2 $\%$ de hogares de esta característica.

\section{Cuadro 2.}

Hogares Línea Paterna. Encuesta Continua de Hogares 2015. Total del país.

\begin{tabular}{|l|l|l|}
\hline & Frecuencia & Porcentaje \\
\hline Hogares línea paterna & 3499 &, $3 \%$ \\
\hline Otros hogares & 1226708 & $99,7 \%$ \\
\hline Total hogares & 1230207 & $100,0 \%$ \\
\hline
\end{tabular}

Fuente: Elaboración propia a partir de la ECH 2015.

Estos datos vienen a reafirmar algunos elementos que ya habíamos detectado cuando comparábamos la cantidad de hogares monoparentales femeninos frente a los masculinos. Solamente que cuando aplicamos esta metodología en particular el fenómeno se visualiza aún con más fuerza.

En tanto que en términos generales los hogares monoparentales guardan una relación de 6 a 1 en cuanto a jefatura femenina frente a masculina. Estos tipos particulares de hogares, que son también hogares de base monoparental, guardan una relación de 10 a 1 en cuanto a jefatura femenina frente a masculina.

Veamos también que los indicadores de pobreza en este caso particular se disparan siendo el porcentaje de hogares por debajo de la línea de pobreza el 19,4 \%, mayor que cualquiera de los tipos de hogar previamente analizados, y abrumadoramente mayor que el 6,4 \% de los hogares en general, según la ECH 2015.

Esto significa que uno de cada cinco de estos hogares no logra superar la línea de pobreza. Sin embargo para tener una noción más clara de la distribución de este tipo particular de hogar puede ser interesante visualizar la distribución según quintiles de ingreso. Esta metodología nos permite describir con precisión si existe una correlación entre la pertenencia a este tipo de arreglo familiar y el ingreso. 
En primer lugar podemos ver la distribución de los hogares monoparentales femeninos en relación a su pertenencia a quintiles de ingreso. Vemos aquí, que si bien existe un importante número de hogares que pertenecen al primer quintil 30,5\% y pocos de estos hogares pertenecen al quintil más rico $11,7 \%$, la distribución en los quintiles intermedios es más similar al promedio de la población.

\section{Gráfico 8.}

Distribución Quintiles de Ingreso de Hogares Monoparentales Femeninos ECH 2015

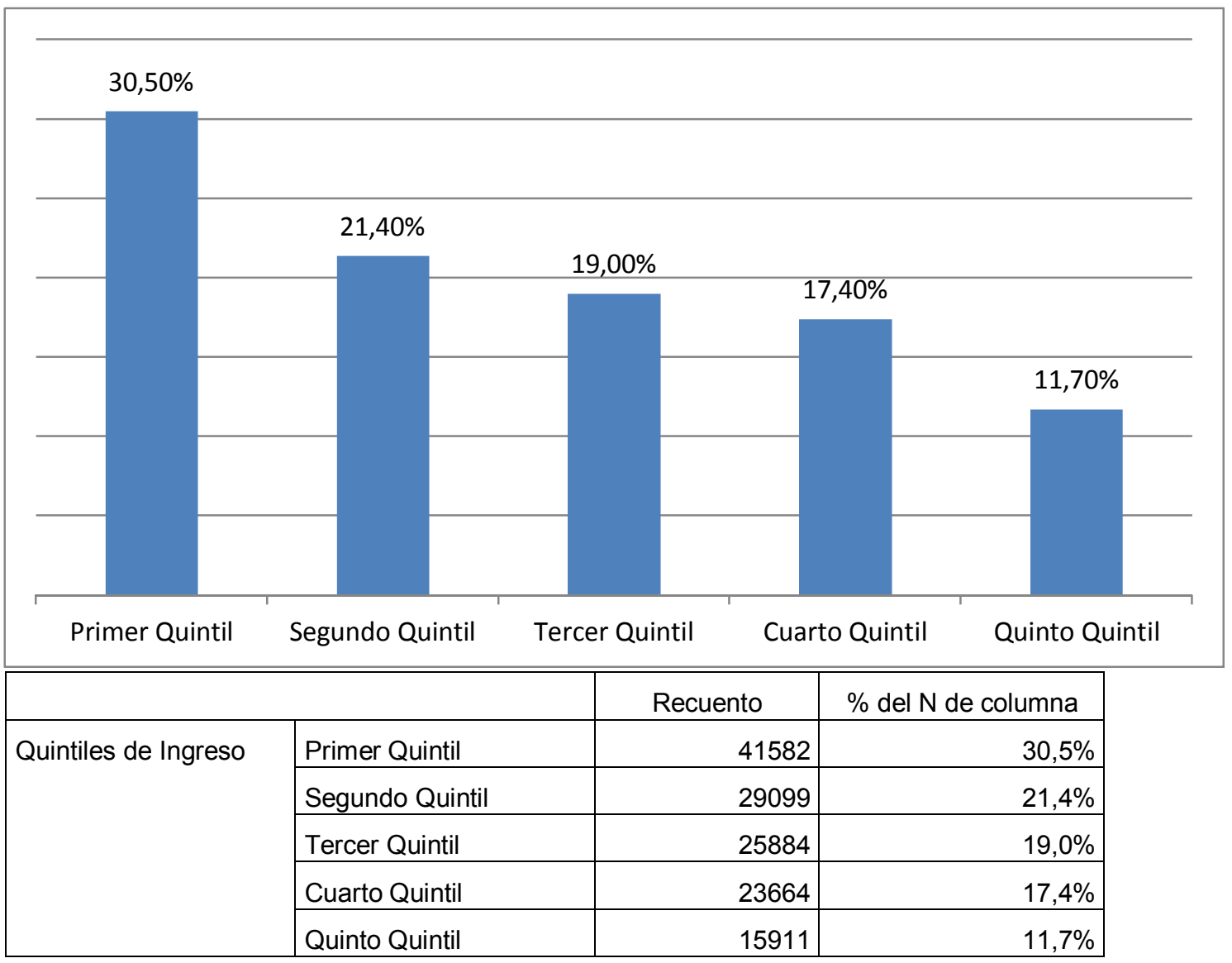

Fuente: Elaboración propia a partir de la ECH 2015.

La pertenencia a los quintiles de ingreso más pobres se torna más evidente cuando vemos los hogares extendidos de base monoparental femenina, en los que el $86,2 \%$ de ellos forma parte del $60 \%$ más pobre de la población, en tanto que solo el 3,6 \% forma parte del 20 \% más rico de la población. 


\section{Gráfico 9.}

Distribución Quintiles de Ingreso de Hogares Extendidos de base Monoparental Femenino ECH 2015

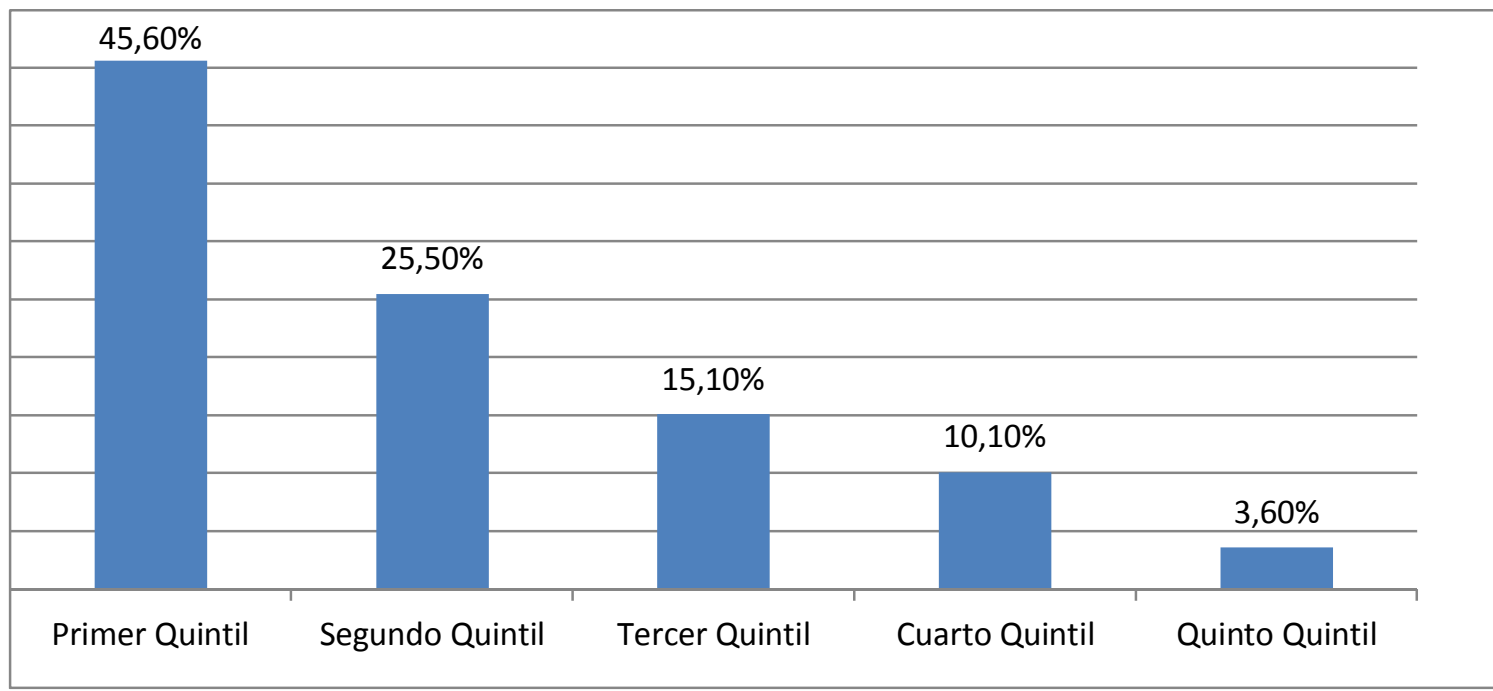

\begin{tabular}{|l|l|r|r|}
\hline \multicolumn{2}{|c|}{} & Recuento & $\%$ del N de columna \\
\hline \multirow{4}{*}{ Quintiles de Ingreso } & Primer Quintil & 18624 & $45,6 \%$ \\
\cline { 2 - 4 } & Segundo Quintil & 10413 & $25,5 \%$ \\
\cline { 2 - 4 } & Tercer Quintil & 6170 & $15,1 \%$ \\
\cline { 2 - 4 } & Cuarto Quintil & 4128 & $10,1 \%$ \\
\cline { 2 - 4 } & Quinto Quintil & 1478 & $3,6 \%$ \\
\hline
\end{tabular}

Fuente: Elaboración propia a partir de la ECH 2015.

Sin embargo, la mayor correlación entre la pertenencia a quintiles más pobres de población la presenta el tipo de hogar que hemos definido como hogar de línea materna tal como puede apreciarse en el gráfico a continuación.

En este caso el $87,7 \%$ de los hogares forma parte del 60 \% más pobre de la población, lo cual para la Encuesta Continua de Hogares en la versión 2015 implicaba contar con menos de 10.500 pesos per cápita por todo concepto de ingreso al mes en Montevideo, y 7.000 pesos en el Interior. 
Gráfico 10.

Distribución según Quintiles de Ingreso de Hogares de Línea Materna ECH 2015

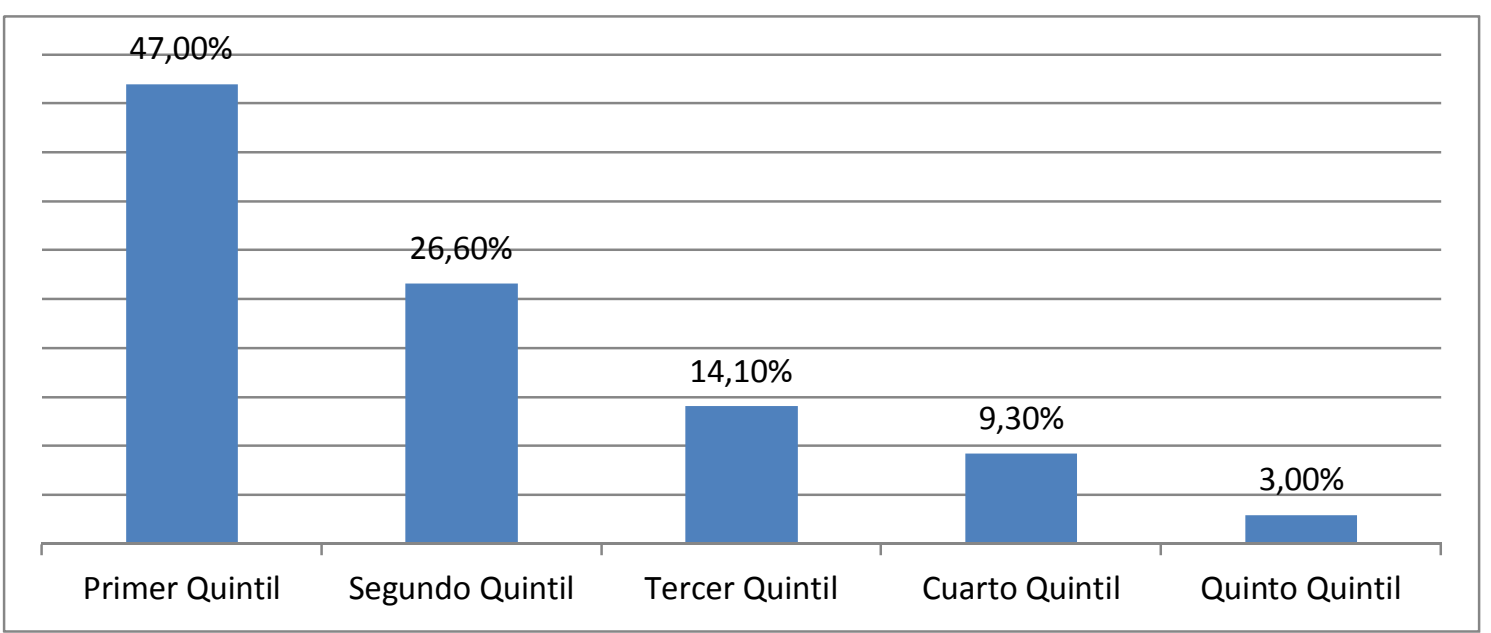

\begin{tabular}{|l|l|r|r|}
\hline \multicolumn{2}{|c|}{} & \multicolumn{1}{|c|}{ Recuento } & \% del N de columna \\
\hline \multirow{3}{*}{ Quintiles de Ingreso } & Primer Quintil & 15245 & $47,0 \%$ \\
\cline { 2 - 4 } & Segundo Quintil & 8642 & $26,6 \%$ \\
\cline { 2 - 4 } & Tercer Quintil & 4570 & $14,1 \%$ \\
\cline { 2 - 4 } & Cuarto Quintil & 3022 & $9,3 \%$ \\
\cline { 2 - 4 } & Quinto Quintil & 990 & $3,0 \%$ \\
\hline
\end{tabular}

Fuente: Elaboración propia a partir de la ECH 2015.

Asimismo los hogares que responden a este tipo particular de arreglo familiar y que pertenecen al $20 \%$ más rico de la población representan tan solo el $3 \%$ del total.

\section{Cuadro 3.}

Distribución de Arreglos Familiares en función de los Quintiles de Ingreso ECH 2015

\begin{tabular}{|l|c|c|c|c|c|}
\hline \multicolumn{1}{|c|}{ Tipo de Arreglo Familiar } & Primer Quintil & Segundo Quintil & Tercer Quintil & Cuarto Quintil & Quinto Quintil \\
\hline Unipersonal masculino & $4,3 \%$ & $11,5 \%$ & $17,4 \%$ & $25,9 \%$ & $40,9 \%$ \\
\hline Unipersonal femenino & $2,1 \%$ & $9,3 \%$ & $19,6 \%$ & $27,5 \%$ & $41,5 \%$ \\
\hline Nuclear sin hijos & $7,1 \%$ & $17,4 \%$ & $22,6 \%$ & $25,8 \%$ & $27,0 \%$ \\
\hline Nuclear con hijos & $27,8 \%$ & $24,3 \%$ & $19,8 \%$ & $16,3 \%$ & $11,8 \%$ \\
\hline Monoparental femenino & $30,5 \%$ & $21,4 \%$ & $19,0 \%$ & $17,4 \%$ & $11,7 \%$ \\
\hline Monoparental masculino & $17,8 \%$ & $19,4 \%$ & $24,1 \%$ & $21,6 \%$ & $17,1 \%$ \\
\hline Extendido base nuclear sin hijos & $23,4 \%$ & $26,0 \%$ & $25,1 \%$ & $15,9 \%$ & $9,6 \%$ \\
\hline Extendido base nuclear con hijos & $40,8 \%$ & $28,3 \%$ & $17,4 \%$ & $9,4 \%$ & $4,2 \%$ \\
\hline Extendido base monop. Femenina & $45,6 \%$ & $25,5 \%$ & $15,1 \%$ & $10,1 \%$ & $3,6 \%$ \\
\hline Extendido base monop. masculina & $38,2 \%$ & $28,5 \%$ & $14,4 \%$ & $14,1 \%$ & $4,8 \%$ \\
\hline Extendido sin base nuclear & $14,8 \%$ & $20,2 \%$ & $25,1 \%$ & $21,3 \%$ & $18,6 \%$ \\
\hline Compuesto & $29,2 \%$ & $24,3 \%$ & $20.9 \%$ & $17,3 \%$ & $8,2 \%$ \\
\hline
\end{tabular}

Fuente: Elaboración propia a partir de la ECH 2015. 
Esta distribución particular en función de los quintiles de ingreso es la menos ventajosa que puede encontrarse, tal como vemos en el cuadro a continuación ningún arreglo familiar tiene una distribución que concentre las familias en los primeros quintiles de ingreso con tal intensidad.

\subsection{Linajes Maternos como Fenómeno Demográfico}

En este capítulo hemos intentado rastrear la presencia de linajes maternos en fuentes de información secundarias del Censo y de la Encuesta Continua de Hogares.

Tal como dijimos al comienzo, dado que el fenómeno está relacionado tanto con el modo en que se estructuran las familias, como con los componentes subjetivos vinculados a las nociones de familia, género y juventud, las fuentes de datos que tomamos en consideración tan solo pueden brindarnos algunos elementos.

Sin embargo, luego de considerados los datos podemos establecer algunas conclusiones interesantes.

La primera de ellas es que los hogares de base monoparental femenina son sin duda mucho más frecuentes que los de base monoparental masculina, representando entre el $13 \%$ y el $14 \%$ del total de los hogares según se mire el Censo o la Encuesta Continua de Hogares.

En segundo lugar podemos decir que estos hogares son mucho más frecuentemente pobres que el resto de los hogares tal como arrojan los datos de la ECH, $13 \%$ de pobreza para los Hogares Monoparentales Femeninos y $19 \%$ para los Hogares Extendidos de base Monoparental Femenina, frente al 6,4 \% de pobreza promedio de los hogares.

Estos datos coinciden con los del Censo 2011 que establece para los hogares monoparentales femeninos un porcentaje de 35,6 \% con Necesidades Básicas Insatisfechas y un $41,4 \%$ para los hogares extendidos de base monoparental femenina, siendo el promedio de los hogares $31,6 \%$.

En tercer lugar, si intentamos detectar elementos de matrilocalidad y matrilinealidad en la estructura de los hogares, a partir del relevamiento de lo que hemos definido como hogares de línea materna, encontramos que existe entre un 2,4 \% y un 2,6 \% según se mire la ECH o el Censo. 
Sin embargo si bien este número puede no parecer tan significativo, se trata de unos 30 mil hogares que responden a una muy restrictiva pauta de arreglo familiar, y representa el $4.2 \%$ de las personas del país, es decir unas 143 mil personas.

Por último podemos afirmar que este tipo de hogar se asocia muy fuertemente con la pobreza. Tal como vimos uno de cada cinco de estos hogares está por debajo de la línea de pobreza y ocho de cada diez pertenece a los tres primeros quintiles de ingreso. 


\section{RESULTADOS DE LA ESTRATEGIA DE INVESTIGACIÓN CUALITATIVA LINAJES MATERNOS COMO FENÓMENO BIOGRÁFICO}

\subsection{Estrategia de Investigación biográfica}

Tal como mencionábamos en el apartado destinado a metodología, la segunda parte del análisis supone un abordaje desde una metodología cualitativa, en particular con entrevistas semi-estructuradas a jefas de hogar pertenecientes al Uruguay Vulnerado, focalizando en un conjunto de tópicos o ejes de análisis, centrados en su biografía y sus nociones respecto de estos tópicos.

La intención es poder vislumbrar la presencia de las dimensiones mencionadas en esta población. Es de esperar que el abordaje de la dimensión subjetiva del fenómeno complemente y amplíe lo visto anteriormente a partir de datos estadísticos.

Desde el punto de vista metodológico estas entrevistas nos permiten profundizar en las dimensiones de análisis con mayor detalle y viéndolas en su relación, de modo sistémico. Tal es la utilidad de la triangulación de técnicas de investigación, y en particular el aporte de las técnicas cualitativas.

Las entrevistas fueron realizadas durante el año 2015 a mujeres jefas de hogar de familias atendidas por el Programa Cercanías del MIDES. La población atendida por el Programa Cercanías forma parte del Uruguay Vulnerable, de hecho es posible afirmar que son aquellas familias con mayor vulneración dado que su selección, en el contexto de la focalización de la política, responde a un doble criterio de vulnerabilidad.

En primer lugar se aplica un índice probabilístico de pobreza económica, denominado Índice de Carencias Críticas (ICC) el cual opera como un indicador proxi de pobreza. El programa solo atiende a aquellas familias que presentan un valor mayor de carencias críticas.

En una segunda evaluación se estima la presencia de un conjunto de vulneraciones particulares de manera cualitativa y se establece un índice de vulneración. De este modo el criterio de focalización del programa garantiza que se trata de familias pobres, con altos niveles de vulneración.

Asimismo la selección de las mujeres a entrevistar fue realizada con el apoyo de los Equipos Técnicos de Atención Familiar (ETAF), seleccionando jefas de hogar que 
estuvieran dispuestas y en situación de contestar una entrevista de tales características.

Se realizaron un total de ocho entrevistas en Montevideo, siguiendo el criterio de saturación, finalizando esta etapa de campo cuando no encontramos novedades significativas. Las edades de las mujeres entrevistadas fueron de 24, 35, 43, 47, 53, 53, 57 y 59 años.

Las dimensiones de análisis fueron las que se han definido teóricamente con anterioridad:

- $\quad$ Relaciones de pareja y matrimoniales.

- $\quad$ Roles de género y expectativas recíprocas.

- $\quad$ Filiación y Parentesco

- Transición a la Vida Adulta

A partir de estos ejes de análisis hemos intentado describir los componentes de lo que aparecen como un modo coherente de concebir la familia y que hemos definido como linaje materno. Los principales elementos que surgen de las entrevistas son los se describen a continuación.

\subsection{Roles de género diferenciados y tradicionales}

Gran parte de lo que esperábamos encontrar en las entrevistas de hecho surgió con bastante nitidez. Encontramos una visión de las relaciones de género tradicional y patriarcal, con roles definidos y diferenciados en función de una división tradicional del trabajo por sexo. Expresada en la asociación del rol femenino al cuidado y lo doméstico y el rol masculino a la provisión material y lo público.

Esto es lo que en otros apartados hemos definido como la dimensión tradicional del modelo, frente a otros aspectos que pueden presentarse como novedosos y que veremos más adelante.

- Y al tiempo conocí a este hombre, un hombre trabajador y todos los días tenía mi comida, la casa, todo y después fueron cambiando las cosas (Sandra, 47 años) 
Un matiz a introducir es el que refiere al rol masculino, el cual en algunas de las entrevistadas aparecía como no exclusivamente proveedor, aunque este papel proveedor no se cuestiona, pero también encontramos en que existía la expectativa que colaborara en el cuidado de los hijos y desarrollara un rol afectivo.

- Para mí, las obligaciones de la madre, bañarlos, cuidarlos, llevarlos a la escuela, la obligación de los padres es todo. Es como el padre, el padre también tiene que preocuparse si ellos están enfermos, si están mal, si les duele algo, si les pasa algo, cómo se sienten. (...)

El trabajo para mi tiene que ser más del padre. La madre más bien es para cuidarlos, preocuparse por ellos, estar. (Elizabeth, 24 años)

En dos casos el discurso presenta ciertas contradicciones, si bien se menciona la igualdad entre hombres y mujeres como un valor positivo, luego se describe una vida en la que no se ha tenido una participación activa en la vida laboral fuera del hogar. Esto puede leerse o bien como una contradicción, o bien como expresión de la diferencia entre un ideal deseado y una realidad vivida.

- Y la desigualdad sí existe, todavía existe. El machismo en este país sigue existiendo, es un asco. (...)

- ¿Cuándo arrancaste? (respecto del trabajo remunerado)

- Y, arranco cuando lo dejo a este muchacho, en el 2013, cuando lo denuncio. (Sandra, 47 años)

Si bien se expresa que idealmente la relación debe ser igualitaria, en la narración de la biografía se establece con claridad que esta convicción, no ha sido llevada a la práctica, y que su rol ha sido claramente tradicional.

Estos dos casos tienen la particular de ser mujeres que, si bien actualmente forman parte del Uruguay Vulnerado, el origen de su familia es de clase media. Esto surge en la biografía en algunos aspectos, como por ejemplo el hecho de que ambas concurrieron a la educación privada.

Sin embargo lo que aparece con mayor contundencia en el relato de vida de todas las mujeres entrevistadas, es que ninguna de ellas cuestiona en ningún momento el hecho de ser quienes deben tener la responsabilidad primera en la crianza de sus hijos. 


\subsection{Indicios de matrilocalidad}

Un segundo elemento, vinculado por supuesto a una noción tradicional de los roles de género es la presencia de indicios de matrilocalidad.

Hemos podido vislumbrar estos indicios al menos en tres aspectos que aparecen en las entrevistas. En primer lugar existe una asociación de los conceptos de hogar y mujer expresada en la mención de los hogares asociados a mujeres significativas (la casa de mi madre, la casa de mi abuela, la casa de mi suegra). En segundo término aparece la idea de que los hijos siempre deben vivir con la madre cuando los padres se separan, y en algunos casos también aparece la idea de que deben continuar viviendo con la madre aun cuando ellos hayan formado su propia pareja. Por último esta dimensión se expresa en la preocupación presente en todas las mujeres de resolver el tema de la vivienda, como extensión de su ejercicio de la maternidad.

Con relación al primer punto pudo vislumbrarse fue la asociación directa de los conceptos de mujer, madre y hogar. Si bien como decíamos esto está relacionado con un rol de género tradicional, la intensidad con que se asocian estos conceptos debe ser destacada.

Esta asociación viene dada también desde el origen familiar ya que muchas de estas mujeres tienen en su propia historia la referencia de mujeres que han participado de su crianza.

- Desde que te fuiste de la casa de tus padres por ejemplo, ¿cómo fue?

- La casa de mis padres no, la casa de mi madre... (Anelia, 35 años)

Desde la perspectiva de estas mujeres todos los hogares están vinculados a una mujer: la casa de la madre, la casa de la abuela, la casa de la suegra.

Asimismo esta dimensión también se expresa en la necesidad planteada por todas las mujeres de la resolución de su problema de vivienda, como una extensión de su obligación como madres.

- Porque yo vivía con la abuela. En realidad vivíamos los dos, porque cuando recién éramos novios, yo después al tiempo quedé embarazada de mi primer hija que tiene 8 años ahora, y vivíamos con mi abuela.

- Vivía en la casa de mi suegra. Primeramente vivíamos en la casa de mi suegra, pero vivir en la casa de mi suegra era como..., ella vivía en otro mundo. (Elizabeth, 24 años) 
A esto se suma que como decíamos en algunos casos se expresa el deseo de que los hijos continúen viviendo con ellas aun cuando formen sus propias parejas. Si bien las dificultades de orden económico y de cuidados pueden ser el motivo por el que estrategia la residencia de la nueva pareja se asocie al hogar materno, esto no es vivido necesariamente como algo negativo.

- Me gustaría verme con una casita, para mí y para ellos, un terrenito por si ellos quieren edificarse al lado mío. Y hoy o mañana ellos verán si formarán familia o no y bueno, si dios me da vida, seguir ayudándolos y dándole para adelante con sus hijos, y que cada uno tenga su hogar o su familia. (Sandra, 47 años)

Concomitantemente en aquellos casos en que la nueva pareja se muda a un hogar propio este es vivido como el hogar de madre con sus hijos, siendo el padre quien debe abandonar el hogar en caso de que la pareja se diluya.

- ¿Y qué pasa cuando se separan? Quién te parece que se tiene que quedar en la casa?

- Para mí, la madre. (Elizabeth, 24 años)

Es importante mencionar que estos elementos no aparecieron en todas las entrevistas del mismo modo. Sin embargo lo que si apareció con mucha fuerza y en todos los casos fue la preocupación por resolver el tema de la vivienda, entendida como una extensión del rol femenino de crianza, y asociado a su vez a la visión de la mujer como la única opción en lo que respecta a hacerse cargo de los hijos luego de una separación.

- Después le pedí a los chicos de Etaf que me hicieran una carta, y la llevé como pude, casi arrastrando con la pierna, allá a la calle, bue, no me acuerdo de la calle, que queda entre Paysandú y Uruguay, la calle del Sunca. Le llevé la carta y como al mes enseguida me llamaron que iban a empezar a venir todos los miércoles. (Beatriz, 59 años)

\subsection{Filiación que presenta indicios de Matrilinealidad}

A la presencia de una estructura de género tradicional, la asociación de la figura femenina al hogar, se agrega la presencia de ciertos indicios de matrilinealidad. 
Estos indicios se pueden percibir en el hecho que no se describe de parte de los varones un rol significativo ni como padres de estas mujeres, ni como padres de sus hijos. De modo que la filiación comienza a ser percibida con mayor fuerza por línea materna.

La importancia asignada a la madre en la familia es superlativa, tanto en lo que tiene que ver con su propia crianza en tanto que hijas, como en el rol que cumplen como madres.

- Y mi mamá también fue jefa de hogar. Y mi abuela también.

- ¿También sola?

- Aja, pero con varios maridos, pero tá. O sea que vengo de un gran linaje que la lucharon, y pobres. (Anelia, 35 años)

Esto se refuerza por el hecho de que la figura materna aparece con mucha importancia, si bien no siempre se tiene una imagen completamente positiva, en tanto que la figura paterna de estas mujeres o bien es negativa, o bien no aparece con fuerza alguna.

- Y antes de juntarte, ¿con quién vivías?

- Con mi madre, prácticamente sí. No me pegaba a la pollera de mi madre, grandota igual andaba siempre con mi madre... (Sonia, 57 años)

Es importante mencionar que en uno de los casos esta dimensión no resulta tan clara, se trata de una de las mujeres cuyo origen es de clase media. También en este caso notamos que si bien el discurso no lo acompaña, en la práctica la crianza estuvo siempre a cargo de la mujer.

\subsection{Nomadismo y dilución de rol masculino}

Como consecuencia lógica de la coexistencia de una mirada tradicional de los roles de género que asigna a los hombres un rol público y proveedor, pero la dificultad de cumplirlo por la pertenencia a sectores de pobreza, encontramos una figura masculina debilitada y que suele visualizarse como negligente respecto a sus responsabilidades. Esta mirada negativa respecto de los hombres suele ser tanto respecto de sus padres, como de sus esposos. 
- Ojalá yo hubiera tenido un padre, en serio, así sea separada, hoy en día la parte paterna hubiera influido en mis dos relaciones con mis hijas. (Mónica, 53 años)

A esto se suma las frecuentes rupturas de la pareja, en las que no se cuestionan dos elementos centrales, los hijos y el hogar están vinculados a la figura femenina, por lo que obviamente es el hombre quien debe abandonar el hogar.

Esta compulsión a abandonar el hogar parece existir en los hombres cuando se rompe el vínculo de pareja, pero también como marcador del pasaje a la vida adulta, como veremos más adelante.

- El papá de los más grandes está en Buenos Aires, hace muchísimos años, cuando Nahuel tenía un año. Y el papá del más chico, lamentablemente está en situación de calle porque es adicto a la pasta base, hace muchos años que estoy separada. (Stella, 53 años)

Por último debemos mencionar que todas las mujeres entrevistadas narran algún episodio de violencia ejercida por hombres hacia ellas, tanto de índole sexual o violencia física, que muchas veces es presentada en la narración como asociada a episodios de consumo problemáticos de drogas o alcohol.

Tuve cinco hijos con ese hombre, casi me llevó a la muerte y por suerte hoy en día me dejé. Hizo lo que quiso conmigo, yo era una esclava, no me podía desprender porque tenía que seguir luchando por el techo y la comida de mis hijos, para que ellos no pasaran por lo que yo pasé y bueno, tá, la vida continúa y bueno. (Sandra, 47 años)

Es posible suponer que estas experiencias hayan deteriorado aún más la percepción de los hombres en la mirada de estas mujeres. Cabe destacar que la totalidad de ellas narra este tipo de episodios.

\subsection{Transiciones a la Vida Adulta diferenciadas por género}

El último punto del modelo supone que la transición a la vida adulta debe estar claramente diferenciada por género.

En tanto que las mujeres se convierten en adultas fundamentalmente a partir del momento en que se vuelven madres, los varones lo hacen a partir de su salida al mundo público y del trabajo. 
En el caso de las mujeres entrevistadas en la amplia mayoría se menciona la maternidad como hito de pasaje a la vida adulta.

No sé. La mujer sí, puedo decir. En mi caso fue tener un hijo, me volví adulta en el mismo momento que lo tuve a él, que tuvo la primer crisis de asma, que la tuvo a los 23 días, y lo tuve internado, y tenía 17 años, y lloraba y necesitaba mi atención, y necesitaba estar así, y el gurí no se quedaba así, y yo me sentaba con él acá. O mi vieja me encontraba llorando con él, o sea llorando porque no podía dormir, las veces que viví con mamá. (Anelia, 35 años)

Aunque en otros casos también se menciona la transición a la vida adulta a partir del comienzo de la realización de trabajo doméstico, o el comienzo de la vida sexual. En este último caso se asocia a la idea de hacerse mujer como pérdida de la inocencia infantil.

- En relación a..., estábamos hablando de cuando vos eras chica, de cuando te juntaste y eso, ¿cuándo sentís vos que te hiciste grande, adulta, en qué momento?

- Yo me sentí adulta de toda una vida, me pasé golpeando, a los 9 años me violaron, y ya me hice así. (Sonia, 59 años)

Con relación a los hombres es más difuso la definición del pasaje a la vida adulta, esto puede deberse al hecho de que la pregunta implicaba responder algo que no remitía directamente a su historia de vida.

Aun así esta construcción de transiciones a la vida adulta diferenciadas por género aparece en varias de las entrevistas.

No, es cuando cumplen cierta edad y ya sienten que tienen que madurar, que ya no son unos adolescentes, que la adolescencia ya pasó.

- ¿Y eso es al mismo tiempo para las mujeres que para los hombres?, ¿o te parece que hay alguna diferencia?

- No, hay un poco de diferencia sí, porque nosotras como mujeres cuando nos damos cuenta que somos madres. (Elizabeth, 24 años)

En muchos casos aparece en estas mujeres expresado el deseo de que sus hijos varones trabajen, como forma de proyectar un futuro de adultos deseable. 
- En el caso de los varones, que trabajen, que estudien también, que no agarren nada malo tampoco, porque hoy por hoy, hay de todo. (Sandra, 47 años)

\subsection{Linajes Maternos como fenómeno biográfico}

En resumen, mirado en su conjunto, y más allá de que obviamente existen diferencias importantes entre la percepción de estas mujeres respecto de los temas abordados podemos afirmar que los siguientes elementos aparecieron con fuerza:

- En primer lugar una construcción tradicional de género, con roles femeninos asociados a la maternidad, al mundo privado del hogar, y a las tareas de cuidado. Por otra parte roles masculinos asociados a la provisión económica y al mundo público.

Esto apareció en la amplia mayoría de las opiniones y en la totalidad de las experiencias de vida narradas.

- En segundo término existen indicios de matrilocalidad expresados en tres dimensiones que aparecen en una u otra entrevista.

En primer lugar existe en varias de las entrevistadas la noción de que la idea de hogar se asocia a alguna figura femenina.

En segundo término surge con fuerza la idea, y también la experiencia de vida narrada, de que ante una separación los hijos deben quedarse con su madre. Esto también podría ser interpretado como un indicio de matrilinealidad.

Asimismo apareció la idea de que es deseable que los hijos, aun cuando hayan constituido parejas nuevas, constituyan su hogar junto a su madre.

Por último, en la totalidad de las entrevistadas aparece la preocupación y la importancia de la vivienda, vivida como una extensión de la responsabilidad materna de crianza.

- En tercer lugar descubrimos en todas las entrevistadas una percepción altamente negativa de los hombres en el cumplimiento de sus roles, siendo vistos como negligentes en el cumplimiento de sus tareas, lo cual desdibuja su función en la familia. 
Esto se asocia a frecuentes narraciones de varones que abandonan el hogar, ya sea sus padres o sus esposos y dejan a las mujeres solas en la crianza de sus hijos.

Es de destacar que en la totalidad de los casos se narran episodios de violencia de género, de índole sexual o física, lo cual probablemente colabore con esta percepción negativa.

- Aparece con fuerza asimismo la concepción de una transición a la vida adulta diferenciada por género.

Para el caso de las mujeres, y en relación a su propia historia, se narra el pasaje a la vida adulta asociado a la maternidad en la mayoría de los casos, o eventualmente al comienzo en el cumplimiento de tareas de orden doméstico, asociadas como decíamos a una construcción de género tradicional.

Para el caso de los varones no aparece con tanta claridad, probablemente porque no responde a su propia biografía, pero en el deseo hacia sus hijos varones aparece siempre el trabajo como elemento de definición de la vida adulta.

- Por último debemos mencionar que entre las ocho entrevistadas, dos de ellas tuvieron algunas diferencias a destacar, particularmente en lo que respecta a su noción de relaciones de género en el plano ideal, así como en lo que respecta a los indicios de matrilinealidad, también en el plano de la percepción del deber ser.

Si bien ambas en la práctica desarrollaron relaciones de género que podrían definirse como tradicionales, y en el contexto de la separación de sus parejas asumieron completamente la crianza de sus hijos, en el plano de la opinión diferían de las otras entrevistadas.

En ambos casos, como hemos mencionado, se trata de mujeres que si bien actualmente pertenecen al Uruguay Vulnerado provienen de familias que podríamos colocar en el Uruguay Corporativo o de clase media. Esto podría explicar esta diferencia en el plano de la opinión, en estos dos aspectos.

Cabe destacar que, en lo referente a la percepción del rol masculino, en lo que respecta a los indicios de matrilocalidad y en lo que tiene que ver con la transición a la vida adulta no mostraron grandes diferencias. 


\section{CONCLUSIONES}

A lo largo de este documento hemos trabajado sobre la idea de que en un cierto sector de la población de nuestro país que ha sido definido como el Uruguay Vulnerado, existen familias en las que las formas de concebir y organizar las familias responden a ciertos patrones que mirados en conjunto conforman lo que hemos denominado Linajes Maternos.

Ya hemos mencionado en este trabajo que no es nuestra expectativa encontrar familias que punto por punto respondan este modelo, sino percibir ciertas tendencias que se expresan tanto en la demografía como en la biografía de personas y familias particulares.

A continuación intentaremos reconstruir el camino que hemos recorrido hasta ahora, para formar una visión de conjunto y poder establecer conclusiones, determinar el alcance de las mismas y trazar líneas de continuidad en la investigación.

\subsection{La familia desde un abordaje conceptual}

En este documento hemos trabajado sobre diversas concepciones teóricas de la familia, descubriendo que los elementos centrales del análisis de su estructura están relacionados con la filiación y las concepciones de maternidad y paternidad en el contexto de la unión conyugal.

El modo en que ambas dimensiones de la estructura familiar se constituyen determina el tipo de arreglo familiar. En los casos en que la filiación legítima se da por vía materna se trata de matirlinajes, asimismo si la autoridad reside en la madre deberíamos hablar de matriarcado. En contraposición, cuando filiación y autoridad se depositan en el padre hablamos de patrilinaje y patriarcado. Si el lugar donde se establece la nueva pareja está asociado a la madre se trataría de un modelo matrilocal y si está asociado al padre se trata de un modelo patrilocal.

Con relación a estas definiciones es importante destacar que los cambios en los modos de organizar y en las formas de concebir las familias no siempre suceden de manera simultánea. En muchas ocasiones la modificación en la organización precede o es posterior al cambio en las construcciones subjetivas asociadas a las familias. 
Este punto es muy importante porque el desfasaje entre los modos de organización real y las formas de concebir los roles y sus responsabilidades asociadas pueden en muchos casos generar importantes conflictos en las personas reales, como veremos más adelante.

Asimismo debemos destacar la importancia de esta clasificación, ya que determina concepciones centrales que los individuos sostienen respecto de los roles que deben cumplir, de su nociones respecto de lo que significa ser varón o mujer, se joven o viejo, ser hijo y ser madre o padre.

Nuestra sociedad occidental, se supone responde a un modelo de filiación bilateral, es decir que los hijos de la pareja pertenecen a la familia de ambos, tal como queda reflejado en el doble apellido, y neolocal, lo que implicaría que la nueva pareja no reside ni con la familia de la mujer ni con la familia del varón sino que se establece de manera independiente.

Con respecto a la autoridad, parece bastante evidente que aun vivimos en una sociedad patriarcal. Más allá de importantes cambios a nivel de discurso, y también de ciertos cambios en la realidad, el rol de los varones continúa siendo diferente al de las mujeres, y además de diferente supone privilegios y mayor autoridad en diversas áreas como el trabajo, la política, y también en la familia.

Todos estos elementos, la filiación bilateral, la residencia neolocal y el patriarcado, son constitutivos de la familia nuclear típica.

Ahora bien, además de las nociones de autoridad, filiación y residencia, que reflejan relaciones y concepciones políticas asociadas al género y las relaciones entre adultos y jóvenes, y por ende de la estructura familiar, las familias deben analizarse de manera diacrónica, atendiendo a ciertos marcadores y cambios que en algunos casos responden a procesos biológicos como el envejecimiento o la reproducción, pero que tienen un correlato social y psicológico.

Este análisis diacrónico ha sido desarrollado por el enfoque Life Course que se basa en un conjunto de principios de investigación y que centra su mirada en la trayectoria biográfica de los individuos, en sus transiciones y puntos de inflexión.

De este modo el pasaje a la vida adulta y los eventos marcadores de esta transición son fundamentales para comprender, no solo la concepciones que las personas 
sostienen sobre lo que es ser joven o adulto, sino también respecto a sus ideas sobre el género y la familia.

Hemos intentado abordar estos elementos de manera integrada, a partir de la concepción de que las ideas que los individuos tienen sobre la filiación, la autoridad, los roles de género, la paternidad y la maternidad, así como el pasaje a la vida adulta, están íntimamente ligados, y las transformaciones que operan sobre unos inevitablemente se reflejan en el resto.

\subsection{El contexto de desarrollo de la familia}

El estudio de las familias sin embargo, no puede realizarse en abstracción del contexto económico y social del que forman parte. De hecho este es precisamente uno de los

principios del enfoque Life Course que hemos mencionado antes, el principio de tiempo y lugar, que se equilibra con el principio de agencia, que establece la necesidad de ver a los individuos y las familias como hacedores de su historia. De ahí la necesidad de estudiar a un tiempo los procesos biográficos y demográficos.

El contexto socio económico del Uruguay posee ciertas particularidades que hacen parte de un modelo de desarrollo latinoamericano, que lo incluyen. Las características de este modelo de desarrollo son: la desigualdad establecida a lo largo de la historia, los procesos de urbanización signados por la pobreza y ciertos procesos demográficos que determinan un breve período de bono demográfico.

Respecto del primero de estos puntos, y contrariamente a lo que en muchos casos ha sido la autopercepción del Uruguay, la desigualdad es un hecho histórico que a pesar de variaciones significativas ha estado siempre presente.

Dicha desigualdad histórica se consolida a partir de la crisis de la década del 60 que instala un proceso caracterizado por la precarización del empleo y la segregación socio-territorial.

Si bien la pobreza y la desigualdad han fluctuado en sus indicadores, estos procesos históricos de larga duración han definido una situación de estratificación que hace posible pensar a nuestro país como tres mundos diferentes, el Uruguay privado, el corporativo y el vulnerado. 
La consolidación de un sector de la población caracterizado por la vulneración de sus derechos fundamentales, responde asimismo a la inadecuación del modelo de protección social pensado para un país de pleno empleo y familia nuclear.

Frente a los cambios en el mercado de trabajo y en el perfil de las familias, las respuestas del Estado no se han adecuado con la suficiente velocidad. La intervención del Estado continúa teniendo fuertes sesgos. Orienta el grueso de su gasto a sectores integrados a partir del gasto en salud y educación, a los más viejos a partir del gasto en la seguridad social, y a los varones toda vez que no toman en cuenta la transferencia de género que supone el trabajo no remunerado desarrollado de manera mayoritaria por las mujeres.

En este contexto las mujeres y los jóvenes pobres son los menos beneficiados por las respuestas del Estado, siendo además quienes tienen mayores dificultades para acceder al empleo.

Es importante destacar que el crecimiento económico de la última década, sumado al incremento del gasto público social desarrollado por los gobiernos progresistas, ha disminuido de manera significativa los indicadores de pobreza e indigencia, y recientemente comienzan a verse signos de disminución de la desigualdad.

No obstante ello, no puede decirse que el país haya vivido un proceso de reformulación profunda del tipo de respuestas brindadas por parte del Estado, ni que el proceso de larga duración que supuso la instalación del Uruguay Vulnerado se haya revertido.

Paralelamente a este proceso de trasformación de la Arquitectura del Bienestar en Uruguay, el país ha vivido fuertes transformaciones demográficas. Ya hemos visto que el Uruguay vivió tempranamente la primera transición demográfica, que supuso la instalación del modelo de familia nuclear. Asimismo el país se encuentra desarrollando la segunda transición demográfica, caracterizada por el cuestionamiento de este modelo como sistema único y la ampliación de la variedad de los arreglos familiares.

Cabe decir que ninguno de los dos procesos fue homogéneo, y que es posible detectar una pauta dual, determinada por el nivel socio-económico. Ni todas las familias transitaron completamente al modelo de familia nuclear en el marco de la primera transición, ni todas las familias han modificado sus arreglos familiares del mismo modo en el contexto de la segunda transición demográfica. 
Estos procesos de cambio repercuten en la Arquitectura del Bienestar, toda vez que como decíamos antes, el modelo de protección social fue pensado para una situación de pleno empleo y familia nuclear.

\subsection{Antecedentes de la aparición del Modelo}

Ahora bien, teniendo en cuenta que nuestro interés está enfocado en un conjunto de procesos, que reflejan la existencia de un modelo de familia y se expresan tanto en el nivel de las ideas, las biografías y la demografía, es importante revisar la existencia de trabajos empíricos previos que den cuenta de este fenómeno.

Como primer elemento debemos dejar en claro que no hemos encontrado en la investigación reciente, trabajos que den cuenta de este modelo en su globalidad, pero sí muchas producciones académicas que visualizan algunos de sus componentes de manera separada, como veremos a continuación.

En primer lugar existen investigaciones que marcan la presencia del fenómeno de la jefatura femenina de hogar destacándose un incremento importante de su aparición en las últimas décadas.

En segundo lugar la evidencia empírica sugiere que las mujeres de los sectores más pobres de la población sostienen visiones más conservadoras, en cuanto a los roles de género, en particular asociados con la maternidad.

Del otro lado, también existen trabajos que muestran que los varones de los sectores más pobres sostienen concepciones tradicionales de género, en particular en cuanto a su rol proveedor, en el contexto de su idea de paternidad. Existen indicios, a su vez de cierta separación de las figuras de pater y genitor, en la medida en que se entiende que quien provee es quien debe ser considerado padre, más allá de serlo o no desde el punto de vista biológico.

Por último hemos visto en algunas investigaciones cualitativas, así como en la ENAJ que existe una fuerte división en lo que respecta al pasaje a la vida adulta en los varones y mujeres de estos sectores. En tanto que las mujeres transitan a la vida a adulta a partir de la maternidad, lo varones asocian este evento a la salida del hogar familiar y al ingreso a la vida activa. 


\subsection{Los resultados del trabajo empírico}

Dado estos antecedentes y en atención del contexto mencionado es hemos abordado la tarea de generar algunos análisis propios cuyos resultados podemos ahora poner en conjunto para su valoración.

En primer lugar abordamos la tarea de realizar un análisis estadístico del fenómeno a partir del trabajo sobre datos del Censo y la Encuesta Continua de Hogares.

A partir de este trabajo podemos afirmar lo siguiente, en primer lugar los hogares que poseen jefatura monoparental femenina (sumando extendidos de base monoparental) alcanzan entre un $13 \%$ y $14 \%$ de los hogares, lo que contrasta frente al entre $2 \%$ y $3 \%$ de los hogares con jefatura monoparental masculina.

En segundo término estos hogares son mucho más frecuentemente pobres según la Encuesta Continua de Hogares, $13 \%$ y $19 \%$ según se considere hogar monoparental de jefatura femenina u hogar monoparental extendido de jefatura femenina, frente a una media de pobreza de $6,4 \%$ en la totalidad de los hogares.

Datos que coinciden con los del Censo 2011 en los que estos tipos de hogares presentaban $35,6 \%$ y $41,4 \%$ con Necesidades Básica Insatisfechas, frente al promedio de los hogares de $31,6 \%$.

En tercer lugar, a partir del modelo creado para visualizar los posibles hogares matrilocales o matrilineales, podemos decir que entre un $2,4 \%$ y un $2,6 \%$ de los hogares, según se considere la ECH o el Censo responden a lo que hemos definido como hogares de línea materna.

Si bien el número puede no parecer tan importante debemos recordar que el modelo suponía un arreglo familiar de tres generaciones conviviendo, en el que todos los adultos eran mujeres.

Asimismo en términos numéricos se trata de unos 30 mil hogares y $4,3 \%$ de las personas, es decir unas 143 en todo el país.

Por último podemos afirmar que este tipo de hogar correlaciona muy fuertemente con la pobreza, más inclusive que los otros tipos de hogar de jefatura monoparental femenina. Tal como vimos uno de cada cinco de estos hogares está por debajo de la línea de pobreza y ocho de cada diez pertenece a los tres primeros quintiles de ingreso. 
Todos estos elementos puestos en conjunto nos permiten afirmar que existe evidencia estadística de este tipo de hogar que hemos definido como Linaje Materno, si bien debemos hacer la salvedad de que el modo de aproximarnos a esta realidad es sin duda indirecto por el hecho de que los datos no fueron relevados específicamente con este fin.

Por otra parte la estrategia de investigación cualitativa nos permite reafirmar algunas informaciones y datos que teníamos de investigaciones anteriores, así como incorporar datos nuevos, pero sobre todo lograr una visión de conjunto.

Tal como esperábamos encontrar, las mujeres entrevistadas sostienen concepciones de género tradicionales respecto de los roles de madre y padre, lo cual es en buena medida coherente con la narración de sus vidas.

Así la crianza aparece como una tarea fuertemente asociada con la madre, en tanto que se espera del padre, aunque no siempre de manera exclusiva, un marcado rol proveedor.

Profundizando en estos aspectos encontramos indicios del modelo matrilocal, en la fuerte asociación que existe en el discurso respecto de las ideas de madre, hogar y vivienda. Asimismo, la filiación, como extensión del rol femenino de crianza comienza a ser más importante por línea materna.

En contraposición, y asociado a un rol proveedor que no pueden cumplir, existe una fuerte desvalorización del rol masculino, con una mirada de negligencia respecto de sus obligaciones. Además se narran frecuentes separaciones en la que la pauta común es la partida del hombre del hogar, o eventualmente, aunque con menos frecuencia, la partida de la mujer pero llevando consigo a sus hijos.

Concomitantemente y de manera coherente las transiciones a la vida adulta se diferencian fuertemente por género, siendo para las mujeres los marcadores más significativos del comienzo de la vida adulta la llegada de los hijos, o en todo caso aunque con menos frecuencia el comienzo de la participación en las tareas domésticas o de la vida sexual. Por otra parte en el caso de los varones la transición está definida fuertemente por el trabajo y el comienzo de la vida pública asociado a la vida fuera del hogar. 


\subsection{Linajes Maternos en el Uruguay Vulnerado, permanencia y cambio}

Todo lo visto hasta ahora parece indicar que existen indicios fuertes de que lo que hemos definido como Linaje Materno es un modelo que tiene un correlato en la realidad uruguaya y que responde a las siguientes características.

Como articulación de elementos de permanencia y cambio, se trata de familias en las que los roles de género son tradicionales, inclusive más que en la media de la población.

En tal sentido, en tanto que en otros sectores de población la concepción patriarcal han sido cuestionada, la evidencia indica que aquí se mantiene y define roles que, en el contexto de la familia implican para las mujeres responsabilidades de crianza, y para los hombres responsabilidades de provisión económica.

Sin embargo, ya sea por cuestiones vinculadas a factores económicos o por otros motivos, los hombres de estas familias no cumplen con este rol plenamente, motivo por el cual son vistos como negligentes por las mujeres.

Hemos hipotetizado que esta percepción desvalorizada de los hombres se encuentra también en el origen de cierta conducta nómade de los hombres, que suelen ser los que abandonan el hogar en caso de la ruptura del vínculo. Paralelamente hay una separación de los roles de pater y genitor, siendo el varón que cumple el rol proveedor quien ocupa el rol de pater, sea o no el padre biológico.

Del otro lado existe una fuerte asociación de la ideas de madre, hogar y casa, que se trasunta una asociación de la madre con sus hijos. En definitiva la filiación se concreta fuertemente por línea materna, siendo los hombres más inconstantes en su presencia física, y una figura que aparece con mucha menos fuerza.

También esta asociación habla de una tendencia matrilocal, explicitada en algunos casos en los que se transmite el deseo de que los hijos vivan con la madre, aun cuando hayan formado sus respectivas familias.

De este modo la filiación por línea femenina, la separación de los roles de pater y genitor asociados a un rol proveedor desvalorizado, son los elementos nuevos del modelo.

No debemos hablar sin embargo de matriarcados, porque como vimos antes, se trata de familias donde los elementos patriarcales están muy fuertemente representados, y las mujeres, lejos de ser quienes ejercen el poder ocupan roles domésticos y privados. 
Por último, y como parte integrante del modelo, las transiciones a la vida adulta de varones y mujeres están claramente diferenciadas, siendo para el caso de las mujeres el convertirse en madres, en tanto que para los varones el ingreso al mundo público y del empleo.

\subsection{Nuevos interrogantes y líneas de investigación futura}

Para terminar de componer el cuadro que comenzamos a delinear quedan varias interrogantes por responder, que eventualmente podrán dar lugar a futuros trabajos de investigación.

En principio surge con claridad el hecho de que en este trabajo nos hemos centrado fundamentalmente en las mujeres pobres, de modo que investigaciones sobre los varones y la paternidad por un lado, y sobre las familias de clase media y alta serían claramente complementarias, y permitirían una comparación más completa.

Respecto de los varones y sus nociones de paternidad es posible hipotetizar que lo que hemos definido como padres desdibujados y el sentimiento de negligencia en el cumplimiento de las responsabilidades propias del rol paterno, pueda ser en parte explicativo del hecho de que la población masculina en situación de calle sea muy superior a la femenina. Tales cuestiones podrían dar lugar a una investigación complementaria.

Asimismo parece evidente que la línea de trabajo asociada a las transiciones a la vida adulta, desde la perspectiva de los jóvenes de estas familias, puede ser una interesante línea de continuidad en esta investigación. Cabría preguntarse a la luz de los resultados de este documento, si la edad en que las jóvenes de estos sectores sociales tienen sus primeros hijos está relacionada con su noción de transición a la vida adulta. Paralelamente el abandono del estudio por la necesidad del ingreso a la vida productiva puede estar relacionado con esta transición en el caso de los varones.

Por último, una interesante línea de trabajo podría abordar la relación de las Políticas Sociales con este tipo particular de familias, y visualizar en qué medida algunas de las características del modelo pueden estar sustentadas sobre la acción asistencial del Estado. 
Sobre el final de este trabajo debemos decir que si bien hemos encontrado evidencia empírica que sustenta en alguna medida las hipótesis que establecíamos al comienzo, en modo alguno podemos dar por cerrada o concluida la labor.

En principio la intención de este trabajo era abordar, a modo de aproximación exploratoria, algunas características que, puestas en conjunto pueden ser visualizadas como un modelo.

Y si bien la existencia del modelo como tal puede ser controvertida, lo que sí parece claro es que los modos en que las personas del Uruguay Vulnerado viven y organizan su vida familiar tienen algunas particularidades que hemos destacado.

Como decíamos en la introducción, si bien la diversidad en las formas en que las familias son concebidas y estructuradas no debería considerarse en sí misma una situación problemática, la situación se torna complejo si traspasamos la delgada frontera entre la diversidad y la desigualdad. El hecho de que las familias no respondan a un único patrón de organización, lejos de ser algo negativo, puede implicar mayores niveles de libertad, en tanto existen más modelos y por ende opciones aceptables a la vista de la sociedad.

Sin embargo cuando los modelos se asocian a sectores de población esto significa que las diferencias que en principio son de orden económico se trasladan a otros aspectos de la vida, algunos de ellos tan íntimos y personales como las concepciones de familia, paternidad, maternidad y filiación, lejos de implicar mayor diversidad supone un proceso de segregación e implica un verdadero desafío en términos de integración. Desafío que debería ser tenido en cuenta en la construcción de Políticas Sociales para estos sectores, y en la acción particular del Trabajo Social con familias. 


\section{BIBLIOGRAFÍA}

- Amorin, David. Carril, Elina y Varela, Carmen. (2006) "Significados de maternidad y paternidad en adolescentes de estratos bajos y medios de Montevideo" en López Gómez Alejandra Proyecto Género y Generaciones Montevideo: Trilce.

- Arim, Rodrigo (2008) Crisis Económica, segregación residencial y exclusión social. El caso de Montevideo. Montevideo: Siglo del Hombre Editores CLACSO.

- Batthyány, Karina (2015) Los tiempos del bienestar social: género, trabajo no remunerado y cuidados en Uruguay Montevideo: INMUJERES-MIDES; U.R-FCS; Cepal; ONU-Mujeres.

- Benedict, Ruth. 1934 Patterns of Culture. Boston and New York: Houghton Mifflin Company.

- Blanco, Mercedes y Pacheco, Edith (2003) "Trabajo y familia desde el enfoque del curso de vida: dos subcohortes de mujeres mexicanas" en Papeles de Población, (México, Universidad Autónoma del Estado de México) vol. 9, núm. 38, pp. 159193.

- Bourideu, Pierre. 2002 "La "juventud" no es más que una palabra." en Bourdieu, Pierre Sociología y Cultura México: Grijalbo - Conaculta, pp. 163-173.

- Bucheli, Marisa, González, Cecilia. y Olivieri, Cecilia. 2010 "Transferencias del sector público a la infancia y la vejez en el Uruguay, 1994-2006" en Notas de Población No. 90 CEPAL pp. 163-185.

- Camarano, Ana Amelia, et al. 2004 "Caminhos para a vida adulta: As multiplas trajetorias dos jovens brasileiros" en Revista Última Década (Valparaiso) No. 21 pp. 11-50.

- Casal, Joaquim 1996 "Modos emergentes de transición a la vida adulta en el umbral del siglo XXI: aproximación sucesiva, precariedad y desestructuración" en Revista Reis Barcelona No. 75 pp. 295-316.

- Casal, Joaquim. Garcia, Maribel. Merino, Rafael y Quesada, Miguel. 2006 “Aportaciones teóricas y metodológicas a la sociología de la juventud desde la perspectiva de la transición" en Revista Papers Barcelona No. 79 pp. 21-48. 
- Ciganda, Daniel. Prado, Ignacio. 2014 “Emancipación y formación de hogares entre los jóvenes uruguayos: las transformaciones recientes." en Pelegrino, Adela. Varela, Carmen. Hacerse adulto en Uruguay. Un estudio demográfico. Montevideo: Zonalibro. pp. 203-231

- Clarke, John. Hall, Stuart, Jefferson, Tony. Roberts, Bryan. 1975 "Subcultures, Cultures and Class" en Hall y Jefferson ed. Resistance through Ritual Londres: Hutchinson.

- Colafranceschi, Marco. Failache, Elisa y Vigorito, Andrea. 2013 Desigualdad multidimensional y dinámica de la pobreza en Uruguay en los años recientes Montevideo: PNUD El Futuro en Foco.

- Colombo, Karina, et al. 2013 ¿Qué es el índice de carencias críticas? Montevido: MIDES-DINEM Serie de documentos Aportes a la conceptualización de la pobreza y la focalización de las políticas sociales en Uruguay.

- Dávila, Oscar. Ghiardo, Felipe. 2011 "Trayectorias sociales juveniles. Cursos y discursos sobre la integración laboral" en Papers Revista de Sociología Chile vol. 96, No. 4. pp. 1181-1209.

- Davinson Pacheco, Luis. 2007 “Una mirada al método genealógico y un ejemplo de su aplicación en un pueblo de Tlaxcala, México" en Robichaux, David Familia y Diversidad en América Latina. Estudios de casos. Buenos Aires CLACSO, Consejo Latinoamericano de Ciencias Sociales.

- de Beauvoir, Símone 1972 El segundo sexo Buenos Aires: Siglo XX.

- Doneschi, Andrea. Patron, Rossana. 2012. Educación y trabajo informal: qué nos dicen las cifras - Uruguay 2001-2012 Montevideo DECON-FCS-UDELAR Documentos de Trabajo No. 04/12

- Durkehim, Emile 1892 "La familia conyugal" en Peusner, Pablo. Nota sobre la pregnancia imaginaria de la "familia conyugal" en la clínica psicoanalítica lacaniana.

- Eisenstadt, Samuel N. 1956 From generation to generation: age groups and social structure London: Free Press.

- Elder, Glen H. Kirkpatrick Johnson, Monica. 2000 "The Life Course and Aging: Challenges, Lessons, and New Directions" en Settersten, Jr. Richard A. Life Course: 
Toward New Understandings of Later Life University of North Carolina at Chapel Hill.

- Engels. Friedrich. 1987 El origen de la familia, la propiedad privada y el Estado, en relación con las investigaciones de L.H. Morgan. Moscú: Progreso

- Esping-Anderesen, Gosta. 1999 Social Foundations of Postindustrial Economies. Nueva York: Oxford University Press

- Evans, Ana. Baxter, Janeen. 2013 Negotiating the life course. Dordrecht: Springer

- Filardo, Verónica. 2008 Segundo Informe. Encuesta Nacional de Adolescencia y Juventud. Montevideo: Ministerio de Desarrollo Social

- Filardo, Verónica. 2010 Transición a la adultez y educación Montevideo: UNFPA.

- Filgueira, Carlos y Filgueira, Fernando. 1994 El largo adiós al país modelo: políticas sociales y pobreza en el Uruguay Montevideo: Arca.

- Filgueira, Carlos. 1998 Emancipación juvenil: trayectorias y destinos. Montevideo: CEPAL

- Filgueira, Fernando 1998 “El nuevo modelo de Transferencias sociales en América Latina: residualismo, eficiencia y ciudadanía estratificada" en Roberts, Brian ed. Ciudadanía y Políticas Sociales. San José de Costa Rica: FLACSO/SSRC

- Filgueira, Fernando 2011 "Fault lines in Latin American Social Development and Welfare Regime Challenges" en Blofield, Merike The Great Gap, Inequality and the Politics of Redistribution in Latin America. Pensylvania: The Pensylvania State University Press.

- Filgueira, Fernando. Rodríguez, Federico. Rafaniello, Claudia. Lijtenstein, Sergio. Y Alegre, Pablo. 2005 "Estructura de riesgo y arquitectura de protección social en el Uruguay actual: crónica de un divorcio anunciado" en Prisma (Montevideo) No. 21 pp. 7-42.

- Giddens, Anthony: 1995 La constitución de la sociedad: Bases para la teoría de la estructuración Buenos Aires: Amorrortu.

- Güida, Carlos. Martínez, Ivonne. Salles, Gonzalo y Scarlatta, Laura. 2007 El lugar de los varones en los sectores de pobreza extrema. Montevideo: Trilce.

- Habermas, Jürgen. 1993 Teoría y Praxis México: Editorial Rei.

- Herrera, Gioconda 1997 “Los enfoques de género: entre la gettoización y la ruptura epistemológica" en Ecuador Debate no. 40 abril de 1997. pp. 187-209 
- Jaes Falicov, Celia. 1991 Transiciones de la familia: continuidad y cambio en el ciclo de vida. Buenos Aires, Amorrortu.

- Lamas, Marta 2000 “Usos, Dificultades y posibilidades de la categoría género" en Lamas, Marta comp. El Género, la construcción cultural de la diferencia sexual México: UNAM. 327-366.

- Leccardi, Carmen. 2002 Tiempo y construcción biográfica en la "sociedad de la incertidumbre": reflexiones sobre las mujeres jóvenes nómadas Bogotá: Redlayc.

- Lesthaeghe, Ron 2011 "The "second demographic transition": a conceptual map for the understanding of late modern demographic developments in fertility and family formation" en Historical Social Research 36, 2, pp. 179-218.

- Lévi-Strauss, Claude. 1991 Las estructuras elementales del parentesco Barcelona: Paidós.

- Macmillan, Ross. 2005. The structure of the life course: standardized? Individualized? Differentiated? Minnesota: Elsevier.

- Margulis, Mario y Urresti, Mario. 2008 La Juventud es más que una palabra Buenos Aires: Biblos.

- Mead, Margaret. 1972 Sexo y temperamento .Buenos Aires: Paidós.

- Merton, Robert K. 2002 Teoría y estructura sociales México: Fondo de Cultura Económica.

- Midaglia, Carmen. 2009 "Las políticas sociales del gobierno de izquierda en Uruguay" en Quiroga Yesco, et all comp. Consenso Progresista. Las Políticas Sociales de los Gobiernos Progresistas del Cono Sur. Santiago de Chile: Fundación Friedrich Ebert Stiftung.

- Morgan, Lewis H. 1986 La sociedad primitiva Madrid: Endymion.

- Nathan, Mathías y Paredes, Mariana 2012 "Jefatura femenina en los hogares uruguayos. Transformaciones en tres décadas". en Revista de Ciencias Sociales, DSFCS, Vol. 25, No. 30, julio 2012. pp. 75-96.

- Notestein, Frank 1945 "Population -the long view" en T. Schultz (ed) Food for the world. Chicago: University Press pp. 35-57.

- Ortner, Sherry B. 1974. "Is female to male as nature is to culture?" en M. Z. Rosaldo and L. Lamphere (eds), Woman, culture, and society. Stanford: Stanford University Press, pp. 68-87. 
- Paredes, Mariana 2003 “Los cambios en la familia en Uruguay: chacia una segunda transición demográfica?" en Nuevas formas de familia Montevideo: UNICEF. pp. 73-102.

- Parsons Talcott 1942 "Age and Sex in the Social Structure of the United States" American Sociological Review, Vol. 7, No. 5 pp. 604-616

Parsons, Talcott y Bales, Robert. 2002 Family socialization and interaction process. Londres: Routledge

- Parsons, Talcott. 1980 "La familia en la sociedad urbana-industrial de los Estados Unido" en Anderson, Michael. 0 Sociología de la familia México: Fondo de Cultura Económica.

- Pérez Islas, José Antonio. 2008 "Juventud: Un concepto en disputa" en Pérez Islas, José Antonio. Valdez, Monica y Suárez, Ma. Herlinda. coords. Teorías sobre la Juventud. Las miradas de los Clásicos, México: UNAM pp. 9-33.

- Peri, Andrés. 2004 "Dimensiones ideológicas del cambio familiar en Montevideo" en Papeles de Población, vol. 10, núm. 40, abril-junio, 2004, pp. 147-169.

- Quiñones, Mariela. 2015 Introducción a la sociología cualitativa: fundamentos epistemológicos y elementos de diseño y análisis. Montevideo: UR. Comisión Sectorial de Educación Permanente.

- Radcliffe-Brown, Alfred. 1972 Estructura y función en la sociedad primitiva Barcelona: Península.

- Rama, Germán. 1987 La democracia en Uruguay: una perspectiva de interpretación Buenos Aires: Grupo Editor Latinoamericano.

- Real de Azúa, Carlos. 1984 Uruguay: ¿una sociedad amortiguadora? Montevideo: CIESU/Ediciones de la Banda Oriental.

- Rial, Virginia. Rodriguez, Eloisa y Vomero, Fabricio. 2011 Procesos de selección social y vulnerabilidad: varones jóvenes viviendo en la calle. Montevideo: Ediciones Universitarias.

- Segalen, Martine. 1992 Antropología histórica de la familia. Madrid: Taurus Universitaria.

- Varela Petito, Carmen. Fostik, Ana y Fernández Soto, Mariana. 2014 “Transición a la maternidad en el Uruguay: convergencia y divergencia en el pasaje a la vida 
adulta." en Pelegrino, Adela y Varela, Carmen. Hacerse adulto en Uruguay. Un estudio demográfico. Montevideo: Zonalibro. pp. 57-84.

- Varela, Carmen. 2007. "Propuesta para la formulación de políticas." en Calvo, Juan José y Mieres, Pablo ed. Importante pero urgente: políticas de población en Uruguay Montevideo: Rumbos, UNFPA pp. 21-50.

- Weber, Max. 1977 Sobre la teoría de las ciencias sociales Barcelona: Península.

\section{SITIOS WEB}

- Instituto Nacional de Estadística Atlas Socio demográfico, fascículo 6 Disponible en: http://www.ine.gub.uy/atlas-sociodemografico (acceso 19/03/2017)

- Administración Nacional de Educación Pública Cercanías estrategia nacional de fortalecimiento de capacidades, documento oficial Disponible en: http://www.cep.edu.uy/documentos/2012/maestroscomunitarios/DocumentoPres entacionCercaniasFINAL-set2012.pdf (acceso 19/03/2017)

- Ministerio de Desarrollo Social. Dirección Nacional de Evaluación y Monitoreo, División de Evaluación. Primer conteo y censo de personas en situación de calle y refugios de Montevideo. Informe preliminar de resultados. 2006. Disponible en: http://www.agev.opp.gub.uy/observatorio docs/publico/11.pdf $\quad$ (acceso 19/03/2017)

- Ministerio de Desarrollo Social. Instituto Nacional de la Juventud Encuesta Nacional de Adolescencia y Juventud. Informe ENAJ 2013. Disponible en: http://www.inju.gub.uy/innovaportal/file/41610/1/informe-tercera-enaj-final.pdf (acceso 19/03/2017) 